Junji Ichikawa, * Yu Iwai, Ryo Nadano, Takashi Mori, Masahiro Ikeda

A New Class of Substrates for Nucleophilic 5-endo-trig Cyclization, 2-Trifluoromethyl-1-alkenes: Synthesis of Five-Membered Hetero- and Carbocycles Bearing Fluorinated One-Carbon Units
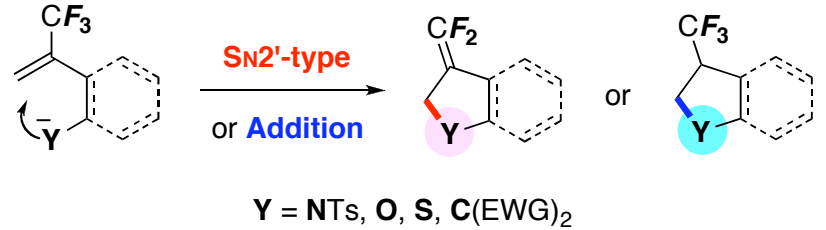

Disfavored ring formation: 5-endo-

trig Cyclizations are achieved in 2trifluoromethyl-1-alkenes with a nucleophilic nitrogen, oxygen, sulfur, or carbon atom via (i) intramolecular $\mathrm{S}_{\mathrm{N}} 2$ ' reaction with loss of a fluoride ion or (ii) intramolecular nucleophilic addition to the vinylic group. 


\title{
A New Class of Substrates for Nucleophilic 5-endo-trig Cyclization, 2- Trifluoromethyl-1-alkenes: Synthesis of Five-Membered Hetero- and Carbocycles Bearing Fluorinated One-Carbon Units
}

\author{
Junji Ichikawa, ${ }^{*[\mathrm{a}]}$ Yu Iwai, ${ }^{[\mathrm{b}]}$ Ryo Nadano, ${ }^{[\mathrm{b}]}$ Takashi Mori, ${ }^{[\mathrm{b}]}$ and Masahiro Ikeda ${ }^{[\mathrm{a}]}$
}

The present work is dedicated to Professor Teruaki Mukaiyama on the occasion of his 80th birthday.

\begin{abstract}
Disfavored 5-endo-trig cyclizations are achieved in 2trifluoromethyl-1-alkenes with a nucleophilic nitrogen, oxygen, sulfur, or carbon atom via (i) intramolecular $\mathrm{S}_{\mathrm{N}} 2^{\prime}$ reaction with loss of a fluoride ion or (ii) intramolecular nucleophilic
\end{abstract}

addition to the vinylic group. This reaction manifold provides a versatile method for the synthesis of indolines, indoles, pyrrolidines, tetrahydrofurans, 2,3-dihydrobenzo $[b]$ thiophenes, tetrahydrothiophenes, cyclopentanes bearing a fluorinated one-carbon unit such as a difluoromethylene, difluoromethyl, or trifluoromethyl group.

\section{Keywords: 5-endo-trig cyclization,} fluorine, heterocycles, carbocycles, synthetic methods

\section{Introduction}

The 5-endo-trig cyclization has long been considered to be a geometrically disfavored process according to Baldwin's rules. ${ }^{1}$ Reported examples of this disfavored ring closure are classified into three categories: nucleophile-driven, ${ }^{2,3}$ electrophile-driven, ${ }^{4}$ and radical-initiated cyclizations. ${ }^{5}$ Among these, nucleophile-driven 5endo-trig cyclizations have rarely been observed in synthetic chemistry, compared with the two other types of cyclization.

In our recent studies, we have accomplished the normally disfavored nucleophilic 5-endo-trig cyclizations with 1,1-difluoro-1alkene substrates (2,2-difluorovinylic compounds) bearing a functional group such as NHTs, OH, $\mathrm{SH}$, or $\mathrm{CH}_{2} \mathrm{I}$ (Scheme 1a). Deprotonation or lithium-iodine exchange of these groups generates $N-, O-, S$-, and $C$-nucleophiles, which successfully undergo a vinylic addition-elimination $(\mathrm{SNV})$ process to construct five-membered ring-fluorinated heterocycles and carbocycles such as indoles, 2-

[a] Prof. Junji Ichikawa, Masahiro Ikeda

Department of Chemistry

Graduate School of Pure and Applied Sciences

University of Tsukuba

Tsukuba, Ibaraki 305-8571 (Japan)

Fax: (+81)29-853-4237

E-mail: junji@chem.tsukuba.ac.jp

[b] Yu Iwai, Dr. Ryo Nadano, Dr. Takashi Mori

Department of Chemistry

Graduate School of Science

The University of Tokyo

Hongo, Bunkyo-ku, Tokyo 113-0033 (Japan)

Supporting information for this article is available on the WWW under pyrrolines, benzo[b]furans, 2,3-dihydrofurans, benzo[b]thiophenes, 2,3-dihydrothiophenes, and cyclopentenes. Such unique reactivities of 1,1-difluoro-1-alkenes are presumably the result of (i) the highly polarized $\mathrm{C}=\mathrm{C}$ double bond, which allows the initial five-membered ring formation by electrostatic attraction of the positive $\mathrm{CF}_{2}$ carbon for the nucleophiles, and (ii) the subsequent elimination of fluoride ion, which suppresses the reverse ring opening.

(a) 2,2-Difluorovinylic compounds

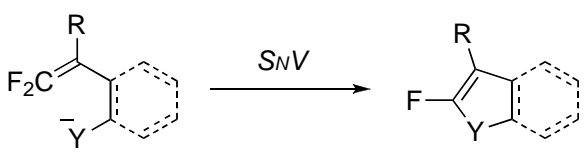

(b) 1-(Trifluoromethyl)vinyl compounds

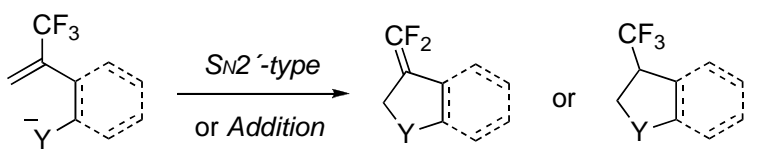

Scheme 1. Nucleophilic 5-endo-trig Cyclization of Fluoroalkenes.

Among fluoroalkenes, 2-trifluoromethyl-1-alkenes are also known to possess an interesting reactivity in nucleophilic reaction, resulting from (i) the highly electrophilic double bond with a strong electron-withdrawing $\mathrm{CF}_{3}$ group and (ii) the good leaving group ability of allylic fluorine atoms. The nucleophilic reaction of 2trifluoromethyl-1-alkene substrates [1-(trifluoromethyl)vinyl compounds] proceeds with the accompanying elimination of an allylic fluorine ( $\mathrm{S}_{\mathrm{N}}{ }^{\prime}$-type process), which provides a potential method for the preparation of 1,1-difluoro-1-alkenes. ${ }^{6}$ We have recently conducted the $\mathrm{S}_{\mathrm{N}} 2^{\prime}$-type reaction with nitrogen and carbon 
nucleophiles in an intramolecular fashion to construct six-membered rings. Furthermore, we have observed them to undergo addition and substitution in the presence and absence of a proton source, respectively. These reactions readily provided quinoline and isoquinoline derivatives bearing a $\mathrm{CF}_{3}, \mathrm{CHF}_{2}$, or $=\mathrm{CF}_{2}$ group under mild reaction conditions. ${ }^{7}$

Such a high reactivity of that 1-(trifluoromethyl)vinyl moiety prompted us to examine the geometrically disfavored 5-endo-trig cyclization, which might allow the development of a new synthetic route to five-membered ring systems bearing fluorinated one-carbon units (Scheme 1b). Indeed, the presence of nucleophilic centers on the position $\beta$ to the 1-(trifluoromethyl)vinyl group might lead to either an intramolecular $\mathrm{S}_{\mathrm{N}} 2^{\prime}$-type process or an addition reaction, depending on the conditions, and thus deliver five-membered cycles.

Five-membered heterocycles and carbocycles constitute important classes of compounds in pharmaceuticals, agrochemicals, materials, and catalysts. In these fields of science, the introduction of a fluorine atom or fluorocarbon substituents has come into wide use as one of the most efficient methods for modification of biological activity as well as of physical and chemical properties. ${ }^{8}$ Among fluorocarbon substituents, fluorinated one-carbon units $\left(\mathrm{CF}_{3}\right.$, $\mathrm{CHF}_{2},=\mathrm{CF}_{2}$, and $\mathrm{CH}_{2} \mathrm{~F}$ ) are quite attractive: ${ }^{9}$ (i) the incorporation of a trifluoromethyl $\left(\mathrm{CF}_{3}\right)$ group into organic molecules increases lipophilicity and affects electron density, ${ }^{10}$ (ii) a difluoromethyl $\left(\mathrm{CHF}_{2}\right)$ group has hydrogen bond donor ability without nucleophilicity and with high lipophilicity, ${ }^{11}$ which makes it a special mimic of a hydroxy group, ${ }^{12}$ and (iii) a difluoromethylene $\left(=\mathrm{CF}_{2}\right)$ group acts as a reactive site towards nucleophiles ${ }^{13}$ and a potential isostere of carbonyl groups, ${ }^{14}$ and provides a $\mathrm{CHF}_{2}$ group via its reduction. ${ }^{15}$ Nevertheless, synthetic methods for heterocycles and carbocycles with these fluorinated one-carbon units are limited and remain to be developed.

The preliminary results of the 5-endo-trig cyclizations of 1(trifluoromethyl)vinyl compounds have been briefly reported in our previous communication, where we focused on those with intramolecular nitrogen nucleophiles. ${ }^{16}$ Combining the results of those obtained with other nucleophiles such as oxygen, sulfur, and carbon resulted in this full account of our studies on the 5-endo-trig cyclizations of 1-(trifluoromethyl)vinyl compounds, yielding difluoromethylene-, difluoromethyl-, and trifluoromethyl-substituted indoline, indole, pyrrolidine, tetrahydrofuran, benzo[b]thiophene, tetrahydrothiophene, and cyclopentane derivatives.

\section{Results and Discussion}

\section{Preparation of the Cyclization Precursors}

\footnotetext{
Abstract in Japanese:

分子内に窒素、酸素、硫黄、炭素求核種を有する 2-トリフル オロメチル-1-アルケンにおいて、これまで困難とされてきた 求核的 5-endo-trig 環化を達成した。この 5 員環形成反応は、

(i) フッ化物イオンの脱離を伴う分子内 $\mathrm{S}_{\mathrm{N}} 2^{\prime}$ 反応、もしくは (ii）ビニル基への分子内求核付加を経て進行する。これら 一連の反応により、ジフルオロメチレン基、ジフルオロメチ ル基、トリフルオロメチル基のような含フッ素 1 炭素ユニッ トを有するインドリン、インドール、ピロリジン、テトラヒ ドロフラン、2,3-ジヒドロベンゾ $[b]$ チオフェン、テトラヒド ロチオフェン、およびシクロペンタンを合成することができ る。
}

We first selected $\alpha$-(trifluoromethyl)styrenes bearing a nucleophilic nitrogen or sulfur at the $o$-position as 2-trifluoromethyl-1-alkene substrates for 5-endo-trig cyclization, because of the previously reported favorable effect of a 1-aryl group in 1(trifluoromethyl)vinyl compounds undergoing $\mathrm{SN}_{\mathrm{N}}{ }^{\prime}$ reaction. ${ }^{6 \mathrm{~b}} 2$ (3,3,3-Trifluoroprop-1-en-2-yl)-substituted anilines 1 were prepared by the palladium-catalyzed coupling reaction of $o$-iodoaniline with (3,3,3-trifluoroprop-1-en-2-yl)boronic acid, obtained from the magnesium-mediated Barbier-type reaction of 2-bromo-3,3,3trifluoropropene with trimethyl borate, following a literature procedure. ${ }^{7 \mathrm{a}, 17}$ Sulfonylation of the amino group of $\mathbf{1}$ gave anilides $\mathbf{2}$ (Scheme 2). Introduction of an $S$-functionality was effected via diazotization of the amino group. Treatment of $1 \mathrm{a}$ with $i$-AmONO and $\mathrm{CF}_{3} \mathrm{CO}_{2} \mathrm{H}$, followed by the addition of sodium thioacetate, gave thiophenol ester $\mathbf{3}$ (Scheme 3).

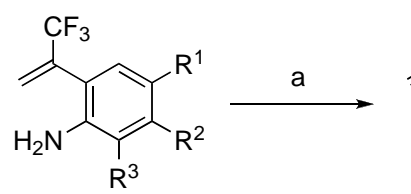

1a: $R^{1}=H, R^{2}=H, R^{3}=H$ 1b: $R^{1}=M e, R^{2}=H, R^{3}=H$ 1c: $R^{1}=H, R^{2}=C l, R^{3}=H$<smiles>[R]c1cc(C(=C)C(F)(F)F)c(N)c([R])c1[R]</smiles>

2a $84 \%$

2b $87 \%$
Scheme 2. Preparation of 2'-(3,3,3-Trifluoroprop-1-en-2-yl) Sulfonanilides 2. Reagents and conditions: (a) $\mathrm{TsCl}$ (1.2 equiv), DMAP $\left(0.1\right.$ equiv), $0{ }^{\circ} \mathrm{C}$ to $\mathrm{rt}, 12 \mathrm{~h}$, pyridine.

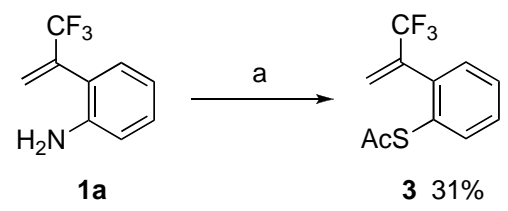

Scheme 3. Preparation of $o$-(3,3,3-Trifluoroprop-1-en-2-yl) Thiophenol Ester 3 Reagents and conditions: (a) TFA ( 2.0 equiv), $i$-AmONO ( 2.0 equiv), $0{ }^{\circ} \mathrm{C}, 0.5 \mathrm{~h}$, $\mathrm{MeCN}$.

In addition, we designed nonconjugated substrates lacking a phenylene tether, 3-(trifluoromethyl)homoallyl sulfonamides, alcohols, thiols, and malonic acid derivatives, as second-type precursors of hetero- and carbocycles. Two methods were employed for the construction of these skeletons: (i) addition of 2trifluoromethyl-substituted allylsilane to aldehydes ${ }^{18}$ and (ii) ring opening of oxiranes with 1-trifluoromethyl-substituted vinyllithium, ${ }^{19}$ prepared by treatment of 2-bromo-3,3,3trifluoropropene with $n$-BuLi, both of which provided 3(trifluoromethyl)homoallyl alcohols 4 . The Mitsunobu reaction of 4 with BocNHTs, ${ }^{20}$ followed by deprotection of the Boc group afforded the cyclization precursors 5 (Scheme 4). 3(Trifluoromethyl)homoallyl alcohol 4a was also adopted as a cyclization precursor feachering a nucleophilic oxygen. $\alpha$-Alkylated ketones 6, prepared from 4 via oxidation and alkylation, were reduced to give homoallyl alcohols 7 bearing 2,2-dialkyl substituents (Scheme 5). S-[3-(Trifluoromethyl)homoallyl] thioacetates $\mathbf{8}$ were prepared by the Mitsunobu reaction of homoallyl alcohols 4. ${ }^{20}$ Treatment with AcSH, DEAD, and $\mathrm{PPh}_{3}$ afforded 8a,b in moderate yields (Scheme 6).

3-(Trifluoromethyl)homoallyl-substituted malonate and malononitrile $\mathbf{1 0}$ and $\mathbf{1 1}$ were prepared for carbocycle synthesis. Conjugate addition of 2-(trifluoromethyl)allylsilane ${ }^{18}$ to diethyl 
benzylidenemalonate 9 and a modified Mitsunobu reaction ${ }^{21}$ of $\mathbf{4 a}$ with malononitrile gave $\mathbf{1 0}$ and $\mathbf{1 1}$, respectively (Scheme 7).<smiles>[R]C([Y])C([R])C(=C)C(F)(F)F</smiles><smiles>[R]C(N[AsH])C([R7])C(=C)C(F)(F)F</smiles>

4a: $\mathrm{R}^{1}=\mathrm{H}, \mathrm{R}^{2}=\mathrm{Ph}, \mathrm{Y}=\mathrm{OH}$
4b: $\mathrm{R}^{1}=\mathrm{H}, \mathrm{R}^{2}=\mathrm{C}_{6} \mathrm{H}_{4}-4-\mathrm{Br}, \mathrm{Y}=\mathrm{OH}$
4c: $\mathrm{R}^{1}=\mathrm{H}, \mathrm{R}^{2}=2$-furyl, $\mathrm{Y}=\mathrm{OH}$
4d: $\mathrm{R}^{1}=\mathrm{H}, \mathrm{R}^{2}=n-\mathrm{C}_{6} \mathrm{H}_{13}, \mathrm{Y}=\mathrm{OH}$
4e: $\mathrm{R}^{1}=\mathrm{Ph}, \mathrm{R}^{2}=\mathrm{H}, \mathrm{Y}=\mathrm{OH}$
4f: $\mathrm{R}^{1}=\mathrm{H}, \mathrm{R}^{2}=\mathrm{H}, \mathrm{Y}=\mathrm{OTs}$

5a $89 \%$

5b $65 \%$

5c $29 \%$

5d $61 \%$

5e $64 \%$

5 f $81 \%$

Scheme 4. Preparation of $\mathrm{N}$-[3-(Trifluoromethyl)homoallyl] Sulfonamides 5. Reagents and conditions: (a) $\mathrm{PPh}_{3}$ (1.5 equiv), DEAD (1.5 equiv), NHTsBoc (1.3 equiv), rt, $6 \mathrm{~h}$, THF (for 4a-e). (b) NaH (1.3 equiv), NHTsBoc (1.4 equiv), $90^{\circ} \mathrm{C}, 4 \mathrm{~h}, \mathrm{DMF}$ (for $\mathbf{4 f}$ ). (c) TFA (10 equiv), rt, $10 \mathrm{~h}, \mathrm{CH}_{2} \mathrm{Cl}_{2}$

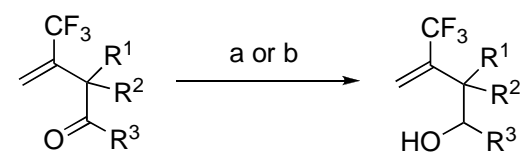
6a: $R^{1}=M e, R^{2}=M e, R^{3}=P h$
6b: $R^{1}, R^{2}=-\left(\mathrm{CH}_{2}\right)_{4^{-}}, \mathrm{R}^{3}=\mathrm{Ph}$
7a $87 \%$
6c: $R^{1}=\mathrm{Me}, \mathrm{R}^{2}=\mathrm{Me}, \mathrm{R}^{3}=\left(\mathrm{CH}_{2}\right)_{2} \mathrm{C}_{6} \mathrm{H}_{5}$
7b $86 \%$
6d: $\mathrm{R}^{1}=\mathrm{Me}, \mathrm{R}^{2}=\mathrm{Me}, \mathrm{R}^{3}=\mathrm{CH}=\mathrm{CHPh}(\mathrm{E})$
7c $83 \%$
7d $77 \%$

Scheme 5. Preparation of 3-(Trifluoromethyl)homoallyl Alcohols 7. Reagents and conditions: (a) $\mathrm{NaBH}_{4}$ (1.5 equiv), reflux, $3-4 \mathrm{~h}, \mathrm{EtOH}$ (for 6a-c). (b), $\mathrm{CeCl}_{3}(1.0$ equiv), $\mathrm{NaBH}_{4}$ (1.0 equiv), $0^{\circ} \mathrm{C}, 3 \mathrm{~h}, \mathrm{MeOH}$ (for $6 \mathbf{d}$ ).

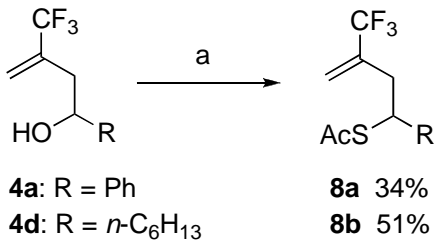

Scheme 6. Preparation of $S$-[3-(Trifluoromethyl)homoallyl] Thioacetates 8. Reagents and conditions: (a) $\mathrm{PPh}_{3}$ (2.0 equiv), DEAD (2.0 equiv), $\mathrm{AcSH}\left(1.5\right.$ equiv), $0{ }^{\circ} \mathrm{C}, 12 \mathrm{~h}$, THF.<smiles>CCOC=C(CC)C(=Cc1ccccc1)OCC</smiles>

9<smiles>C=C(CC(O)c1ccccc1)C(F)(F)F</smiles>

$4 a$<smiles>C=C(CC(c1ccccc1)C(COCC)C(F)(F)F)C(C)(F)F</smiles>

$1041 \%$
$1129 \%$

Scheme 7. Preparation of 3-(Trifluoromethyl)homoallyl-Substituted Malonate and Malononitrile 10 and 11. Reagents and conditions: (a) $\mathrm{CH}_{2}=\mathrm{C}\left(\mathrm{CF}_{3}\right) \mathrm{CH}_{2} \mathrm{Si}\left(\mathrm{CH}_{3}\right)_{3}(1.0$ equiv), TBAF ( 0.12 equiv), MS4 $\AA$, rt, 12 h, THF. (b) $n-\mathrm{Bu}_{3} \mathrm{P}=\mathrm{CHCN}$ (1.5 equiv), malononitrile ( 1.5 equiv), rt, $24 \mathrm{~h}$, benzene.

\section{Synthesis of Indolines and Indoles Bearing Fluorinated One- Carbon Units}

We first examined the reaction of sulfonanilides $\mathbf{2}$ as precursors of indolines. The cyclization of $\mathbf{2 a}$ was attempted by treatment with 1.2 equiv of $\mathrm{NaH}$ in several solvents. While the reaction in THF or 1,4-dioxane gave no cyclized products, the use of DMF successfully promoted the desired 5-endo-trig cyclization via an $\mathrm{S}_{\mathrm{N}} 2^{\prime}$ reaction to afford 3-(difluoromethylene)indoline 12a in $84 \%$ yield (Scheme $8) .{ }^{16,22}$ On the other hand, a similar reaction of $\mathbf{2 a}$ conducted in the presence of a proton source was expected to afford the addition product, 3-(trifluoromethyl)indoline 13a. ${ }^{16,23,24}$ The cyclization was examined by employing DBU instead of $\mathrm{NaH}$ as a base, where the sulfonamide $\mathrm{NH}$ group of $\mathbf{2 a}$ and/or $\mathrm{DBU} \cdot \mathrm{H}^{+}$acted as a proton donor. Whereas 1 equiv of DBU gave 3-(trifluoromethyl)indoline 13a only in $18 \%$ yield, 0.3 equiv of DBU surprisingly improved the yield of 13a to $81 \%$ (Scheme 8 ). When this reaction was monitored by ${ }^{19} \mathrm{~F}$ NMR after heating at $80{ }^{\circ} \mathrm{C}$ for $2 \mathrm{~h}$, the formation of 12a and 13a was observed. The mixture, when heated at $120^{\circ} \mathrm{C}$, finally gave rise to 13a. These facts indicate that $\mathrm{DBU} \cdot \mathrm{HF}$ acted as an HF source, which transformed 12a to the trifluoromethylated indoline 13a during the reaction.

These two types of 5-endo-trig products, the $\mathrm{SN}_{\mathrm{N}}{ }^{\prime}$ and the addition products, were also obtained from other sulfonamides $\mathbf{2 b}, \mathbf{c}$ bearing a methyl or a chlorine group on the benzene ring. The corresponding $o$-nitrobenzenesulfonamides (nosylamides) ${ }^{25}$ also underwent these reactions, albeit slightly less effectively. Thus, indolines 12 and 13 bearing a difluoromethylene or trifluoromethyl group were selectively obtained from common substrates $\mathbf{2}$ by choosing the base and the reaction conditions (Scheme 8).

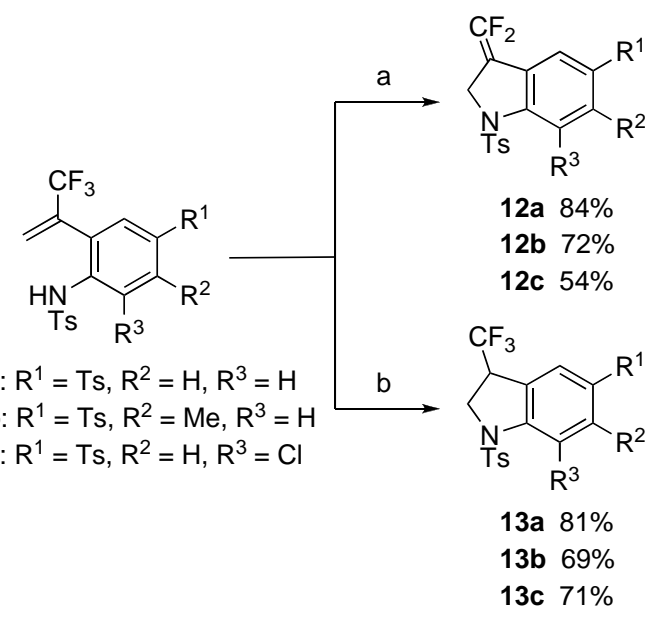

Scheme 8. Synthesis of 3-Difluoromethylene and 3-Trifluoromethyl Indolines 12 and $\mathbf{1 3}$ Reagents and conditions: (a) $\mathrm{NaH}\left(1.2\right.$ equiv), $80^{\circ} \mathrm{C}, 5-7 \mathrm{~h}$, DMF. (b) DBU ( 0.3 equiv), $120^{\circ} \mathrm{C}, 0.5-1 \mathrm{~h}, \mathrm{DMF}$

Derivatization of indoline 12a was examined in order to synthesize indoles bearing fluorinated one-carbon units. An attempted double bond isomerization leading to aromatization of 12a failed under acidic (camphor sulfonic acid) and basic (DBU) conditions. ${ }^{22}$ We then tried addition of electrophiles (XY) such as IF, $\mathrm{Br}_{2}$, and $\mathrm{HI}$ to the exocyclic double bond of 12a. Subsequent elimination of $\mathrm{HX}$ including an $\mathrm{H}$ at the 2-position from the adducts would allow the desired aromatization (Scheme 9). When 12a was treated with 2.4 equiv of $N$-iodosuccinimide (NIS) and 2.5 equiv of $\mathrm{Et}_{3} \mathrm{~N} \cdot 3 \mathrm{HF},{ }^{26}$ addition of IF followed by elimination of HI readily 
occurred to give 3-(trifluoromethyl)indole $\mathbf{1 4}$ in $90 \%$ yield. Similarly, treatment of 12a with 1.3 equiv of $\mathrm{Br}_{2}$ gave 3(bromodifluoromethyl)indole $\mathbf{1 5}$ in $96 \%$ yield. Furthermore, when $\mathrm{HI}$ [generated from $\mathrm{NaI}$ (1.6 equiv), TMSCl (1.6 equiv), and $\mathrm{H}_{2} \mathrm{O}$ $(0.8 \text { equiv) }]^{27}$ was added to $\mathbf{1 2 a}$, 3-(difluoromethyl)indole $\mathbf{1 6}$ was obtained in $96 \%$ yield. ${ }^{28}$ While the opposite regioselectivity in the $\mathrm{HI}$ addition of 12a would be kinetically favorable because of the $\alpha$ cation-stabilizing effect of fluorine, ${ }^{29}$ the addition product with that regiochemistry underwent elimination of $\mathrm{HI}$ to regenerate 12a. Consequently, the synthesis of indoles 14-16 with a variety of fluorinated one-carbon units is readily accomplished from a common starting material, 12a.

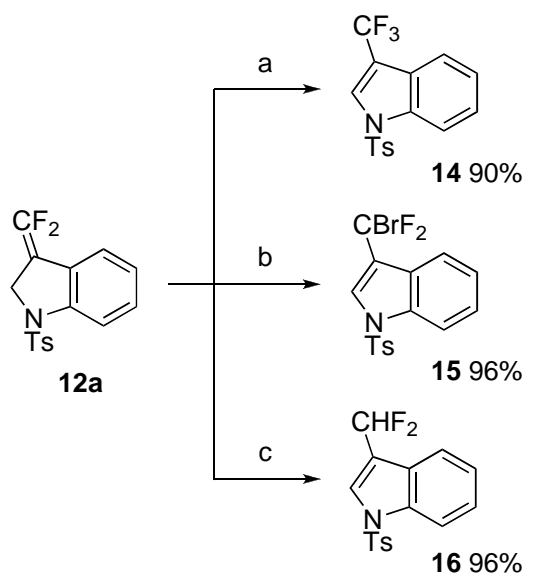

Scheme 9. Synthesis of Indoles 14-16 Bearing Fluorinated One-Carbon Units. Reagent and conditions: (a) NIS (2.4 equiv), $\mathrm{Et}_{3} \mathrm{~N} \cdot 3 \mathrm{HF}$ (2.5 equiv), $-10^{\circ} \mathrm{C}, 2 \mathrm{~h}, \mathrm{CH}_{2} \mathrm{Cl}_{2}$. (b) $\mathrm{Br}_{2}$ ( 1.3 equiv), rt, $3 \mathrm{~h}, \mathrm{CCl}_{4}$. (c) $\mathrm{NaI}$ ( 1.6 equiv), TMSCl ( 1.6 equiv), $\mathrm{H}_{2} \mathrm{O}$ ( 0.8 equiv), rt, 10 h, $\mathrm{CH}_{3} \mathrm{CN}$.

\section{Synthesis of 2,3-Dihydrobenzo $[b]$ thiophenes Bearing Fluorinated One-Carbon Units}

As a further example of the intramolecular cyclization, we examined a sulfur nucleophile, although 5-endo-trig cyclizations with sulfur nucleophiles are not a disfavored process by Baldwin's rules because of the large atom size of sulfur. ${ }^{1}$ A solution of a thiophenolate, generated in situ by treatment of thiophenol ester $\mathbf{3}$ with 1.1 equiv of potassium tert-butoxide $(\mathrm{KO} t$-Bu) in THF, was heated at reflux to afford 3-difluoromethylene-2,3dihydrobenzothiophene $\mathbf{1 7}$ in $65 \%$ yield (Scheme 10). The intramolecular addition process of the sulfur nucleophile under protic conditions was also examined. On treatment of $\mathbf{3}$ with 1.1 equiv of $\mathrm{K}_{2} \mathrm{CO}_{3}$ in $\mathrm{MeOH}$, the desired 3-trifluoromethyl-2,3dihydrobenzothiophene $\mathbf{1 8}$ was obtained in $61 \%$ yield (Scheme 10). ${ }^{30}$ These cyclizations of sulfur nucleophiles proceeded under milder conditions than those required for nitrogen nucleophiles.
Scheme 10. Synthesis of 3-Difluoromethylene and 3-Trifluoromethyl 2,3Dihydrobenzo[b]thiophenes $\mathbf{1 7}$ and 18. Reagents and conditions: (a) $\mathrm{KO}$ - $\mathrm{Bu}(1.1$ equiv), reflux, 2 h, THF. (b) $\mathrm{K}_{2} \mathrm{CO}_{3}$ (1.1 equiv), reflux, 1 h, MeOH.

\section{Synthesis of Pyrrolidines Bearing Fluorinated One-Carbon Units}

Substrates $\mathbf{2}$ and $\mathbf{3}$ have a benzene ring tethering the nucleophilic heteroatom and the 1-(trifluoromethyl)vinyl group, which could allow a $6 \pi$-electrocyclization process to operate. To rule out the possibility of the $6 \pi$-electrocyclization mechanism and to broaden the scope for these types of 5-endo-trig cyclizations, we investigated the reaction of a nonconjugated system, $N$-[3(trifluoromethyl)homoallyl] sulfonamides $\mathbf{5}$ bearing a two-sp ${ }^{3}$ carbon tether. Whereas the 1-(trifluoromethyl)vinyl system without a 1 -aryl group is known to possess a reduced $\mathrm{S}_{\mathrm{N}} 2^{\prime}$ reactivity, ${ }^{6 \mathrm{~b}}$ we expected activation of the substrates by conducting the reactions in an intramolecular fashion.

Treatment of 5a with 1.3 equiv of $\mathrm{NaH}$ in DMF successfully promoted a similar cyclization to afford 4(difluoromethylene)pyrrolidine 19a in $91 \%$ yield (Scheme 11). ${ }^{15,16,31}$ In contrast, the intermolecular reaction of 5-phenyl-2(trifluoromethyl)pent-1-ene with 4-methyl- $\mathrm{N}$ propylbenzenesulfonamide gave only $2 \%$ yield of the corresponding $\mathrm{SN}_{\mathrm{N}}$ ' product under similar reaction conditions. These results clearly indicate that (i) the reactions proceeds via the nucleophilic 5-endotrig cyclization, not via the electrocyclization, and (ii) substrate $\mathbf{5 a}$ preserves good $\mathrm{S}_{\mathrm{N}}{ }^{\prime}$ reactivity due to the intramolecular nature of the reaction. We further examined the intramolecular $\mathrm{S}_{\mathrm{N}} 2^{\prime}$ reaction of several other $N$-[3-(trifluoromethyl)homoallyl] sulfonamides $\mathbf{5 b}$ e bearing a 1-aryl, 1-alkyl, or 2-aryl group, and 1,2-unsubstituted homoallyl sulfonamide $\mathbf{5 f}$. The reactions afforded good to excellent yields of the desired 4-difluoromethylene-substituted pyrrolidines 19b-f.

Cyclization of $\mathbf{5}$ in the presence of a proton source was attempted for the synthesis of (trifluoromethyl)pyrrolidines. In contrast to (trifluoromethyl)indoline synthesis, treatment of $\mathbf{5 a}$ with $\mathrm{DBU}$ in DMF promoted the $\mathrm{S}_{\mathrm{N}} 2^{\prime}$ reaction and not the addition reaction. When the reaction was conducted with 5 equiv of $\mathrm{KOH}$ in ethylene glycol or ethylene glycol-THF (10:1), the desired addition product, 4-(trifluoromethyl)pyrrolidine 20a, was obtained in $85 \%$ yield with high 2,4-trans selectivity (trans: cis $=92: 8$ ) (Scheme 11)..$^{15,16,32}$ We conducted the intramolecular addition reaction of other sulfonamides $\mathbf{5 b}-\mathbf{e}$, which afforded good to high yields of the desired 4-(trifluoromethyl)pyrrolidines 20b-e with 2,4-trans selectivity $(\mathbf{2 0 b}-\mathbf{d})^{33}$ or 3,4 -trans selectivity $(\mathbf{2 0 e}){ }^{34}$ Under the cyclization conditions, neither the cis nor the trans isomer of $\mathbf{2 0 b}$ underwent cis/trans isomerization, which indicates that the ratios represent the kinetic selectivity of the cyclization.

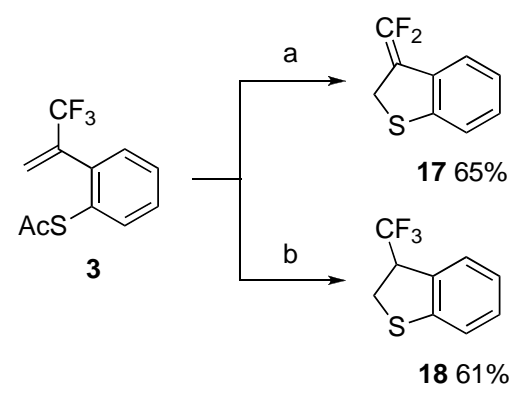




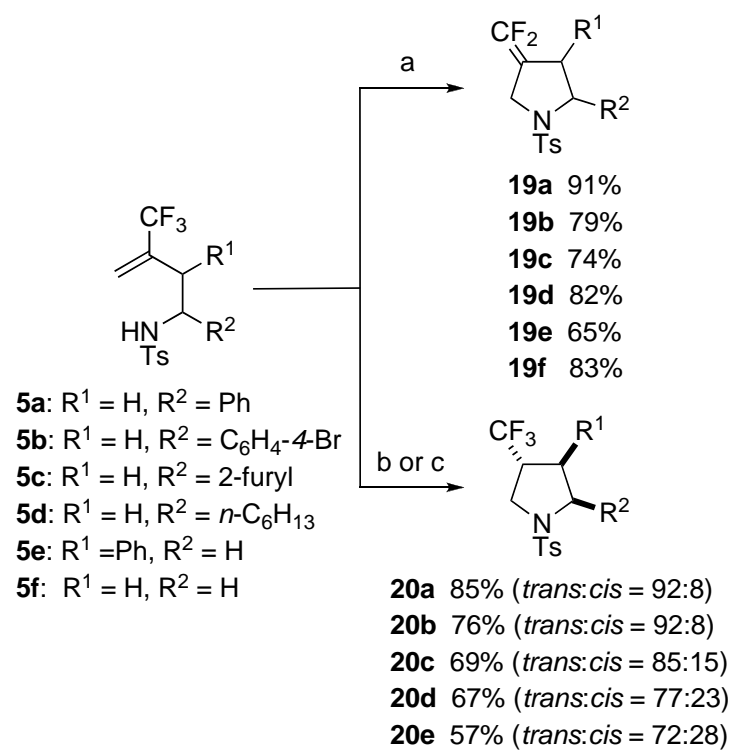

Scheme 11. Synthesis of 4-Difluoromethylene- and 4-Trifluoromethyl Pyrrolidines 19 and 20. Reagents and conditions: (a) $\mathrm{NaH}$ (1.3 equiv), $120-130{ }^{\circ} \mathrm{C}, 0.5-4 \mathrm{~h}, \mathrm{DMF}$. (b) $\mathrm{KOH}$ (5 equiv), $130{ }^{\circ} \mathrm{C}, 20 \mathrm{~h},\left(\mathrm{CH}_{2} \mathrm{OH}\right)_{2}$ (for 20a-c and 20e). (c) $\mathrm{KOH}$ (5 equiv), $130{ }^{\circ} \mathrm{C}, 20 \mathrm{~h},\left(\mathrm{CH}_{2} \mathrm{OH}\right)_{2}-\mathrm{THF}(10: 1)$ (for 20d).

\section{Synthesis of Tetrahydrofurans Bearing a Difluoromethylene Group}

We then focused on the construction of oxygen heterocycles. An attempted $\mathrm{S}_{\mathrm{N}} 2^{\prime}$-type cyclization of homoallyl alcohol $\mathbf{4 a}$ resulted in its intramolecular dehydration without accompanying cyclized products. Thus, we examined substrates 7 bearing two alkyl groups at the allylic position to prevent dehydration and to take advantage of the gem-dialkyl effect in cyclization. ${ }^{35}$ On treatment with $\mathrm{KO} t$-Bu in THF at $70{ }^{\circ} \mathrm{C}$, homoallyl alcohols $7 \mathbf{a}-\mathbf{c}$ underwent an $\mathrm{S}_{\mathrm{N}} 2^{\prime}$-type reaction, leading to 4-difluoromethylene-substituted tetrahydrofurans 21a-c in high yields (Scheme 12). ${ }^{36}$ The 1-styrylsubstituted substrate 7d $\left[\mathrm{R}^{1}=\mathrm{R}^{2}=\mathrm{Me}, \mathrm{R}^{3}=\mathrm{CH}=\mathrm{CHPh}(E)\right]$, however, gave a complex mixture presumably due to 3,3 sigmatropic rearrangement. The reaction of $\mathbf{7 a}$ with $\mathrm{KO} t$ - $\mathrm{Bu}$, even when conducted in $t$-BuOH, gave 21a as well as 4(trifluoromethyl)tetrahydrofuran.

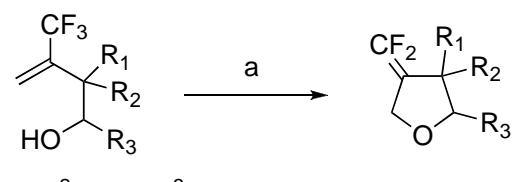

$$
\begin{array}{ll}
\text { 7a: } R^{1}=M e, R^{2}=M e, R^{3}=P h & \text { 21a } 80 \% \\
\text { 7b: } R^{1}, R^{2}=-\left(C_{2}\right)_{4}-, R^{3}=P h & \text { 21b } 70 \% \\
\text { 7c: } R^{1}=M e, R^{2}=M e, R^{3}=\left(C_{2}\right)_{2} C_{6} H_{5} & \text { 21c } 87 \%
\end{array}
$$

Scheme 12. Synthesis of 4-Difluoromethylene Tetrahydrofurans 21. Reagents and conditions: (a) $\mathrm{KO} t-\mathrm{Bu}\left(1.3\right.$ equiv), $70^{\circ} \mathrm{C}, 2.5-6 \mathrm{~h}$, THF.

\section{Synthesis of Tetrahydrothiophenes Bearing Fluorinated One- Carbon Units}

A sulfur nucleophile was employed in the cyclizations for the construction of the tetrahydrothiophene ring. Treatment of thioacetates 8a,b with 1.3 equiv of $\mathrm{NaOMe}$ in DMF generated the corresponding thiolate, which underwent an $\mathrm{S}_{\mathrm{N}} 2^{\prime}$-type reaction to afford 4-(difluoromethylene)tetrahydrothiophenes 22a,b in $82 \%$ and $75 \%$ yield, respectively (Scheme 13). ${ }^{37}$ The addition reaction of $8 \mathbf{a}, \mathbf{b}$ was also readily effected on treatment with 1.1 equiv of $\mathrm{K}_{2} \mathrm{CO}_{3}$ in $\mathrm{MeOH}$ as a proton source (Scheme 13). The desired 4(trifluoromethyl)tetrahydrothiophenes 23a,b were obtained in $90 \%$ and $82 \%$ yield, respectively. ${ }^{38}$

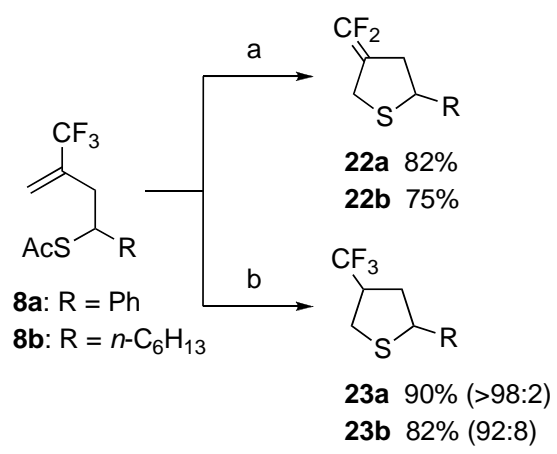

Scheme 13. Synthesis of 3-Difluoromethylene and 3-Trifluoromethyl Tetrahydrothiophenes 22 and 23. Reagents and conditions: (a) $\mathrm{NaOMe}$ (1.3 equiv), $100{ }^{\circ} \mathrm{C}, 10-15 \mathrm{~h}$, DMF. (b) $\mathrm{K}_{2} \mathrm{CO}_{3}$ (1.1 equiv), reflux, $1-2 \mathrm{~h}, \mathrm{MeOH}$.

\section{Synthesis of Cyclopentanes Bearing a Difluoromethylene Group}

Having accomplished heterocycle synthesis, we turned our attention to the 5-endo-trig cyclization of 1-(trifluoromethyl)vinyl compounds with carbon nucleophiles, which would allow the construction of five-membered carbocycles with a fluorinated onecarbon unit. When 3-(trifluoromethyl)homoallyl-substituted malonate and malononitrile $\mathbf{1 0}$ and $\mathbf{1 1}$ were treated with 1.3 equiv of $\mathrm{NaH}$ in DMF, the SN2'-type cyclization successfully proceeded to give difluoromethylene-substituted cyclopentanes $\mathbf{2 4}$ and $\mathbf{2 5}$ in $\mathbf{7 7 \%}$ and $61 \%$ yield, respectively (Scheme 14$).{ }^{39}$

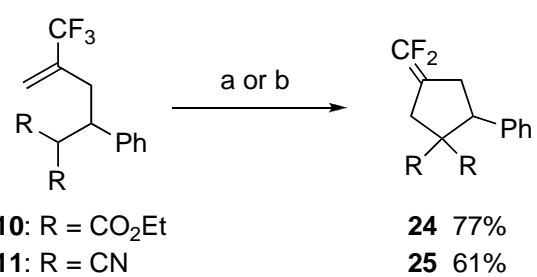

Scheme 14. Synthesis of Difluoromethylene Cyclopentanes 24 and 25. Reagents and conditions: (a) $\mathrm{KH}$ (1.6 equiv), $110^{\circ} \mathrm{C}, 3 \mathrm{~h}, \mathrm{DMF}$ (for 10 ). (b) $\mathrm{NaH}\left(1.3\right.$ equiv), $100{ }^{\circ} \mathrm{C}$, $3 \mathrm{~h}, \mathrm{DMF}$ (for 11)

\section{Conclusion}

In conclusion, we have found that the 1-(trifluoromethyl)vinyl system with a nucleophilic moiety constitutes a new class of compounds that undergoes the normally disfavored 5-endo-trig cyclization. These 'anti-Baldwin' results, based on the intramolecular substitution and addition concept, provide a highyielding process for a variety of five-membered heterocycles and carbocycles. The resulting indolines, indoles, pyrrolidines, tetrahydrofurans, 2,3-dihydrobenzo[b]thiophenes, tetrahydrothiophenes, and cyclopentanes bearing fluorinated onecarbon units $\left(=\mathrm{CF}_{2}, \mathrm{CF}_{3}, \mathrm{CHF}_{2}\right.$, and $\left.\mathrm{CBrF}_{2}\right)$ have so far been less accessible, despite their increasing and potential utility as agrochemicals, pharmaceuticals, and other materials. The 
intramolecular substitution and addition concept opens the way to these fluorinated cyclic compounds.

\section{Experimental Section}

General: IR spectra were recorded by ATR (attenuated total reflectance) method. NMR spectra were recorded in $\mathrm{CDCl}_{3}$ at $500 \mathrm{MHz}\left({ }^{1} \mathrm{H} \mathrm{NMR}\right), 126 \mathrm{MHz}\left({ }^{13} \mathrm{C} \mathrm{NMR}\right)$, and 470 $\mathrm{MHz}\left({ }^{19} \mathrm{~F}\right.$ NMR). Chemical shift values were given in ppm relative to internal $\mathrm{Me}_{4} \mathrm{Si}$ (for ${ }^{1} \mathrm{H}$ NMR: $\delta 0.00$ ), $\mathrm{CDCl}_{3}$ (for ${ }^{13} \mathrm{C}$ NMR: $\delta 77.0$ ), and $\mathrm{C}_{6} \mathrm{~F}_{6}$ (for ${ }^{19} \mathrm{~F}$ NMR: $\delta_{\mathrm{F}} 0.0$ ). Column chromatography and preparative thin-layer chromatography (PTLC) were performed on silica gel. All reactions were conducted under argon. Toluene, $N, N$ dimethylformamide (DMF), $\mathrm{CH}_{2} \mathrm{Cl}_{2}$, THF, and diethylether $\left(\mathrm{Et}_{2} \mathrm{O}\right)$ were dried by passing over a column of activated alumina (A-2, Purity) followed by a column of Q-5 scavenger (Engelhard). $\mathrm{MeOH}$, ethane-1,2-diol, and $\mathrm{EtOH}$ was distilled from $\mathrm{Na}$, and stored over molecular sieves $3 \AA$. Acetonitrile $\left(\mathrm{CH}_{3} \mathrm{CN}\right)$ was distilled from $\mathrm{P}_{2} \mathrm{O}_{5}$ and then from $\mathrm{CaH}_{2}$, and stored over molecular sieves $3 \AA$. Pyridine was distilled from $\mathrm{KOH}$, and stored over molecular sieves $4 \AA$. Benzene was distilled to remove water azeotropically, and stored over molecular sieves $4 \AA$. 2-(3,3,3-Trifluoroprop-1-en-2yl)aniline (1) ${ }^{17}$ [2-(trifluoromethyl)prop-2-en-1-yl] trimethylsilane, ${ }^{18} 3$ (trifluoromethyl)homoallyl alcohols $4,{ }^{18,19}$ tert-butyl $N$ - $(4$

methylbenzenesulfonyl)carbamate, ${ }^{40}$ methyl trifluoromathanesulfonate,${ }^{41}$ and cyano(tributylphosphaniumyl)methanide $\left(\mathrm{Bu}_{3} \mathrm{P}=\mathrm{CHCN}\right)^{21}$ were prepared according to the literature.

\section{Preparation of 4-methyl- $\mathrm{N}$-[2-(3,3,3-trifluoroprop-1-en-2-}

yl)phenyl]benzenesulfonamides (2): To a solution of 2-(3,3,3-trifluoroprop-1-en-2yl)aniline (1) $(0.5 \mathrm{mmol})$ in pyridine $(2.5 \mathrm{~mL})$ was added 4-methylbenzenesulfonyl chloride ( $\mathrm{TsCl}, 0.6 \mathrm{mmol})$ and a catalytic amount of 4-(dimethylamino)pyridine (DMAP, $0.1 \mathrm{mmol}$ ) at $0{ }^{\circ} \mathrm{C}$. The reaction mixture was stirred for $3 \mathrm{~h}$ at rt. The reaction was quenched with phosphate buffer $(\mathrm{pH} 7,10 \mathrm{~mL})$. Organic materials were extracted with EtOAc $(10 \mathrm{~mL} \times 3)$. The combined extracts were washed with aqueous $\mathrm{HCl}(10$ $\mathrm{mL})$, brine $(10 \mathrm{~mL})$, and dried over $\mathrm{MgSO}_{4}$. After removal of the solvent under reduced pressure, the residue was purified by preparative thin layer chromatography to give $\mathbf{2}$. 4-Methyl- $N$-[2-(3,3,3-trifluoroprop-1-en-2-yl)phenyl]benzenesulfonamide (2a): Colorless crystals; yield 84\%; IR (neat): 3282, 1495, 1412, 1346, 1188, 1130, 916, 812, $771,669 \mathrm{~cm}^{-1} ;{ }^{1} \mathrm{H}$ NMR: $\delta=2.38(3 \mathrm{H}, \mathrm{s}), 5.07\left(1 \mathrm{H}, \mathrm{q}, J_{\mathrm{HF}}=1.4 \mathrm{~Hz}\right), 6.07\left(1 \mathrm{H}, \mathrm{q}, J_{\mathrm{HF}}=\right.$ $1.4 \mathrm{~Hz}), 6.42(1 \mathrm{H}, \mathrm{br} \mathrm{s}), 7.10-7.12(2 \mathrm{H}, \mathrm{m}), 7.23(2 \mathrm{H}, \mathrm{d}, J=8.3 \mathrm{~Hz}), 7.32-7.36(1 \mathrm{H}, \mathrm{m})$ $7.64(2 \mathrm{H}, \mathrm{d}, J=8.3 \mathrm{~Hz}), 7.66(1 \mathrm{H}, \mathrm{d}, J=8.4 \mathrm{~Hz}),{ }^{13} \mathrm{C}$ NMR: $\delta=21.5,121.1,122.4(\mathrm{q}$, $\left.J_{\mathrm{CF}}=274 \mathrm{~Hz}\right), 124.6,124.9,125.5\left(\mathrm{q}, J_{\mathrm{CF}}=5 \mathrm{~Hz}\right), 127.3,129.6,130.2,130.5,134.6(\mathrm{q}$ $\left.J_{\mathrm{CF}}=32 \mathrm{~Hz}\right), 134.8,136.1,144.2 ;{ }^{19} \mathrm{~F} \mathrm{NMR}: \delta_{\mathrm{F}}=94.4(\mathrm{br} \mathrm{s})$; elemental analysis: calcd (\%) for $\mathrm{C}_{16} \mathrm{H}_{14} \mathrm{~F}_{3} \mathrm{NO}_{2} \mathrm{~S}$ : C 56.30, H 4.13, N 4.10, found: C 56.49, H 4.29, N 3.97. 4-Methyl- $N$-[4-methyl-2-(3,3,3-trifluoroprop-1-en-2-yl)phenyl]benzenesulfonamide (2b): Colorless crystals; yield 87\%; IR (neat): 3286, 1601, 1496, 1392, 1342, 1161 , $1132,904,727 \mathrm{~cm}^{-1}$; ${ }^{1} \mathrm{H}$ NMR: $\delta=2.28(3 \mathrm{H}, \mathrm{s}), 2.38(3 \mathrm{H}, \mathrm{s}), 4.97\left(1 \mathrm{H}, \mathrm{q}, J_{\mathrm{HF}}=1.2 \mathrm{~Hz}\right)$, $6.00\left(1 \mathrm{H}, \mathrm{q}, J_{\mathrm{HF}}=1.2 \mathrm{~Hz}\right), 6.45(1 \mathrm{H}, \mathrm{s}), 6.91(1 \mathrm{H}, \mathrm{s}), 7.14(1 \mathrm{H}, \mathrm{d}, J=8.4 \mathrm{~Hz}), 7.22(2 \mathrm{H}$, $\mathrm{d}, J=8.3 \mathrm{~Hz}), 7.53(1 \mathrm{H}, \mathrm{d}, J=8.4 \mathrm{~Hz}), 7.61(2 \mathrm{H}, \mathrm{d}, J=8.3 \mathrm{~Hz}) ;{ }^{13} \mathrm{C}$ NMR: $\delta=20.6$, $21.4,122.0,122.4\left(\mathrm{q}, J_{\mathrm{CF}}=274 \mathrm{~Hz}\right), 125.2\left(\mathrm{q}, J_{\mathrm{CF}}=5 \mathrm{~Hz}\right), 125.5,127.3,129.6,130.8$, $130.9,132.1,134.7\left(\mathrm{q}, J_{\mathrm{CF}}=32 \mathrm{~Hz}\right), 134.8,136.3,144.0 ;{ }^{19} \mathrm{~F}$ NMR: $\delta_{\mathrm{F}}=94.6(\mathrm{br} \mathrm{s})$; elemental analysis: calcd (\%) for $\mathrm{C}_{17} \mathrm{H}_{16} \mathrm{~F}_{3} \mathrm{NO}_{2} \mathrm{~S}$ : C $57.46, \mathrm{H} 4.54, \mathrm{~N} 3.94$, found: $\mathrm{C}$ $57.42, \mathrm{H} 4.78, \mathrm{~N} 3.69$

$\mathrm{N}$-[5-Chloro-2-(3,3,3-trifluoroprop-1-en-2-yl)phenyl]-4-methylbenzenesulfonamide (2c): Colorless crystals; yield 92\%; IR (neat): $3388,3282,1597,1493,1389,1342$, $1163,1122,1092 \mathrm{~cm}^{-1}$; ${ }^{1} \mathrm{H}$ NMR: $\delta=2.40(3 \mathrm{H}, \mathrm{s}), 5.15\left(1 \mathrm{H}, \mathrm{q}, J_{\mathrm{HF}}=1.2 \mathrm{~Hz}\right), 6.12(1 \mathrm{H}$, $\left.\mathrm{q}, J_{\mathrm{HF}}=1.2 \mathrm{~Hz}\right), 6.68(1 \mathrm{H}, \mathrm{br} \mathrm{s}), 7.04(1 \mathrm{H}, \mathrm{d}, J=8.3 \mathrm{~Hz}), 7.08(1 \mathrm{H}, \mathrm{dd}, J=8.3,1.9 \mathrm{~Hz})$, $7.27(2 \mathrm{H}, \mathrm{d}, J=8.4 \mathrm{~Hz}), 7.67(2 \mathrm{H}, \mathrm{d}, J=8.4 \mathrm{~Hz}), 7.70(1 \mathrm{H}, \mathrm{d}, J=1.9 \mathrm{~Hz}) ;{ }^{13} \mathrm{C}$ NMR $\delta=21.5,120.6,122.1\left(\mathrm{q}, J_{\mathrm{CF}}=274 \mathrm{~Hz}\right), 122.6,124.6,126.3\left(\mathrm{q}, J_{\mathrm{CF}}=5 \mathrm{~Hz}\right), 127.3$, $129.8,131.4,133.7\left(\mathrm{q}, J_{\mathrm{CF}}=32 \mathrm{~Hz}\right), 135.6,136.0,136.1,144.6 ;{ }^{19} \mathrm{~F} \mathrm{NMR}: \delta_{\mathrm{F}}=94.3(\mathrm{br}$ s); HRMS (FAB): calcd for $\mathrm{C}_{16} \mathrm{H}_{14} \mathrm{ClF}_{3} \mathrm{NO}_{2} \mathrm{~S}\left([\mathrm{M}+\mathrm{H}]^{+}\right) 376.0386$, found 376.0381 $S$-[2-(3,3,3-trifluoroprop-1-en-2-yl)phenyl] ethanethioate (3): To a solution of 2(3,3,3-trifluoroprop-1-en-2-yl)aniline (1a) $(522 \mathrm{mg}, 2.79 \mathrm{mmol})$ in $\mathrm{CH}_{3} \mathrm{CN}(8 \mathrm{~mL})$ were added trifluoroacetic acid (TFA, $0.43 \mathrm{~mL}, 5.6 \mathrm{mmol}$ ) and 3-methylbutyl nitirite $(i$ AmONO, $0.75 \mathrm{~mL}, 5.6 \mathrm{mmol}$ ) at $0{ }^{\circ} \mathrm{C}$. The reaction mixture was stirred for $0.5 \mathrm{~h}$. The solution was treated with AcSNa [prepared from thioacetic $S$-acid (AcSH, $0.60 \mathrm{~mL}, 8.4$ $\mathrm{mmol}$ ) and sodium hydride ( $\mathrm{NaH}, 60 \%$ dispersion in mineral oil; $335 \mathrm{mg}, 8.4 \mathrm{mmol}$ ) in $\operatorname{DMF}(5 \mathrm{~mL})$ at $\left.0{ }^{\circ} \mathrm{C}\right]$, and stirred for $3 \mathrm{~h}$ at $\mathrm{rt}$. The reaction was quenched with phosphate buffer $(\mathrm{pH} 7,10 \mathrm{~mL})$. The mixture was filtered through Celite, and then organic materials were extracted with $\mathrm{Et}_{2} \mathrm{O}(15 \mathrm{~mL} \times 3)$. After removal of the solvent under reduced pressure, the residue was purified by column chromatography (hexaneEtOAc, 10:1) to give $\mathbf{3}$ (214 mg, 31\%) as a pale yellow liquid. IR (neat): 1705, 1473, $1402,1346,1171,1111,1093,906,729 \mathrm{~cm}^{-1}$; ${ }^{1} \mathrm{H}$ NMR: $\delta=2.38(3 \mathrm{H}, \mathrm{s}), 5.52(1 \mathrm{H}, \mathrm{s})$, $6.06(1 \mathrm{H}, \mathrm{s}), 7.36-7.38(1 \mathrm{H}, \mathrm{m}), 7.43-7.45(2 \mathrm{H}, \mathrm{m}), 7.51-7.53(1 \mathrm{H}, \mathrm{m}) ;{ }^{13} \mathrm{C}$ NMR: $\delta=$ $30.0,122.6\left(\mathrm{q}, J_{\mathrm{CF}}=274 \mathrm{~Hz}\right), 123.5\left(\mathrm{q}, J_{\mathrm{CF}}=5 \mathrm{~Hz}\right), 128.1,129.6,129.8,130.7,136.8$, $137.2\left(\mathrm{q}, J_{\mathrm{CF}}=33 \mathrm{~Hz}\right), 138.2,193.4 ;{ }^{19} \mathrm{~F}$ NMR: $\delta_{\mathrm{F}}=95.1(\mathrm{br} \mathrm{s})$; HRMS (FAB): calcd for $\mathrm{C}_{11} \mathrm{H}_{10} \mathrm{~F}_{3} \mathrm{OS}\left([\mathrm{M}+\mathrm{H}]^{+}\right) 247.0404$, found 247.0415 .

Preparation of 4-methyl- $N$-[3-(trifluoromethyl)but-3-en-1-yl]benzenesulfonamides (5):

To a solution of 3-(trifluoromethyl)but-3-en-1-ol (4) (2.0 mmol), triphenylphosphine $\left(\mathrm{PPh}_{3}, 1.05 \mathrm{~g}, 4.00 \mathrm{mmol}\right)$, and tert-butyl $\mathrm{N}$-(4-methylbenzenesulfonyl)carbamate (814 $\mathrm{mg}, 3.00 \mathrm{mmol})$ in THF $(10 \mathrm{~mL})$ was added diethyl azodicarboxylate (DEAD, $40 \%$ in toluene; $1.36 \mathrm{~mL}, 4.0 \mathrm{mmol}$ ) at $0{ }^{\circ} \mathrm{C}$. The reaction mixture was stirred at $0{ }^{\circ} \mathrm{C}$ for $10 \mathrm{~h}$. After removal of the solvent under reduced pressure, the residue was purified by column chromatography to give tert-butyl $N$-(4-methylbenzenesulfonyl)- $N$-[3(trifluoromethyl)but-3-en-1-yl]carbamate. To a solution of tert-butyl $\mathrm{N}$-(4methylbenzenesulfonyl)- $N$-[3-(trifluoromethyl)but-3-en-1-yl]carbamate $(1.5 \mathrm{mmol})$ in $\mathrm{CH}_{2} \mathrm{Cl}_{2}(15 \mathrm{~mL})$ was added TFA $(15 \mathrm{mmol})$ at $\mathrm{rt}$. The reaction mixture was stirred at $\mathrm{rt}$ for $10 \mathrm{~h}$. The reaction was quenched with aqueous $\mathrm{Na}_{2} \mathrm{CO}_{3}(20 \mathrm{~mL})$, and organic materials were extracted with $\mathrm{CH}_{2} \mathrm{Cl}_{2}(15 \mathrm{~mL} \times 3)$. The combined extracts were washed with brine, and dried over $\mathrm{Na}_{2} \mathrm{SO}_{4}$. After removal of the solvent under reduced pressure, the residue was purified by column chromatography to give 5 .

4-Methyl- $\boldsymbol{N}$-[1-phenyl-3-(trifluoromethyl)but-3-en-1-yl]benzenesulfonamide (5a): Colorless crystals; yield 89\%; m.p. 78-80 ${ }^{\circ} \mathrm{C}$; IR (neat): 3269, 3064, 3030, 2927, 1456, 1325, 1159, 1120, $912 \mathrm{~cm}^{-1}$; ${ }^{1} \mathrm{H}$ NMR: $\delta=2.37(3 \mathrm{H}, \mathrm{s}), 2.58(1 \mathrm{H}, \mathrm{dd}, J=15.3,7.2 \mathrm{~Hz})$, $2.71(1 \mathrm{H}, \mathrm{dd}, J=15.3,7.8 \mathrm{~Hz}), 4.49(1 \mathrm{H}, \mathrm{ddd}, J=7.8,7.3,7.2 \mathrm{~Hz}), 4.91(1 \mathrm{H}, \mathrm{br} \mathrm{s})$, $5.19(1 \mathrm{H}, \mathrm{s}), 5.63(1 \mathrm{H}, \mathrm{s}), 7.02-7.04(2 \mathrm{H}, \mathrm{m}), 7.14(2 \mathrm{H}, \mathrm{d}, J=8.2 \mathrm{~Hz}), 7.17-7.19(3 \mathrm{H}$, m), $7.54(2 \mathrm{H}, \mathrm{d}, J=8.2 \mathrm{~Hz}) ;{ }^{13} \mathrm{C}$ NMR: $\delta=21.4,37.6,56.5,121.9\left(\mathrm{q}, J_{\mathrm{CF}}=5 \mathrm{~Hz}\right), 123.3$ $\left(\mathrm{q}, J_{\mathrm{CF}}=272 \mathrm{~Hz}\right), 126.6,127.1,127.8,128.6,129.3,133.4\left(\mathrm{q}, J_{\mathrm{CF}}=30 \mathrm{~Hz}\right), 137.2$, 139.5, 143.2; ${ }^{19} \mathrm{~F}$ NMR: $\delta_{\mathrm{F}}=93.4$ (br s); elemental analysis: calcd $(\%)$ for $\mathrm{C}_{18} \mathrm{H}_{18} \mathrm{~F}_{3} \mathrm{NO}_{2} \mathrm{~S}$ : C 58.53, H 4.91, N 3.79, found: C 58.56, H 5.08, N 3.80. $\mathrm{N}$-[1-(4-Bromophenyl)-3-(trifluoromethyl)but-3-en-1-yl]-4methylbenzenesulfonamide (5b): Colorless crystals; yield $65 \%$; m.p. $131-133{ }^{\circ} \mathrm{C}$; IR (neat): $3263,3066,3030,2924,2872,1489,1321,1155,1117,953 \mathrm{~cm}^{-1} ;{ }^{1} \mathrm{H}$ NMR: $\delta=$ $2.39(3 \mathrm{H}, \mathrm{s}), 2.49(1 \mathrm{H}, \mathrm{dd}, J=15.2,7.2 \mathrm{~Hz}), 2.64(1 \mathrm{H}, \mathrm{dd}, J=15.2,8.0 \mathrm{~Hz}), 4.46(1 \mathrm{H}$ ddd, $J=8.0,7.6,7.2 \mathrm{~Hz}), 5.21(1 \mathrm{H}, \mathrm{s}), 5.61(1 \mathrm{H}, \mathrm{s}), 5.91(1 \mathrm{H}, \mathrm{br} \mathrm{s}), 6.90(2 \mathrm{H}, \mathrm{d}, J=8.4$ $\mathrm{Hz}), 7.12(2 \mathrm{H}, \mathrm{d}, J=8.1 \mathrm{~Hz}), 7.25(2 \mathrm{H}, \mathrm{d}, J=8.1 \mathrm{~Hz}), 7.50(2 \mathrm{H}, \mathrm{d}, J=8.4 \mathrm{~Hz}) ;{ }^{13} \mathrm{C}$ NMR: $\delta=21.4,37.4,55.9,121.6,122.3\left(\mathrm{q}, J_{\mathrm{CF}}=6 \mathrm{~Hz}\right), 123.2\left(\mathrm{q}, J_{\mathrm{CF}}=272 \mathrm{~Hz}\right), 127.0$, $128.4,129.4,131.5,133.0\left(\mathrm{q}, J_{\mathrm{CF}}=30 \mathrm{~Hz}\right), 136.9,138.4,143.6 ;{ }^{19} \mathrm{~F}$ NMR: $\delta_{\mathrm{F}}=93.5(\mathrm{br}$ s); elemental analysis: calcd (\%) for $\mathrm{C}_{18} \mathrm{H}_{17} \mathrm{BrF}_{3} \mathrm{NO}_{2} \mathrm{~S}$ : C 48.23, H 3.82, N 3.12, found: C 48.14, H 3.77, N 2.89

$N$-[1-(2-Furyl)-3-(trifluoromethyl)but-3-en-1-yl]-4-methylbenzenesulfonamide (5c): Colorless crystals; yield 29\%; IR (neat): $3269,1599,1326,1157,1114,1011,949 \mathrm{~cm}^{-1}$; ${ }^{1} \mathrm{H}$ NMR: $\delta=2.38(3 \mathrm{H}, \mathrm{s}), 2.66(1 \mathrm{H}, \mathrm{dd}, J=15.1,8.0 \mathrm{~Hz}), 2.70(1 \mathrm{H}, \mathrm{dd}, J=15.1,7.5$ $\mathrm{Hz}), 4.61(1 \mathrm{H}, \mathrm{ddd}, J=8.6,8.0,7.5 \mathrm{~Hz}), 5.24(1 \mathrm{H}, \mathrm{s}), 5.32(1 \mathrm{H}, \mathrm{d}, J=8.6 \mathrm{~Hz}), 5.64$ $(1 \mathrm{H}, \mathrm{s}), 5.92(1 \mathrm{H}, \mathrm{d}, J=3.2 \mathrm{~Hz}), 6.10(1 \mathrm{H}, \mathrm{dd}, J=3.2,1.8 \mathrm{~Hz}), 7.16(1 \mathrm{H}, \mathrm{d}, J=1.8 \mathrm{~Hz})$ $7.19(2 \mathrm{H}, \mathrm{d}, J=8.1 \mathrm{~Hz}), 7.61(2 \mathrm{H}, \mathrm{d}, J=8.1 \mathrm{~Hz}) ;{ }^{13} \mathrm{C}$ NMR: $\delta=21.4,35.0,50.2,107.8$, $110.0,121.9\left(\mathrm{q}, J_{\mathrm{CF}}=6 \mathrm{~Hz}\right), 123.3\left(\mathrm{q}, J_{\mathrm{CF}}=272 \mathrm{~Hz}\right), 127.0,129.4,132.1\left(\mathrm{q}, J_{\mathrm{CF}}=30\right.$ $\mathrm{Hz}), 137.3,142.1,143.3,151.2 ;{ }^{19} \mathrm{~F}$ NMR: $\delta_{\mathrm{F}}=93.4$ (br s); HRMS (FAB): calcd for $\mathrm{C}_{16} \mathrm{H}_{17} \mathrm{~F}_{3} \mathrm{NO}_{3} \mathrm{~S}\left([\mathrm{M}+\mathrm{H}]^{+}\right) 360.0881$, found 360.0878 4-Methyl- $\boldsymbol{N}$-[2-(trifluoromethyl)dec-1-en-4-yl]benzenesulfonamide (5d): Colorles crystals; yield $61 \%$; m.p. $65-67{ }^{\circ} \mathrm{C}$; IR (neat): $3276,3020,2956,2929,2860,1217$, $1159,1120 \mathrm{~cm}^{-1}$; ${ }^{1} \mathrm{H}$ NMR: $\delta=0.84(3 \mathrm{H}, \mathrm{t}, J=7.1 \mathrm{~Hz}), 1.02-1.32(9 \mathrm{H}, \mathrm{m}), 1.42-1.50$ $(1 \mathrm{H}, \mathrm{m}), 2.26(1 \mathrm{H}, \mathrm{dd}, J=14.9,7.3 \mathrm{~Hz}), 2.37(1 \mathrm{H}, \mathrm{dd}, J=14.9,6.6 \mathrm{~Hz}), 2.42(3 \mathrm{H}, \mathrm{s})$, $3.37-3.44(1 \mathrm{H}, \mathrm{m}), 4.29(1 \mathrm{H}, \mathrm{br} \mathrm{s}), 5.33(1 \mathrm{H}, \mathrm{s}), 5.66(1 \mathrm{H}, \mathrm{s}), 7.29(2 \mathrm{H}, \mathrm{d}, J=8.3 \mathrm{~Hz})$ $7.74(2 \mathrm{H}, \mathrm{d}, J=8.3 \mathrm{~Hz}) ;{ }^{13} \mathrm{C}$ NMR: $\delta=14.0,21.4,22.4,24.9,28.7,31.5,34.3,36.0$, $52.4,121.3\left(\mathrm{q}, J_{\mathrm{CF}}=6 \mathrm{~Hz}\right), 123.2\left(\mathrm{q}, J_{\mathrm{CF}}=272 \mathrm{~Hz}\right), 127.0,129.5,134.3\left(\mathrm{q}, J_{\mathrm{CF}}=29 \mathrm{~Hz}\right)$ 137.9, 143.3; ${ }^{19} \mathrm{~F}$ NMR: $\delta_{\mathrm{F}}=93.6(\mathrm{br} \mathrm{s})$; elemental analysis: calcd $(\%)$ for $\mathrm{C}_{18} \mathrm{H}_{26} \mathrm{~F}_{3} \mathrm{NO}_{2} \mathrm{~S}$ : C 57.27, H 6.94, N 3.71, found: C 57.03, H 7.20, N 3.59.

4-Methyl- $\boldsymbol{N}$-[2-phenyl-3-(trifluoromethyl)but-3-en-1-yl]benzenesulfonamide (5e): Colorless crystals; yield $64 \%$; m.p. $108-110{ }^{\circ} \mathrm{C}$; IR (neat): $3282,3032,1417,1325$, $1159,1124,1093 \mathrm{~cm}^{-1}$; ${ }^{1} \mathrm{H}$ NMR: $\delta=2.44(3 \mathrm{H}, \mathrm{s}), 3.27(1 \mathrm{H}, \mathrm{ddd}, J=13.1,8.1,5.3 \mathrm{~Hz})$, $3.46(1 \mathrm{H}, \mathrm{ddd}, J=13.1,7.4,7.1 \mathrm{~Hz}), 3.62(1 \mathrm{H}, \mathrm{dd}, J=8.1,7.4 \mathrm{~Hz}), 4.51(1 \mathrm{H}, \mathrm{dd}, J=$ $7.1,5.3 \mathrm{~Hz}), 5.45\left(1 \mathrm{H}, \mathrm{q}, J_{\mathrm{HF}}=1.0 \mathrm{~Hz}\right), 5.90\left(1 \mathrm{H}, \mathrm{q}, J_{\mathrm{HF}}=1.0 \mathrm{~Hz}\right), 7.07(2 \mathrm{H}, \mathrm{d}, J=8.1$ $\mathrm{Hz}), 7.25-7.32(5 \mathrm{H}, \mathrm{s}), 7.68(2 \mathrm{H}, \mathrm{d}, J=8.1 \mathrm{~Hz}) ;{ }^{13} \mathrm{C}$ NMR: $\delta=21.5,44.6,46.2,119.9$ $\left(\mathrm{q}, J_{\mathrm{CF}}=6 \mathrm{~Hz}\right), 123.2\left(\mathrm{q}, J_{\mathrm{CF}}=275 \mathrm{~Hz}\right), 127.0,127.8,127.8,129.0,129.8,136.6,137.5$, $138.4\left(\mathrm{q}, J_{\mathrm{CF}}=29 \mathrm{~Hz}\right), 143.7 ;{ }^{19} \mathrm{~F}$ NMR: $\delta_{\mathrm{F}}=94.5(\mathrm{br} \mathrm{s})$; elemental analysis: calcd $(\%)$ for $\mathrm{C}_{18} \mathrm{H}_{18} \mathrm{~F}_{3} \mathrm{NO}_{2} \mathrm{~S}$ : C 58.53, H 4.91, N 3.79, found: C 58.72, H 5.05, N 3.54 4-Methyl- $N$-[3-(trifluoromethyl)but-3-en-1-yl]benzenesulfonamide (5f): To a solution of 3-(trifluoromethyl)but-3-en-1-yl 4-methylbenzenesulfonate (4f) $(506 \mathrm{mg}$, $1.72 \mathrm{mmol})$ and tert-butyl $\mathrm{N}$-(4-methylbenzenesulfonyl)carbamate $(661 \mathrm{mg}, 2.44 \mathrm{mmol})$ in DMF (10 mL) was added $\mathrm{NaH}$ (55\% dispersion in mineral oil; $97 \mathrm{mg}, 2.2 \mathrm{mmol})$ at $0{ }^{\circ} \mathrm{C}$. After being stirred at that temperature for $0.5 \mathrm{~h}$, the reaction mixture was heated at $90{ }^{\circ} \mathrm{C}$ for $4 \mathrm{~h}$. The reaction was quenched with phosphate buffer $(\mathrm{pH} 7,20 \mathrm{~mL})$, and organic materials were extracted with EtOAc $(20 \mathrm{~mL} \times 3)$. The combined extracts were washed with brine $(20 \mathrm{~mL})$, and dried over $\mathrm{MgSO}_{4}$. After removal of the solvent under reduced pressure, crude tert-butyl (4-methylbenzenesulfonyl)- $N$-[3-

(trifluoromethyl)but-3-en-1-yl]carbamate (715 mg) was obtained. To a solution of crude tert-butyl $N$-(4-methylbenzenesulfonyl)- $N$-[3-(trifluoromethyl)but-3-en-1-yl]carbamate $(715 \mathrm{mg})$ in $\mathrm{CH}_{2} \mathrm{Cl}_{2}(20 \mathrm{~mL})$ was added TFA $(1.5 \mathrm{~mL}, 20 \mathrm{mmol})$ at rt. After the mixture was stirred for $6 \mathrm{~h}$, the reaction was quenched with aqueous $\mathrm{NaHCO}_{3}(40 \mathrm{~mL})$. Organic materials were extracted with $\mathrm{CH}_{2} \mathrm{Cl}_{2}(20 \mathrm{~mL} \times 3)$. The combined extracts were washed with brine $(20 \mathrm{~mL})$, and dried over $\mathrm{MgSO}_{4}$. After removal of the solvent under reduced pressure, the residue was purified by column chromatography (hexane-EtOAc, 2:1) to give $\mathbf{5 f}(408 \mathrm{mg}, 81 \%)$ as colorless crystals. m.p. $54-55^{\circ} \mathrm{C}$; IR (neat): $3263,1427,1315$, $1153,1117,945,928,814 \mathrm{~cm}^{-1} ;{ }^{1} \mathrm{H}$ NMR: $\delta=2.42(2 \mathrm{H}, \mathrm{t}, J=6.9 \mathrm{~Hz}), 2.44(3 \mathrm{H}, \mathrm{s})$, $3.14(2 \mathrm{H}, \mathrm{dt}, J=6.9,6.9 \mathrm{~Hz}), 4.50(1 \mathrm{H}, \mathrm{br} \mathrm{s}), 5.37\left(1 \mathrm{H}, \mathrm{q}, J_{\mathrm{HF}}=1.3 \mathrm{~Hz}\right), 5.76(1 \mathrm{H}, \mathrm{q}$, $\left.J_{\mathrm{HF}}=1.4 \mathrm{~Hz}\right), 7.33(2 \mathrm{H}, \mathrm{d}, J=8.1 \mathrm{~Hz}), 7.75(2 \mathrm{H}, \mathrm{d}, J=8.1 \mathrm{~Hz}) ;{ }^{13} \mathrm{C} \mathrm{NMR:} \delta=21.5$, $30.2,41.0,120.9\left(\mathrm{q}, J_{\mathrm{CF}}=6 \mathrm{~Hz}\right), 123.3\left(\mathrm{q}, J_{\mathrm{CF}}=274 \mathrm{~Hz}\right), 127.0,129.8,134.4\left(\mathrm{q}, J_{\mathrm{CF}}=\right.$ $30 \mathrm{~Hz}), 136.7,143.7 ;{ }^{19} \mathrm{~F}$ NMR: $\delta_{\mathrm{F}}=93.3(\mathrm{br} \mathrm{s})$; elemental analysis: calcd $(\%)$ for $\mathrm{C}_{12} \mathrm{H}_{14} \mathrm{~F}_{3} \mathrm{NO}_{2} \mathrm{~S}$ : C 49.14, H 4.81, N 4.78, found: C 49.27, H 4.96, N 4.59. 1-Phenyl-3-(trifluoromethyl)but-3-en-1-one (26): To a mixture of pyridinium chlorochromate $(38.4 \mathrm{~g}, 178 \mathrm{mmol})$ and silica gel $(38.4 \mathrm{~g})$ in $\mathrm{CH}_{2} \mathrm{Cl}_{2}(350 \mathrm{~mL})$ was added 1-phenyl-3-(trifluoromethyl)but-3-en-1-ol (4a) (13.9 g, $64.4 \mathrm{mmol})$. The reaction mixture was stirred for $2 \mathrm{~h}$ at $\mathrm{rt}$, and then diluted with $\mathrm{Et}_{2} \mathrm{O}$. The solid materials were removed by filtration through a short column of Florisil. After removal of the solvent under reduced pressure, the residue was purified by column chromatography (hexaneEtOAc, 4:1) to give $\mathbf{2 6}(12.2 \mathrm{~g}, 88 \%)$ as colorless crystals. IR (neat): $3062,1689,1414$, $1358,1323,1169,1115,1005,949,754,688 \mathrm{~cm}^{-1} ;{ }^{1} \mathrm{H}$ NMR: $\delta=3.85(2 \mathrm{H}, \mathrm{s}), 5.51(1 \mathrm{H}$ br s), $5.95(1 \mathrm{H}, \mathrm{br} \mathrm{s}), 7.48(2 \mathrm{H}, \mathrm{dd}, J=7.7,7.7 \mathrm{~Hz}), 7.60(1 \mathrm{H}, \mathrm{t}, J=7.7 \mathrm{~Hz}), 7.96(2 \mathrm{H}, \mathrm{d}$ $J=7.7 \mathrm{~Hz}) ;{ }^{13}$ C NMR: $\delta=38.7,122.6\left(\mathrm{q}, J_{\mathrm{CF}}=6 \mathrm{~Hz}\right), 123.1\left(\mathrm{q}, J_{\mathrm{CF}}=272 \mathrm{~Hz}\right), 128.3$, $128.7,131.8\left(\mathrm{q}, J_{\mathrm{CF}}=31 \mathrm{~Hz}\right), 133.5,135.9,194.8 ;{ }^{19} \mathrm{~F} \mathrm{NMR:} \delta_{\mathrm{F}}=92.9(\mathrm{br} \mathrm{s})$; elemental analysis: calcd (\%) for $\mathrm{C}_{11} \mathrm{H}_{9} \mathrm{~F}_{3} \mathrm{O}$ : C $61.68, \mathrm{H} 4.24$, found: $\mathrm{C} 61.75, \mathrm{H} 4.39$ 2-Methyl-1-phenyl-3-(trifluoromethyl)but-3-en-1-one (27): To a solution of 1 phenyl-3-(trifluoromethyl)but-3-en-1-one (26) $(500 \mathrm{mg}, 2.33 \mathrm{mmol})$ in $\mathrm{Et}_{2} \mathrm{O}(20 \mathrm{~mL})$ was added a solution of potassium hexamethyldisilazide (KHMDS, $0.56 \mathrm{M}$ in toluene; 
$4.1 \mathrm{~mL}, 2.3 \mathrm{mmol}$ ) dropwise, and the reaction mixture was stirred for $40 \mathrm{~min}$ at $-78^{\circ} \mathrm{C}$. Methyl trifluoromethanesulfonate $(0.26 \mathrm{~mL}, 2.3 \mathrm{mmol})$ was added at that temperature, and then the mixture was allowed to warm up to rt. After stirring for $6 \mathrm{~h}$, reaction was quenched with phosphate buffer $(\mathrm{pH} 7,20 \mathrm{~mL})$, and organic materials were extracted with EtOAc $(10 \mathrm{~mL} \times 3)$. The combined extracts were washed with brine $(10 \mathrm{~mL})$, and dried over $\mathrm{MgSO}_{4}$. After removal of the solvent under reduced pressure, the residue wa purified by preparative thin layer chromatography (hexane-EtOAc, 4:1) to give 27 (429 $\mathrm{mg}, 81 \%$ ) as a colorless liquid. IR (neat): $2987,2943,1687,1273,1219,1169,1115$, $962,704,687 \mathrm{~cm}^{-1}$; ${ }^{1} \mathrm{H}$ NMR: $\delta=1.42(3 \mathrm{H}, \mathrm{d}, J=6.8 \mathrm{~Hz}), 4.36(1 \mathrm{H}, \mathrm{q}, J=6.8 \mathrm{~Hz})$, $5.52(1 \mathrm{H}, \mathrm{br} \mathrm{s}), 5.87(1 \mathrm{H}, \mathrm{br} \mathrm{s}), 7.47(2 \mathrm{H}, \mathrm{dd}, J=7.2,7.2 \mathrm{~Hz}), 7.58(1 \mathrm{H}, \mathrm{t}, J=7.2 \mathrm{~Hz})$ $7.90(2 \mathrm{H}, \mathrm{d}, J=7.2 \mathrm{~Hz}) ;{ }^{13} \mathrm{C}$ NMR: $\delta=17.8,40.2,120.7\left(\mathrm{q}, J_{\mathrm{CF}}=6 \mathrm{~Hz}\right), 123.5\left(\mathrm{q}, J_{\mathrm{CF}}=\right.$ $272 \mathrm{~Hz}), 128.4,128.7,133.3,135.5,137.9\left(\mathrm{q}, J_{\mathrm{CF}}=30 \mathrm{~Hz}\right), 198.5 ;{ }^{19} \mathrm{~F}$ NMR: $\delta_{\mathrm{F}}=94.0$ (br s); elemental analysis: calcd (\%) for $\mathrm{C}_{12} \mathrm{H}_{11} \mathrm{~F}_{3} \mathrm{O}$ : C 63.16, $\mathrm{H} 4.86$, found: $\mathrm{C} 63.13, \mathrm{H}$ 5.05 .

2,2-Dimethyl-1-phenyl-3-(trifluoromethyl)but-3-en-1-one (6a): To a solution of 2methyl-1-phenyl-3-(trifluoromethyl)but-3-en-1-one (27) (205 mg, $0.90 \mathrm{mmol})$ in $\mathrm{Et}_{2} \mathrm{O}$ $(10 \mathrm{~mL})$ was added a solution of KHMDS $(0.56 \mathrm{M}$ in toluene; $1.6 \mathrm{~mL}, 0.90 \mathrm{mmol})$ dropwise, and the reaction mixture was stirred for $1 \mathrm{~h}$ at $-78^{\circ} \mathrm{C}$. Methyl trifluoromethanesulfonate $(0.11 \mathrm{~mL}, 0.90 \mathrm{mmol})$ was added at that temperature, and then the mixture was allowed to warm up to rt. After stirring for $12 \mathrm{~h}$, reaction was quenched with phosphate buffer $(\mathrm{pH} 7,10 \mathrm{~mL})$, and organic materials were extracted with EtOAc $(10 \mathrm{~mL} \times 3)$. The combined extracts were washed with brine $(10 \mathrm{~mL})$, and dried over $\mathrm{MgSO}_{4}$. After removal of the solvent under reduced pressure, the residue was purified by column chromatography (hexane-EtOAc, $5: 1)$ to give $\mathbf{6 a}(110 \mathrm{mg}, 51 \%)$ as a colorless liquid. IR (neat): 2987, 1684, 1323, 1246, 1178, 1119, 1092, 972, 719, 690 $\mathrm{cm}^{-1} ;{ }^{1} \mathrm{H}$ NMR: $\delta=1.53(6 \mathrm{H}, \mathrm{s}), 5.60(1 \mathrm{H}, \mathrm{br} \mathrm{s}), 5.93(1 \mathrm{H}, \mathrm{br} \mathrm{s}), 7.38(2 \mathrm{H}, \mathrm{dd}, J=8.0$ $8.0 \mathrm{~Hz}), 7.48(1 \mathrm{H}, \mathrm{t}, J=8.0 \mathrm{~Hz}), 7.85(2 \mathrm{H}, \mathrm{d}, J=8.0 \mathrm{~Hz}) ;{ }^{13} \mathrm{C} \mathrm{NMR:} \delta=26.4,49.8$, $120.4\left(\mathrm{q}, J_{\mathrm{CF}}=6 \mathrm{~Hz}\right), 123.6\left(\mathrm{q}, J_{\mathrm{CF}}=276 \mathrm{~Hz}\right), 128.1,129.2,132.1,135.6,143.5\left(\mathrm{q}, J_{\mathrm{CF}}\right.$ $=27 \mathrm{~Hz}), 200.8 ;{ }^{19} \mathrm{~F}$ NMR: $\delta_{\mathrm{F}}=100.3(\mathrm{br} \mathrm{s})$; elemental analysis: calcd $(\%)$ for $\mathrm{C}_{13} \mathrm{H}_{13} \mathrm{~F}_{3} \mathrm{O}$ : C 64.46, H 5.41, found: C 64.25, H 5.58

Phenyl[1-(3,3,3-trifluoroprop-1-en-2-yl)cyclopentyl]methanone (6b): To a solution of 1-phenyl-3-(trifluoromethyl)but-3-en-1-one (4a) $(1.29 \mathrm{~g}, 6.0 \mathrm{mmol})$ in $\mathrm{Et}_{2} \mathrm{O}(30 \mathrm{~mL})$ was added a solution of KHMDS $(0.50 \mathrm{M}$ in toluene; $12.6 \mathrm{~mL}, 6.3 \mathrm{mmol})$ dropwise at $78{ }^{\circ} \mathrm{C}$. The reaction mixture was stirred for $10 \mathrm{~min}$ at $0{ }^{\circ} \mathrm{C}$, and was transferred to a solution of 1,4-diiodobutane $(4.7 \mathrm{~mL}, 36 \mathrm{mmol})$ and hexamethylphosphoric triamide (HMPA, $10 \mathrm{~mL}$ ) in $\mathrm{Et}_{2} \mathrm{O}(30 \mathrm{~mL})$ at $-78^{\circ} \mathrm{C}$. The reaction mixture was allowed to warm up to rt, and stirred for $12 \mathrm{~h}$. Reaction was quenched with phosphate buffer $(\mathrm{pH} 7,30$ $\mathrm{mL})$, and organic materials were extracted with EtOAc $(10 \mathrm{~mL} \times 3)$. The combined extracts were washed with brine $(10 \mathrm{~mL})$, and dried over $\mathrm{MgSO}_{4}$. After removal of the solvent under reduced pressure, the residue was purified by column chromatography (hexane-EtOAc, 20:1 to 5:1) to give a mixture of $\mathbf{6 b}$ and 2-(4-iodobutyl)-1-phenyl-3(trifluoromethyl)but-3-en-1-one (1.82 $\mathrm{g}$ ) as a colorless liquid. To a solution of the mixture $(1.43 \mathrm{~g})$ in $\mathrm{Et}_{2} \mathrm{O}(30 \mathrm{~mL})$ was added a solution of KHMDS $(0.50 \mathrm{M}$ in toluene; $7.22 \mathrm{~mL}, 3.6 \mathrm{mmol}$ ) dropwise at $-78^{\circ} \mathrm{C}$. The reaction mixture was stirred for $5 \mathrm{~min}$ at $78^{\circ} \mathrm{C}$, and allowed to warm up to rt. After stirring for $4 \mathrm{~h}$, the reaction was quenched with phosphate buffer $(\mathrm{pH} 7,30 \mathrm{~mL})$, and organic materials were extracted with EtOAc $(10 \mathrm{~mL} \times 3)$. The combined extracts were washed with brine $(10 \mathrm{~mL})$, and dried over $\mathrm{MgSO}_{4}$. After removal of the solvent under reduced pressure, the residue was purified by column chromatography (hexane-EtOAc, 20:1) to give $\mathbf{6 b}(0.90 \mathrm{~g}, 67 \%$ for 2 steps) as a colorless liquid. IR (neat): 2958, 2925, 2854, 1684, 1317, 1234, 1167, $1126 \mathrm{~cm}^{-1}$, ${ }^{1} \mathrm{H}$ NMR: $\delta=1.56-1.64(2 \mathrm{H}, \mathrm{m}), 1.67-1.76(2 \mathrm{H}, \mathrm{m}), 2.02(2 \mathrm{H}, \mathrm{ddd}, J=13.0,6.5,6.5$ $\mathrm{Hz}), 2.46(2 \mathrm{H}$, ddd, $J=13.0,6.5,6.5 \mathrm{~Hz}), 5.55\left(1 \mathrm{H}, \mathrm{q}, J_{\mathrm{HF}}=1.0 \mathrm{~Hz}\right), 5.87\left(1 \mathrm{H}, \mathrm{q}, J_{\mathrm{HF}}=\right.$ $0.9 \mathrm{~Hz}), 7.38(2 \mathrm{H}, \mathrm{dd}, J=7.5,7.5 \mathrm{~Hz}), 7.48(1 \mathrm{H}, \mathrm{t}, J=7.5 \mathrm{~Hz}), 7.88(2 \mathrm{H}, \mathrm{d}, J=7.5$ $\mathrm{Hz}) ;{ }^{13} \mathrm{C}$ NMR: $\delta=24.3,35.9,60.7,119.9\left(\mathrm{q}, J_{\mathrm{CF}}=6 \mathrm{~Hz}\right), 123.6\left(\mathrm{q}, J_{\mathrm{CF}}=277 \mathrm{~Hz}\right)$, $128.1,129.5,132.2,135.4,142.1\left(\mathrm{q}, J_{\mathrm{CF}}=27 \mathrm{~Hz}\right), 199.2 ;{ }^{19} \mathrm{~F}$ NMR: $\delta_{\mathrm{F}}=99.9(\mathrm{br} \mathrm{s})$ HRMS (FAB): calcd for $\mathrm{C}_{15} \mathrm{H}_{16} \mathrm{~F}_{3} \mathrm{O}\left([\mathrm{M}+\mathrm{H}]^{+}\right)$269.1153, found 269.1178 .

1-Phenyl-5-(trifluoromethyl)hex-5-en-3-one (28): To a mixture of pyridinium chlorochromate $(13.6 \mathrm{~g}, 63.2 \mathrm{mmol})$ and silica gel $(14 \mathrm{~g})$ in dichloromethane $(126 \mathrm{~mL})$ was added 5-trifluoromethyl-1-phenylhex-5-en-3-ol (10.3 g, $42.2 \mathrm{mmol})$. The reaction mixture was stirred for $12 \mathrm{~h}$ at rt, and then diluted with $\mathrm{Et}_{2} \mathrm{O}$. The solid materials were removed by filtration through Celite. After removal of the solvent under reduced pressure, the residue was purified by column chromatography (hexane- $\mathrm{Et}_{2} \mathrm{O}, 5: 1$ ) to give $28(9.81 \mathrm{~g}, 96 \%)$ as a colorless liquid. IR (neat): 3030, 2927, 1722, 1604, 1496 , $1456,1412,1363,1308,1169,1113,950,748,698 \mathrm{~cm}^{-1} ;{ }^{1} \mathrm{H}$ NMR: $\delta=2.82(2 \mathrm{H}, \mathrm{t}, J=$ $7.6 \mathrm{~Hz}), 2.92(2 \mathrm{H}, \mathrm{t}, J=7.6 \mathrm{~Hz}), 3.25(2 \mathrm{H}, \mathrm{s}), 5.45\left(1 \mathrm{H}, \mathrm{q}, J_{\mathrm{HF}}=1.1 \mathrm{~Hz}\right), 5.89(1 \mathrm{H}, \mathrm{q}$ $\left.J_{\mathrm{HF}}=1.5 \mathrm{~Hz}\right), 7.17-7.22(3 \mathrm{H}, \mathrm{m}), 7.29(2 \mathrm{H}, \mathrm{dd}, J=7.6,7.6 \mathrm{~Hz}) ;{ }^{13} \mathrm{C} \mathrm{NMR}: \delta=29.5$, $43.2,43.9,122.7\left(\mathrm{q}, J_{\mathrm{CF}}=6 \mathrm{~Hz}\right), 123.0\left(\mathrm{q}, J_{\mathrm{CF}}=274 \mathrm{~Hz}\right), 126.2,128.3,128.5,131.3(\mathrm{q}$ $\left.J_{\mathrm{CF}}=31 \mathrm{~Hz}\right), 140.5,204.2 ;{ }^{19} \mathrm{~F}$ NMR: $\delta_{\mathrm{F}}=92.7(\mathrm{br} \mathrm{s})$; elemental analysis: calcd $(\%)$ for $\mathrm{C}_{13} \mathrm{H}_{13} \mathrm{~F}_{3} \mathrm{O}: \mathrm{C} 64.46$, H 5.41, found: C 64.68, H 5.60.

4-Methyl-1-phenyl-5-(trifluoromethyl)hex-5-en-3-one (29): To a solution of 1phenyl-5-(trifluoromethyl)hex-5-en-3-one (28) $(9.81 \mathrm{~g}, 40.5 \mathrm{mmol})$ in $\mathrm{Et}_{2} \mathrm{O}(200 \mathrm{~mL})$ was added a solution of KHMDS $(0.70 \mathrm{M}$ in toluene; $59.6 \mathrm{~mL}, 41.7 \mathrm{mmol})$ dropwise at $-78^{\circ} \mathrm{C}$, and the reaction mixture was stirred for $1 \mathrm{~h}$ at that temperature. Methyl trilfluoromethanesulfonate $(9.2 \mathrm{~mL}, 81 \mathrm{mmol})$ was added, and the mixture was stirred for $15 \mathrm{~min}$. After being allowed to warm up to rt, the reaction mixture was stirred for 12

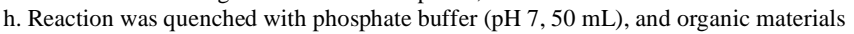
were extracted with EtOAc $(30 \mathrm{~mL} \times 3)$. The combined extracts were washed with brine $(30 \mathrm{~mL})$, and dried over $\mathrm{MgSO}_{4}$. After removal of the solvent under reduced pressure, the residue was purified by column chromatography (hexane-EtOAc, 20:1) to give $\mathbf{2 9}$ $(9.74 \mathrm{~g}, 94 \%)$ as a colorless liquid. IR (neat): $3030,2983,2941,1720,1604,1496,1454$ $1415,1304,1277,1171,1115,953,748,698 \mathrm{~cm}^{-1} ;{ }^{1} \mathrm{H}$ NMR: $\delta=1.25(3 \mathrm{H}, \mathrm{d}, J=7.0$ $\mathrm{Hz}), 2.71-2.78(1 \mathrm{H}, \mathrm{m}), 2.81-2.90(3 \mathrm{H}, \mathrm{m}), 3.37(1 \mathrm{H}, \mathrm{q}, J=7.0 \mathrm{~Hz}), 5.35(1 \mathrm{H}, \mathrm{s}), 5.80$ $(1 \mathrm{H}, \mathrm{s}), 7.15-7.20(3 \mathrm{H}, \mathrm{m}), 7.27(2 \mathrm{H}, \mathrm{dd}, J=7.5,7.5 \mathrm{~Hz}) ;{ }^{13} \mathrm{C}$ NMR: $\delta=16.5,29.7$ $42.6,45.7,120.3\left(\mathrm{q}, J_{\mathrm{CF}}=6 \mathrm{~Hz}\right), 123.4\left(\mathrm{q}, J_{\mathrm{CF}}=274 \mathrm{~Hz}\right), 126.1,128.3,128.4,137.6(\mathrm{q}$ $\left.J_{\mathrm{CF}}=30 \mathrm{~Hz}\right), 140.7,207.3 ;{ }^{19} \mathrm{~F}$ NMR: $\delta_{\mathrm{F}}=93.3(\mathrm{br} \mathrm{s})$; elemental analysis: calcd $(\%)$ for $\mathrm{C}_{14} \mathrm{H}_{15} \mathrm{~F}_{3} \mathrm{O}$ : C 65.62, H 5.90, found: C 65.84, H 6.13.

4,4-Dimethyl-1-phenyl-5-(trifluoromethyl)hex-5-en-3-one (6c): To a solution of 4methyl-1-phenyl-5-(trifluoromethyl)hex-5-en-3-one (29) (5.72 g, $22.3 \mathrm{mmol}$ ) in $\mathrm{Et}_{2} \mathrm{O}$
(200 mL) was added a solution of KHMDS (0.70 M in toluene; $33.5 \mathrm{~mL}, 23.4 \mathrm{mmol})$ dropwise at $-105{ }^{\circ} \mathrm{C}$, and the reaction mixture was stirred for $30 \mathrm{~min}$ at $-90{ }^{\circ} \mathrm{C}$. Methyl trifluoromethanesulfonate $(5.05 \mathrm{~mL}, 44.6 \mathrm{mmol})$ was added at $-105{ }^{\circ} \mathrm{C}$, and the mixture was stirred for $10 \mathrm{~min}$ at that temperature. After being allowed to warm up to rt, the mixture was stirred for $2 \mathrm{~h}$. Reaction was quenched with phosphate buffer $(\mathrm{pH} 7,30$ $\mathrm{mL})$, and organic materials were extracted with EtOAc $(30 \mathrm{~mL} \times 3)$. The combined extracts were washed with brine $(30 \mathrm{~mL})$, and dried over $\mathrm{MgSO}_{4}$. After removal of the solvent under reduced pressure, the residue was purified by column chromatography (hexane-EtOAc, $20: 1)$ to give $\mathbf{6 c}(4.38 \mathrm{~g}, 73 \%)$ as a colorless liquid. IR (neat): 3028 , 2983, 2941, 1716, 1454, 1325, 1176, 1126, 1099, $953 \mathrm{~cm}^{-1}$; ${ }^{1} \mathrm{H}$ NMR: $\delta=1.31(6 \mathrm{H}, \mathrm{s})$ $2.73(2 \mathrm{H}, \mathrm{t}, J=7.6 \mathrm{~Hz}), 2.89(2 \mathrm{H}, \mathrm{t}, J=7.6 \mathrm{~Hz}), 5.56(1 \mathrm{H}, \mathrm{s}), 5.91(1 \mathrm{H}, \mathrm{s}), 7.19(2 \mathrm{H}, \mathrm{d}$, $J=7.5 \mathrm{~Hz}), 7.20(1 \mathrm{H}, \mathrm{t}, J=7.5 \mathrm{~Hz}), 7.29(2 \mathrm{H}, \mathrm{dd}, J=7.5,7.5 \mathrm{~Hz}) ;{ }^{13} \mathrm{C} \mathrm{NMR}: \delta=23.5$, $30.1,38.7,50.4,120.8\left(\mathrm{q}, J_{\mathrm{CF}}=6 \mathrm{~Hz}\right), 123.7\left(\mathrm{q}, J_{\mathrm{CF}}=277 \mathrm{~Hz}\right), 126.0,128.3,128.4$, for $\mathrm{C}_{15} \mathrm{H}_{10} \mathrm{~F}_{3} \mathrm{O}\left([\mathrm{M}+\mathrm{H}]^{+}\right) 271.1310$, found 271.1281 .

4,4-Dimethyl-1-phenyl-5-(trifluoromethyl)hexa-1,5-dien-3-one (6d): To a solution of 4,4-dimethyl-1-phenyl-5-(trifluoromethyl)hex-5-en-3-one $(\mathbf{6 c})(2.71 \mathrm{~g}, 10 \mathrm{mmol})$ was added a solution of KHMDS $(0.50 \mathrm{M}$ in toluene; $21.1 \mathrm{~mL}, 10.5 \mathrm{mmol})$ dropwise at -

$78{ }^{\circ} \mathrm{C}$, and the reaction mixture was stirred for $10 \mathrm{~min}$ at $0{ }^{\circ} \mathrm{C}$. Trimethylsilyl chloride ( $2.6 \mathrm{~mL}, 20.1 \mathrm{mmol}$ ) was added at $-78^{\circ} \mathrm{C}$, and the mixture was stirred for $15 \mathrm{~min}$. Afte being allowed to warm up to rt, reaction was quenched with phosphate buffer $(\mathrm{pH} 7,50$ $\mathrm{mL})$, and organic materials were extracted with EtOAc $(30 \mathrm{~mL} \times 3)$. The combined extracts were washed with brine $(30 \mathrm{~mL})$, and dried over $\mathrm{MgSO}_{4}$. After removal of the solvent under reduced pressure, the crude silyl enolate was obtained as pale brown liquid. Then, the crude product was dissolved into $\mathrm{CH}_{3} \mathrm{CN}(20 \mathrm{~mL})$, and the solution was added to a solution of $\mathrm{Pd}(\mathrm{OAc})_{2}(2.9 \mathrm{~g}, 13 \mathrm{mmol})$ in $\mathrm{CH}_{3} \mathrm{CN}(20 \mathrm{~mL})$ at rt. After stirred for $12 \mathrm{~h}$ at $\mathrm{rt}, \mathrm{Et}_{2} \mathrm{O}(50 \mathrm{~mL})$ was added, and the solid materials were removed through Celite. After removal of the solvent under reduced pressure, the residue was purified by column chromatography (hexane-EtOAc, 20:1 to 5:1) to give $6 \mathbf{d}(1.91 \mathrm{~g}$, $71 \%$ ) as a colorless liquid. IR (neat): $2983,2941,1689,1610,1323,1176,1120,1099$, 1053, 982, $953 \mathrm{~cm}^{-1}$; ${ }^{1} \mathrm{H}$ NMR: $\delta=1.42(6 \mathrm{H}, \mathrm{s}), 5.68(1 \mathrm{H}, \mathrm{s}), 6.00(1 \mathrm{H}, \mathrm{s}), 6.91(1 \mathrm{H}, \mathrm{d}$ $J=15.7 \mathrm{~Hz}), 7.37-7.38(3 \mathrm{H}, \mathrm{m}), 7.53(2 \mathrm{H}, \mathrm{dd}, J=3.2,3.2 \mathrm{~Hz}), 7.72(1 \mathrm{H}, \mathrm{d}, J=15.7$ $\mathrm{Hz}) ;{ }^{13} \mathrm{C}$ NMR: $\delta=23.8,49.8,120.2,121.0\left(\mathrm{q}, J_{\mathrm{CF}}=6 \mathrm{~Hz}\right), 123.7\left(\mathrm{q}, J_{\mathrm{CF}}=277 \mathrm{~Hz}\right)$, $128.4,128.8,130.5,134.5,142.8\left(\mathrm{q}, J_{\mathrm{CF}}=28 \mathrm{~Hz}\right), 143.7,198.6 ;{ }^{19} \mathrm{~F} \mathrm{NMR}: \delta_{\mathrm{F}}=$ 100.2 (br s); elemental analysis: calcd (\%) for $\mathrm{C}_{15} \mathrm{H}_{15} \mathrm{~F}_{3} \mathrm{O}$ : C 67.16, H 5.64, found: $\mathrm{C}$ 67.23, H 5.81

Preparation of 2,2-dialkyl- 3-(trifluoromethyl)homoallyl alcohol (7): To a solution of 1-substituted 2,2-dialkyl-3-trifluoromethylbut-3-en-1-one (6) (1.45 mmol) in EtOH $(14 \mathrm{~mL})$ was added sodium borohydride $(84 \mathrm{mg}, 2.2 \mathrm{mmol})$ at $\mathrm{rt}$. The reaction mixture was heated to reflux for $3 \mathrm{~h}$, and then phosphate buffer $(\mathrm{pH} 7,30 \mathrm{~mL})$ was added to quench the reaction. The mixture was extracted with $\mathrm{Et}_{2} \mathrm{O}(5 \mathrm{~mL} \times 3)$. The combined organic extracts were washed with brine, and dried over $\mathrm{Na}_{2} \mathrm{SO}_{4}$. After removal of the solvent under reduced pressure, the residue was purified by preparative thin layer chromatography (hexane-EtOAc, 5:1) to give 7.

2,2-Dimethyl-1-phenyl-3-(trifluoromethyl)but-3-en-1-ol (7a): A colorless liquid; yield 87\%; IR (neat): 3464, 3064, 3022, 2987, 2924, 1454, 1321, 1115, 1092, 1039, 949 $727,702 \mathrm{~cm}^{-1}$; ${ }^{1} \mathrm{H}$ NMR: $\delta=1.08(3 \mathrm{H}, \mathrm{s}), 1.19(3 \mathrm{H}, \mathrm{s}), 1.94(1 \mathrm{H}, \mathrm{d}, J=2.8 \mathrm{~Hz}), 4.85$ $(1 \mathrm{H}, \mathrm{d}, J=2.8 \mathrm{~Hz}), 5.49\left(1 \mathrm{H}, \mathrm{q}, J_{\mathrm{HF}}=1.8 \mathrm{~Hz}\right), 5.92\left(1 \mathrm{H}, \mathrm{q}, J_{\mathrm{HF}}=1.2 \mathrm{~Hz}\right), 7.23-7.32$ $(5 \mathrm{H}, \mathrm{m}) ;{ }^{13} \mathrm{C}$ NMR: $\delta=21.7,23.8,43.0,77.7,122.0\left(\mathrm{q}, J_{\mathrm{CF}}=7 \mathrm{~Hz}\right), 124.4\left(\mathrm{q}, J_{\mathrm{CF}}=277\right.$ $\mathrm{Hz}), 127.5,127.6,128.0,140.2,143.3\left(\mathrm{q}, J_{\mathrm{CF}}=27 \mathrm{~Hz}\right) ;{ }^{19} \mathrm{~F}$ NMR: $\delta_{\mathrm{F}}=100.9(\mathrm{br} \mathrm{s})$; elemental analysis: calcd (\%) for $\mathrm{C}_{13} \mathrm{H}_{15} \mathrm{~F}_{3} \mathrm{O}$ : C 63.93, H 6.19, found: $\mathrm{C} 64.12, \mathrm{H} 6.46$. Phenyl[1-(3,3,3-trifluoroprop-1-en-2-yl)cyclopentyl]methanol (7b): A colorless liquid; yield 86\%; IR (neat): 3464, 3064, 3032, 2962, 2879, 1454, 1301, 1159, 1115 $1078,947,704 \mathrm{~cm}^{-1}$; ${ }^{1} \mathrm{H}$ NMR: $\delta=1.50-1.59(4 \mathrm{H}, \mathrm{m}), 1.78-1.80(1 \mathrm{H}, \mathrm{m}), 1.88-1.94$ $(3 \mathrm{H}, \mathrm{m}), 2.07(1 \mathrm{H}, \mathrm{d}, J=3.0 \mathrm{~Hz}), 4.87(1 \mathrm{H}, \mathrm{d}, J=3.0 \mathrm{~Hz}), 5.29\left(1 \mathrm{H}, \mathrm{q}, J_{\mathrm{HF}}=1.5 \mathrm{~Hz}\right)$, $5.86\left(1 \mathrm{H}, \mathrm{q}, J_{\mathrm{HF}}=1.2 \mathrm{~Hz}\right), 7.24-7.31(5 \mathrm{H}, \mathrm{m}) ;{ }^{13} \mathrm{C} \mathrm{NMR}: \delta=22.7,22.8,32.1,32.6$, $55.9,76.6,123.0\left(\mathrm{q}, J_{\mathrm{CF}}=7 \mathrm{~Hz}\right), 124.4\left(\mathrm{q}, J_{\mathrm{CF}}=277 \mathrm{~Hz}\right), 127.6,127.6,127.7,141.1$, $141.1\left(\mathrm{q}, J_{\mathrm{CF}}=26 \mathrm{~Hz}\right) ;{ }^{19} \mathrm{~F}$ NMR: $\delta_{\mathrm{F}}=101.8(\mathrm{br} \mathrm{s})$; HRMS (FAB): calcd for $\mathrm{C}_{15} \mathrm{H}_{18} \mathrm{~F}_{3} \mathrm{O}$ $\left([\mathrm{M}+\mathrm{H}]^{+}\right) 271.1310$, found 271.1308 .

4,4-Dimethyl-1-phenyl-5-(trifluoromethyl)hex-5-en-3-ol (7c): A colorless liquid; yield $83 \%$; IR (neat): 3456, 3028, 2981, 2929, 1319, 1153, 1117, 1092, 949, 748, 698 $\mathrm{cm}^{-1}$; ${ }^{1} \mathrm{H}$ NMR: $\delta=1.14(3 \mathrm{H}, \mathrm{s}), 1.19(3 \mathrm{H}, \mathrm{s}), 1.55(1 \mathrm{H}, \mathrm{d}, J=5.2 \mathrm{~Hz}), 1.57-1.64(1 \mathrm{H}$, $\mathrm{m}), 1.74-1.82(1 \mathrm{H}, \mathrm{m}), 2.62(1 \mathrm{H}, \mathrm{ddd}, J=13.6,10.0,6.8 \mathrm{~Hz}), 2.92(1 \mathrm{H}, \mathrm{ddd}, J=13.6$, $10.4,5.2 \mathrm{~Hz}), 3.69(1 \mathrm{H}, \mathrm{dd}, J=10.4,5.2 \mathrm{~Hz}), 5.50\left(1 \mathrm{H}, \mathrm{q}, J_{\mathrm{HF}}=2.2 \mathrm{~Hz}\right), 5.88(1 \mathrm{H}, \mathrm{d}$, $\left.J_{\mathrm{HF}}=0.8 \mathrm{~Hz}\right), 7.19-7.30(5 \mathrm{H}, \mathrm{m}) ;{ }^{13} \mathrm{C}$ NMR: $\delta=22.2,23.4,33.4,33.4,42.7,75.5$, $121.1\left(\mathrm{q}, J_{\mathrm{CF}}=7 \mathrm{~Hz}\right), 124.2\left(\mathrm{q}, J_{\mathrm{CF}}=277 \mathrm{~Hz}\right), 125.9,128.4,128.4,142.0,143.8\left(\mathrm{q}, J_{\mathrm{C}}\right.$ $=26 \mathrm{~Hz}) ;{ }^{19} \mathrm{~F}$ NMR: $\delta_{\mathrm{F}}=101.3($ br s $)$; HRMS $(\mathrm{FAB})$ : calcd for $\mathrm{C}_{15} \mathrm{H}_{20} \mathrm{~F}_{3} \mathrm{O}\left([\mathrm{M}+\mathrm{H}]^{+}\right)$ 273.1466 , found 273.1473

4,4-Dimethyl-1-phenyl-5-(trifluoromethyl)hexa-1,5-dien-3-ol (7d): To a solution of 4,4-dimethyl-1-phenyl-5-trifluoromethyl-hexa-1,5-dien-3-one (6d) (150 mg, 0.56 $\mathrm{mmol})$ in $\mathrm{MeOH}(1.3 \mathrm{~mL}$ ) was added cerium (III) chloride $(140 \mathrm{mg}, 0.57 \mathrm{mmol})$ and stirred at $\mathrm{rt}$ for $0.5 \mathrm{~h}$. After cooling the mixture to $0{ }^{\circ} \mathrm{C}$, sodium borohydride $(21 \mathrm{mg}$, $0.56 \mathrm{mmol}$ ) was added to the mixture. The reaction mixture was stirred for $3 \mathrm{~h}$, and then phosphate buffer $(\mathrm{pH} 7,10 \mathrm{~mL})$ was added to quench the reaction. Organic materials were extracted with ether three times. The combined organic extracts were washed with brine, and dried over $\mathrm{Na}_{2} \mathrm{SO}_{4}$. After removal of the solvent under reduced pressure, the residue was purified by preparative thin layer chromatography (hexane-EtOAc, 5:1) to give 7d (117 mg, 77\%) as a colorless liquid. IR (neat): 3433, 3028, 2983, 2887, 1496, $1408,1323,1153,1115,1086,968,754,692 \mathrm{~cm}^{-1}$; ${ }^{1} \mathrm{H}$ NMR: $\delta=1.20(3 \mathrm{H}, \mathrm{s}), 1.26(3 \mathrm{H}$ s), $1.77(1 \mathrm{H}, \mathrm{br} \mathrm{d}, J=3.0 \mathrm{~Hz}), 4.38(1 \mathrm{H}, \mathrm{dd}, J=6.7,3.0 \mathrm{~Hz}), 5.60\left(1 \mathrm{H}, \mathrm{q}, J_{\mathrm{HF}}=1.8 \mathrm{~Hz}\right)$, $5.94\left(1 \mathrm{H}, \mathrm{q}, J_{\mathrm{HF}}=1.2 \mathrm{~Hz}\right), 6.20(1 \mathrm{H}, \mathrm{dd}, J=15.9,6.7 \mathrm{~Hz}), 6.62(1 \mathrm{H}, \mathrm{d}, J=15.9 \mathrm{~Hz})$, $7.25(1 \mathrm{H}, \mathrm{t}, J=7.2 \mathrm{~Hz}), 7.32(2 \mathrm{H}, \mathrm{dd}, J=7.8,7.2 \mathrm{~Hz}), 7.38(2 \mathrm{H}, \mathrm{d}, J=7.8 \mathrm{~Hz}) ;{ }^{13} \mathrm{C}$ NMR: $\delta=22.5,23.4,42.6,76.9,121.6\left(\mathrm{q}, J_{\mathrm{CF}}=7 \mathrm{~Hz}\right), 124.3\left(\mathrm{q}, J_{\mathrm{CF}}=277 \mathrm{~Hz}\right), 126.5$, $127.8,127.8,128.6,132.7,136.6,143.3\left(\mathrm{q}, J_{\mathrm{CF}}=28 \mathrm{~Hz}\right) ;{ }^{19} \mathrm{~F}$ NMR: $\delta_{\mathrm{F}}=101.3(\mathrm{br} \mathrm{s})$; HRMS (FAB): calcd for $\mathrm{C}_{15} \mathrm{H}_{18} \mathrm{~F}_{3} \mathrm{O}\left([\mathrm{M}+\mathrm{H}]^{+}\right) 271.1310$, found 271.1334 $S$-[1-Phenyl-3-(trifluoromethyl)but-3-en-1-yl] ethanethioate (8a): To a solution of 1 phenyl-3-(trifluoromethyl)but-3-en-1-ol (4a) $(520 \mathrm{mg}, 2.41 \mathrm{mmol}), \mathrm{PPh}_{3}(1.90 \mathrm{~g}, 7.23$ $\mathrm{mmol})$, and thioacetic acid $(0.345 \mathrm{~mL}, 3.6 \mathrm{mmol})$ in THF $(15 \mathrm{~mL})$ was added DEAD 
( $40 \%$ in toluene solution; $3.45 \mathrm{~mL}, 6.83 \mathrm{mmol}$ ) at $-10^{\circ} \mathrm{C}$. The reaction mixture was stirred at $0{ }^{\circ} \mathrm{C}$ for $12 \mathrm{~h}$. After removal of the solvent under reduced pressure, the residue was purified by column chromatography (hexane-EtOAc, 50:1) to give $8 \mathbf{a}(224 \mathrm{mg}$, $34 \%$ ) as a pale yellow liquid. IR (neat): $3064,3032,2929,1693,1217,1169,1124 \mathrm{~cm}^{-1}$ ${ }^{1} \mathrm{H}$ NMR: $\delta=2.30(3 \mathrm{H}, \mathrm{s}), 2.82(1 \mathrm{H}, \mathrm{dd}, J=15.8,8.7 \mathrm{~Hz}), 2.87(1 \mathrm{H}, \mathrm{dd}, J=15.8,7.2$ $\mathrm{Hz}), 4.81(1 \mathrm{H}, \mathrm{dd}, J=8.7,7.2 \mathrm{~Hz}), 5.21(1 \mathrm{H}, \mathrm{s}), 5.66(1 \mathrm{H}, \mathrm{s}), 7.23-7.33(5 \mathrm{H}, \mathrm{m}) ;{ }^{13} \mathrm{C}$ NMR: $\delta=30.3,35.7,45.8,120.9\left(\mathrm{q}, J_{\mathrm{CF}}=6 \mathrm{~Hz}\right), 123.4\left(\mathrm{q}, J_{\mathrm{CF}}=272 \mathrm{~Hz}\right), 127.7,127.7$, $128.7,134.6\left(\mathrm{q}, J_{\mathrm{CF}}=30 \mathrm{~Hz}\right), 140.1,194.0 ;{ }^{19} \mathrm{~F}$ NMR: $\delta_{\mathrm{F}}=93.4(\mathrm{br} \mathrm{s})$; elemental analysis: calcd (\%) for $\mathrm{C}_{13} \mathrm{H}_{13} \mathrm{~F}_{3} \mathrm{OS}$ : C $56.92, \mathrm{H} 4.78$, found: C $56.89, \mathrm{H} 4.90$. $S$-[2-(Trifluoromethyl)dec-1-en-4-yl] ethanethioate $(8 \mathrm{~b})$ : To a solution of 2 (trifluoromethyl)dec-1-en-4-ol (4d) (540 mg, $2.41 \mathrm{mmol}), \mathrm{PPh}_{3}(1.29 \mathrm{~g}, 4.90 \mathrm{mmol})$, and thioacetic acid $(258 \mu \mathrm{L}, 3.6 \mathrm{mmol})$ in THF $(15 \mathrm{~mL})$ was added DEAD $(40 \%$ in toluene solution; $3.45 \mathrm{~mL}, 6.81 \mathrm{mmol})$ at $-10{ }^{\circ} \mathrm{C}$. The reaction mixture was stirred at $0{ }^{\circ} \mathrm{C}$ for $20 \mathrm{~h}$. After removal of the solvent under reduced pressure, the residue was purified by column chromatography (hexane) to give $\mathbf{8 b}(346 \mathrm{mg}, 51 \%)$ as a pale yellow liquid. IR (neat): 2956, 2929, 2858, 1695, 1458, 1417, 1354, 1319, 1169, 1122, $951 \mathrm{~cm}^{-1}$; ${ }^{1} \mathrm{H}$ NMR: $\delta=0.87(3 \mathrm{H}, \mathrm{t}, J=6.5 \mathrm{~Hz}), 1.27-1.75(10 \mathrm{H}, \mathrm{m}), 2.32(3 \mathrm{H}, \mathrm{s}), 2.47$ $(2 \mathrm{H}, \mathrm{d}, J=7.6 \mathrm{~Hz}), 3.66-3.73(1 \mathrm{H}, \mathrm{m}), 5.41(1 \mathrm{H}, \mathrm{s}), 5.78(1 \mathrm{H}, \mathrm{s}) ;{ }^{13} \mathrm{C}$ NMR: $\delta=14.0$, $22.5,26.6,29.0,30.7,31.6,34.2,34.9,42.4,120.1\left(\mathrm{q}, J_{\mathrm{CF}}=6 \mathrm{~Hz}\right), 123.5\left(\mathrm{q}, J_{\mathrm{CF}}=274\right.$ $\mathrm{Hz}), 135.4\left(\mathrm{q}, J_{\mathrm{CF}}=30 \mathrm{~Hz}\right), 195.2 ;{ }^{19} \mathrm{~F}$ NMR: $\delta_{\mathrm{F}}=93.3(\mathrm{br} \mathrm{s})$; HRMS (FAB): calcd for $\mathrm{C}_{13} \mathrm{H}_{22} \mathrm{~F}_{3} \mathrm{OS}\left([\mathrm{M}+\mathrm{H}]^{+}\right)$283.1343, found 283.1326.

Diethyl [1-phenyl-3-(trifluoromethyl)but-3-en-1-yl]malonate (10): To a mixture of trimethyl[2-(trifluoromethyl)prop-2-en-1-yl]silane (1.06g, $5.82 \mathrm{mmol})$, diethyl 2benzylidenemalonate $(9)(1.44 \mathrm{~g}, 5.80 \mathrm{mmol})$ and molecular sieves $4 \AA(1.0 \mathrm{~g})$ in THF $(15 \mathrm{~mL})$ was added a solution of tetrabutylammonium fluoride (TBAF, $1 \mathrm{M}$ in THF; $0.69 \mathrm{~mL}, 0.69 \mathrm{mmol}$ ) at $\mathrm{rt}$, and the mixture was stirred for $12 \mathrm{~h}$ at $\mathrm{rt}$. The reaction was

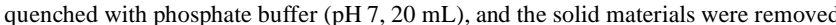
through Celite. After organic materials were extracted with EtOAc $(10 \mathrm{~mL} \times 3)$, the combined extracts were washed with water $(10 \mathrm{~mL} \times 2)$, brine $(10 \mathrm{~mL})$, and dried over $\mathrm{MgSO}_{4}$. After removal of the solvent under reduced pressure, the residue was purified by column chromatography (benzene) to give $\mathbf{1 0}(857 \mathrm{mg}, 41 \%)$ as a colorless liquid. IR (neat): 3032, 2983, 2939, 2906, 1749, 1732, 1369, 1219, 1167, $1122 \mathrm{~cm}^{-1} ;{ }^{1} \mathrm{H}$ NMR: $\delta=0.96(3 \mathrm{H}, \mathrm{t}, J=7.2 \mathrm{~Hz}), 1.29(3 \mathrm{H}, \mathrm{t}, J=7.2 \mathrm{~Hz}), 2.53(1 \mathrm{H}, \mathrm{dd}, J=15.0,10.1 \mathrm{~Hz})$, $2.73(1 \mathrm{H}, \mathrm{dd}, J=15.0,3.2 \mathrm{~Hz}), 3.66(1 \mathrm{H}, \mathrm{d}, J=10.1 \mathrm{~Hz}), 3.68(1 \mathrm{H}, \mathrm{ddd}, J=10.1,10.1$, $3.2 \mathrm{~Hz}), 3.90(2 \mathrm{H}, \mathrm{q}, J=7.1 \mathrm{~Hz}), 4.23(1 \mathrm{H}, \mathrm{dq}, J=10.8,7.2 \mathrm{~Hz}), 4.26(1 \mathrm{H}, \mathrm{dq}, J=10.8$ $7.2 \mathrm{~Hz}), 4.96(1 \mathrm{H}, \mathrm{s}), 5.51(1 \mathrm{H}, \mathrm{s}), 7.19(2 \mathrm{H}, \mathrm{dd}, J=7.6,7.6 \mathrm{~Hz}), 7.20(1 \mathrm{H}, \mathrm{t}, J=7.6$ $\mathrm{Hz}), 7.27(2 \mathrm{H}, \mathrm{d}, J=7.6 \mathrm{~Hz}) ;{ }^{13} \mathrm{C}$ NMR: $\delta=13.6,13.9,33.8,43.7,58.4,61.3,61.7$, $120.8\left(\mathrm{q}, J_{\mathrm{CF}}=6 \mathrm{~Hz}\right), 123.5\left(\mathrm{q}, J_{\mathrm{CF}}=272 \mathrm{~Hz}\right), 127.2,128.3,128.5,134.8\left(\mathrm{q}, J_{\mathrm{CF}}=30\right.$ $\mathrm{Hz}), 139.0,167.4,167.9 ;{ }^{19} \mathrm{~F}$ NMR: $\delta_{\mathrm{F}}=93.5(\mathrm{br} \mathrm{s})$; elemental analysis: calcd $(\%)$ for $\mathrm{C}_{18} \mathrm{H}_{21} \mathrm{~F}_{3} \mathrm{O}_{4}$ : C 60.33, H 5.91, found: C 60.26, H 6.01

[1-Phenyl-3-(trifluoromethyl)but-3-en-1-yl]propanedinitrile (11): To a solution of 1phenyl-3-(trifluoromethyl)but-3-en-1-ol (4a) $(64 \mathrm{mg}, 0.30 \mathrm{mmol})$, and malononitrile (28 $\mathrm{mg}, 0.43 \mathrm{mmol})$ in benzene $(2 \mathrm{~mL})$ was added $\mathrm{Bu}_{3} \mathrm{P}=\mathrm{CHCN}(107 \mathrm{mg}, 0.44 \mathrm{mmol})$ at $\mathrm{rt}$, and the reaction mixture was stirred at $\mathrm{rt}$ for $24 \mathrm{~h}$. After removal of the solvent under reduced pressure, the residue was purified by column chromatography (hexane-EtOAc, 20:1) to give $\mathbf{1 1}(23 \mathrm{mg}, 29 \%)$ as a colorless liquid. IR (neat): 3070, 3035, 2908, 2260, $2192,1456,1348,1169,1120,957 \mathrm{~cm}^{-1} ;{ }^{1} \mathrm{H}$ NMR: $\delta=2.91(1 \mathrm{H}, \mathrm{dd}, J=15.1,8.8 \mathrm{~Hz})$, $2.98(1 \mathrm{H}, \mathrm{dd}, J=15.1,7.0 \mathrm{~Hz}), 3.49-3.54(1 \mathrm{H}, \mathrm{m}), 3.99(1 \mathrm{H}, \mathrm{d}, J=5.4 \mathrm{~Hz}), 5.35(1 \mathrm{H}$, s), $5.79(1 \mathrm{H}, \mathrm{s}), 7.35-7.45(5 \mathrm{H}, \mathrm{m}) ;{ }^{13} \mathrm{C}$ NMR: $\delta=29.3,32.8,44.2,111.2,111.3,123.0$ $\left(\mathrm{q}, J_{\mathrm{CF}}=6 \mathrm{~Hz}\right), 123.1\left(\mathrm{q}, J_{\mathrm{CF}}=272 \mathrm{~Hz}\right), 127.9,129.4,129.4,133.4\left(\mathrm{q}, J_{\mathrm{CF}}=30 \mathrm{~Hz}\right)$ 135.1; ${ }^{19} \mathrm{~F}$ NMR: $\delta_{\mathrm{F}}=94.1$ (br s); elemental analysis: calcd $(\%)$ for $\mathrm{C}_{14} \mathrm{H}_{11} \mathrm{~F}_{3} \mathrm{~N}_{2}: \mathrm{C} 63.63$, H 4.20, N 10.60, found: C 63.38, H 4.33, N 10.33 .

Cyclization of 2 under aprotic conditions: To a suspension of $\mathrm{NaH}$ (60\% dispersion in mineral oil; $104 \mathrm{mg}, 2.6 \mathrm{mmol})$ in DMF ( $3 \mathrm{~mL})$ was added $2(2 \mathrm{mmol})$ in DMF (10 $\mathrm{mL}$ ) at $0{ }^{\circ} \mathrm{C}$. The reaction mixture was stirred for $5-7 \mathrm{~h}$ at $80{ }^{\circ} \mathrm{C}$, and then phosphate buffer $(\mathrm{pH} 7,20 \mathrm{~mL})$ was added to quench the reaction. Organic materials were extracted with EtOAc $(20 \mathrm{~mL} \times 3)$. The combined extracts were washed with water and brine, and dried over $\mathrm{MgSO}_{4}$. After removal of the solvent under reduced pressure, the residue was purified by column chromatography to give 3-difluoromethylene-1-(4methylbenzenesulfonyl)indoline (12).

3-Difluoromethylene-1-(4-methylbenzenesulfonyl)indoline (12a): Colorless crystals; yield $84 \%$; IR (neat): $1760,1597,1475,1464,1362,1269,1169,812,752 \mathrm{~cm}^{-1} ;{ }^{1} \mathrm{H}$ NMR: $\delta=2.37(3 \mathrm{H}, \mathrm{s}), 4.55\left(2 \mathrm{H}, \mathrm{dd}, J_{\mathrm{HF}}=4.1,4.1 \mathrm{~Hz}\right), 7.03(1 \mathrm{H}, \mathrm{dd}, J=7.5,7.5 \mathrm{~Hz})$, 7.22-7.27 (4H, m), 7.67-7.71 (3H, m); ${ }^{13} \mathrm{C}$ NMR: $\delta=21.5,49.2\left(\mathrm{~d}, J_{\mathrm{CF}}=4 \mathrm{~Hz}\right), 88.2$ $\left(\mathrm{dd}, J_{\mathrm{CF}}=22,22 \mathrm{~Hz}\right), 114.8,123.3\left(\mathrm{~d}, J_{\mathrm{CF}}=2 \mathrm{~Hz}\right), 123.4\left(\mathrm{~d}, J_{\mathrm{CF}}=2 \mathrm{~Hz}\right), 124.2,127.2$ $129.0,129.9,133.5,142.7\left(\mathrm{~d}, J_{\mathrm{CF}}=5 \mathrm{~Hz}\right), 144.6,149.8\left(\mathrm{dd} . J_{\mathrm{CF}}=287,287 \mathrm{~Hz}\right) ;{ }^{19} \mathrm{~F}$ NMR: $\delta_{\mathrm{F}}=74.9\left(1 \mathrm{~F}, \mathrm{dt}, J_{\mathrm{FF}}=43 \mathrm{~Hz}, J_{\mathrm{FH}}=4 \mathrm{~Hz}\right), 77.8\left(1 \mathrm{~F}, \mathrm{dt}, J_{\mathrm{FF}}=43 \mathrm{~Hz}, J_{\mathrm{FH}}=4 \mathrm{~Hz}\right)$ elemental analysis: calcd (\%) for $\mathrm{C}_{16} \mathrm{H}_{13} \mathrm{~F}_{2} \mathrm{NO}_{2} \mathrm{~S}$ : C $59.80, \mathrm{H} 4.08, \mathrm{~N} 4.36$, found: $\mathrm{C}$ $59.96, \mathrm{H} 4.25, \mathrm{~N} 4.18$.

\section{3-Difluoromethylene-5-methyl-1-(4-methylbenzenesulfonyl)indoline (12b)}

Colorless crystals; yield 72\%; IR (neat): 2924, 1755, 1475, 1358, 1165, 912, $742 \mathrm{~cm}^{-1}$; ${ }^{1} \mathrm{H}$ NMR: $\delta=2.28(3 \mathrm{H}, \mathrm{s}), 2.36(3 \mathrm{H}, \mathrm{s}), 4.52\left(2 \mathrm{H}, \mathrm{dd}, J_{\mathrm{HF}}=4.3,4.3 \mathrm{~Hz}\right), 7.04(1 \mathrm{H}, \mathrm{d}, J$ $=8.2 \mathrm{~Hz}), 7.06(1 \mathrm{H}, \mathrm{s}), 7.23(2 \mathrm{H}, \mathrm{d}, J=8.3 \mathrm{~Hz}), 7.58(1 \mathrm{H}, \mathrm{d}, J=8.2 \mathrm{~Hz}), 7.65(2 \mathrm{H}, \mathrm{d}, J$ $=8.3 \mathrm{~Hz}) ;{ }^{13} \mathrm{C}$ NMR: $\delta=20.9,21.5,49.4\left(\mathrm{~d}, J_{\mathrm{CF}}=3 \mathrm{~Hz}\right), 88.3\left(\mathrm{dd}, J_{\mathrm{CF}}=22,22 \mathrm{~Hz}\right)$, $114.7,123.7\left(\mathrm{~d}, J_{\mathrm{CF}}=9 \mathrm{~Hz}\right), 124.3\left(\mathrm{dd}, J_{\mathrm{CF}}=6,4 \mathrm{~Hz}\right), 127.2,129.7,129.8,133.5,134.0$ 140.5, 144.4, $149.6\left(\mathrm{dd} . J_{\mathrm{CF}}=288,288 \mathrm{~Hz}\right) ;{ }^{19} \mathrm{~F} \mathrm{NMR}: \delta_{\mathrm{F}}=74.6\left(1 \mathrm{~F}, \mathrm{dt}, J_{\mathrm{FF}}=43 \mathrm{~Hz}\right.$, $\left.J_{\mathrm{FH}}=4 \mathrm{~Hz}\right), 77.5\left(1 \mathrm{~F}, \mathrm{dt}, J_{\mathrm{FF}}=43 \mathrm{~Hz}, J_{\mathrm{FH}}=4 \mathrm{~Hz}\right)$; elemental analysis: calcd $(\%)$ for $\mathrm{C}_{17} \mathrm{H}_{15} \mathrm{~F}_{2} \mathrm{NO}_{2} \mathrm{~S}$ : C 60.88, H 4.51, N 4.18, found: C 60.73, H 4.78, N 3.92. 6-Chloro-3-difluoromethylene-1-(4-methylbenzenesulfonyl)indoline (12c): Colorless crystals; yield 54\%; IR (neat): 3020, 2927, 1757, 1597, 1475, 1363, 1215 , $1167,966 \mathrm{~cm}^{-1}$; ${ }^{1} \mathrm{H}$ NMR: $\delta=2.36(3 \mathrm{H}, \mathrm{s}), 4.52\left(2 \mathrm{H}, \mathrm{dd}, J_{\mathrm{HF}}=4.3,4.3 \mathrm{~Hz}\right), 7.04(1 \mathrm{H}, \mathrm{d}$, $J=8.2 \mathrm{~Hz}), 7.06(1 \mathrm{H}, \mathrm{s}), 7.23(2 \mathrm{H}, \mathrm{d}, J=8.3 \mathrm{~Hz}), 7.58(1 \mathrm{H}, \mathrm{d}, J=8.2 \mathrm{~Hz}), 7.65(2 \mathrm{H}, \mathrm{d}$, $J=8.3 \mathrm{~Hz}) ;{ }^{13} \mathrm{C}$ NMR: $\delta=21.6,49.6\left(\mathrm{~d}, J_{\mathrm{CF}}=3 \mathrm{~Hz}\right), 87.6\left(\mathrm{dd}, J_{\mathrm{CF}}=27,27 \mathrm{~Hz}\right), 114.9$, $122.8\left(\mathrm{dd}, J_{\mathrm{CF}}=4,4 \mathrm{~Hz}\right), 123.9\left(\mathrm{dd}, J_{\mathrm{CF}}=9,2 \mathrm{~Hz}\right), 124.2,127.2,130.0,133.3,134.8$, $143.6\left(\mathrm{~d}, J_{\mathrm{CF}}=5 \mathrm{~Hz}\right), 144.9,149.8\left(\mathrm{dd} . J_{\mathrm{CF}}=289,289 \mathrm{~Hz}\right) ;{ }^{19} \mathrm{~F}$ NMR: $\delta_{\mathrm{F}}=75.7(1 \mathrm{~F}$, dt, $\left.J_{\mathrm{FF}}=41 \mathrm{~Hz}, J_{\mathrm{FH}}=4 \mathrm{~Hz}\right), 78.4\left(1 \mathrm{~F}, \mathrm{dt}, J_{\mathrm{FF}}=41 \mathrm{~Hz}, J_{\mathrm{FH}}=4 \mathrm{~Hz}\right)$; HRMS (FAB): calcd for $\mathrm{C}_{16} \mathrm{H}_{13} \mathrm{ClF}_{2} \mathrm{NO}_{2} \mathrm{~S}\left([\mathrm{M}+\mathrm{H}]^{+}\right)$356.0324, found 356.0332.
Cyclization of 2 under protic conditions: To a solution of $\mathbf{2}(0.30 \mathrm{mmol})$ in DMF ( 3 $\mathrm{mL}$ ) was added 1,8-diazabicyclo[5.4.0]undec-7-ene (DBU, $1.5 \mathrm{mg}, 0.010 \mathrm{mmol}$ ) at rt. After the mixture was stirred at $120^{\circ} \mathrm{C}$ for $0.5-2 \mathrm{~h}$, phosphate buffer $(\mathrm{pH} 7,10 \mathrm{~mL})$ was added to quench the reaction. Organic materials were extracted with $\mathrm{Et}_{2} \mathrm{O}(10 \mathrm{~mL} \times 3)$. The combined extracts were washed with brine and dried over $\mathrm{MgSO}_{4}$. After removal of the solvent under reduced pressure, the residue was purified by column chromatography to give 1-(4-methylbenzenesulfonyl)-3-(trifluoromethyl)indoline (13).

1-(4-Methylbenzenesulfonyl)-3-(trifluoromethyl)indoline (13a): Colorless crystals; yield $81 \%$; IR (neat): 2924, 1597, 1481, 1462, 1360, 1273, 1167, 1124, 1090, 814, 756, $660 \mathrm{~cm}^{-1}$; ${ }^{1} \mathrm{H}$ NMR: $\delta=2.37(3 \mathrm{H}, \mathrm{s}), 3.82-3.90(1 \mathrm{H}, \mathrm{m}), 4.05(1 \mathrm{H}, \mathrm{dd}, J=11.8,5.6 \mathrm{~Hz})$, $4.11(1 \mathrm{H}, \mathrm{dd}, J=11.8,10.3 \mathrm{~Hz}), 7.05(1 \mathrm{H}, \mathrm{dd}, J=7.8,7.8 \mathrm{~Hz}), 7.24(2 \mathrm{H}, \mathrm{d}, J=8.2 \mathrm{~Hz})$ $7.25(1 \mathrm{H}, \mathrm{d}, J=7.8 \mathrm{~Hz}), 7.34(1 \mathrm{H}, \mathrm{dd}, J=7.8,7.8 \mathrm{~Hz}), 7.68(2 \mathrm{H}, \mathrm{d}, J=8.2 \mathrm{~Hz}), 7.70$ $(1 \mathrm{H}, \mathrm{d}, J=7.8 \mathrm{~Hz}) ;{ }^{13} \mathrm{C}$ NMR: $\delta=21.5,44.3\left(\mathrm{q}, J_{\mathrm{CF}}=30 \mathrm{~Hz}\right), 49.2\left(\mathrm{q}, J_{\mathrm{CF}}=3 \mathrm{~Hz}\right)$, $114.9,124.0,124.3,125.3$ (q, $\left.J_{\mathrm{CF}}=279 \mathrm{~Hz}\right), 126.1,127.2,129.8,130.2,133.5,142.9$, 144.6; ${ }^{19} \mathrm{~F}$ NMR: $\delta_{\mathrm{F}}=90.0\left(\mathrm{~d}, J_{\mathrm{FH}}=9 \mathrm{~Hz}\right)$; elemental analysis: calcd $(\%)$ for $\mathrm{C}_{16} \mathrm{H}_{14} \mathrm{~F}_{3} \mathrm{NO}_{2} \mathrm{~S}$ : C 56.30, H 4.13, N 4.10, found: C 56.42, H 4.23, N 4.09. 5-Methyl-1-(4-methylbenzenesulfonyl)-3-(trifluoromethyl)indoline (13b): Colorless crystals; yield 69\%; IR (neat): 3022, 2924, 2362, 1599, 1489, 1358, 1217, 1167, 912 , $771,748 \mathrm{~cm}^{-1}$; ${ }^{1} \mathrm{H}$ NMR: $\delta=2.30(3 \mathrm{H}, \mathrm{s}), 2.37(3 \mathrm{H}, \mathrm{s}), 3.77-3.82(1 \mathrm{H}, \mathrm{m}), 4.02(1 \mathrm{H}$, $\mathrm{dd}, J=11.5,5.6 \mathrm{~Hz}), 4.07(1 \mathrm{H}, \mathrm{dd}, J=11.5,11.5 \mathrm{~Hz}), 7.05(1 \mathrm{H}, \mathrm{s}), 7.14(1 \mathrm{H}, \mathrm{d}, J=8.3$ $\mathrm{Hz}), 7.23(2 \mathrm{H}, \mathrm{d}, J=8.0 \mathrm{~Hz}), 7.59(1 \mathrm{H}, \mathrm{d}, J=8.3 \mathrm{~Hz}), 7.66(2 \mathrm{H}, \mathrm{d}, J=8.0 \mathrm{~Hz}) ;{ }^{13} \mathrm{C}$ NMR: $\delta=20.9,21.5,44.4\left(\mathrm{q}, J_{\mathrm{CF}}=30 \mathrm{~Hz}\right), 49.4\left(\mathrm{q}, J_{\mathrm{CF}}=3 \mathrm{~Hz}\right), 114.9,124.5\left(\mathrm{q}, J_{\mathrm{CF}}=\right.$ $2 \mathrm{~Hz}), 125.4\left(\mathrm{q}, J_{\mathrm{CF}}=279 \mathrm{~Hz}\right), 126.5,127.3,129.8,130.8,133.4,133.9,140.6,144.4$; ${ }^{19} \mathrm{~F}$ NMR: $\delta_{\mathrm{F}}=90.1\left(\mathrm{~d}, J_{\mathrm{FH}}=9 \mathrm{~Hz}\right)$; HRMS $(\mathrm{FAB})$ : calcd for $\mathrm{C}_{17} \mathrm{H}_{17} \mathrm{~F}_{3} \mathrm{NO}_{2} \mathrm{~S}\left([\mathrm{M}+\mathrm{H}]^{+}\right)$ 356.0932, found 356.0947 .

6-Chloro-1-(4-methylbenzenesulfonyl)-3-(trifluoromethyl)indoline (13c): Colorless crystals; yield 71\%; IR (neat): 2920, 1601, 1481, 1358, 1267, 1161, 1117, 1090, 1074 $\mathrm{cm}^{-1}$; ${ }^{1} \mathrm{H}$ NMR: $\delta=2.40(3 \mathrm{H}, \mathrm{s}), 3.78-3.87(1 \mathrm{H}, \mathrm{m}), 4.06(1 \mathrm{H}, \mathrm{dd}, J=11.1,5.1 \mathrm{~Hz})$, $4.12(1 \mathrm{H}, \mathrm{dd}, J=11.1,9.8 \mathrm{~Hz}), 7.02(1 \mathrm{H}, \mathrm{dd}, J=7.7,1.9 \mathrm{~Hz}), 7.16(1 \mathrm{H}, \mathrm{d}, J=7.7 \mathrm{~Hz})$, $7.29(2 \mathrm{H}, \mathrm{d}, J=7.6 \mathrm{~Hz}), 7.69(2 \mathrm{H}, \mathrm{d}, J=7.6 \mathrm{~Hz}), 7.70(1 \mathrm{H}, \mathrm{d}, J=1.9 \mathrm{~Hz}) ;{ }^{13} \mathrm{C}$ NMR: $\delta=21.6,43.8\left(\mathrm{q}, J_{\mathrm{CF}}=30 \mathrm{~Hz}\right), 49.6\left(\mathrm{q}, J_{\mathrm{CF}}=3 \mathrm{~Hz}\right), 115.1,124.1,125.0\left(\mathrm{q}, J_{\mathrm{CF}}=279\right.$ $\mathrm{Hz}), 126.9,127.2,130.0,133.2,136.3,144.0,144.9,149.8 ;{ }^{19} \mathrm{~F}$ NMR: $\delta_{\mathrm{F}}=89.7\left(\mathrm{~d}, J_{\mathrm{FH}}\right.$ $=9 \mathrm{~Hz}$ ); HRMS (FAB): calcd for $\mathrm{C}_{16} \mathrm{H}_{14} \mathrm{ClF}_{3} \mathrm{NO}_{2} \mathrm{~S}\left([\mathrm{M}+\mathrm{H}]^{+}\right)$376.0386, found 376.0381 .

1-(4-Methylbenzenesulfonyl)-3-trifluoromethyl- $1 \mathrm{H}$-indole (14): To a solution of 12a ( $226 \mathrm{mg}, 0.704 \mathrm{mmol})$ in $\mathrm{CH}_{2} \mathrm{Cl}_{2}(3 \mathrm{~mL})$ was added $\mathrm{Et}_{3} \mathrm{~N} \cdot 3 \mathrm{HF}(285 \mathrm{mg}, 1.77 \mathrm{mmol})$ and $\mathrm{N}$-iodosuccinimide $(364 \mathrm{mg}, 1.62 \mathrm{mmol})$ at $-10^{\circ} \mathrm{C}$. After the reaction mixture was stirred at $-10{ }^{\circ} \mathrm{C}$ for $2.5 \mathrm{~h}$, aqueous $\mathrm{Na}_{2} \mathrm{~S}_{2} \mathrm{O}_{3}$ was added to quench the reaction. Organic materials were extracted with EtOAc $(15 \mathrm{~mL} \times 3)$. The combined extracts were washed with brine, and dried over $\mathrm{Na}_{2} \mathrm{SO}_{4}$. After removal of the solvent under reduced pressure, the residue was purified by column chromatography (hexane-EtOAc, 5:1) to give $\mathbf{1 4}$ $(214 \mathrm{mg}, 90 \%)$ as colorless crystals. IR (neat): $3124,3064,2978,1595,1448,1387$, 1176, 1147, 1030, $912 \mathrm{~cm}^{-1}$; ${ }^{\mathrm{H}} \mathrm{NMR}: \delta=2.37(3 \mathrm{H}, \mathrm{s}), 7.28(2 \mathrm{H}, \mathrm{d}, J=8.5 \mathrm{~Hz}), 7.33$ $(1 \mathrm{H}, \mathrm{dd}, J=7.7,7.7 \mathrm{~Hz}), 7.40(1 \mathrm{H}, \mathrm{dd}, J=7.7,7.7 \mathrm{~Hz}), 7.66(1 \mathrm{H}, \mathrm{d}, J=7.7 \mathrm{~Hz}), 7.82$ $(2 \mathrm{H}, \mathrm{d}, J=8.5 \mathrm{~Hz}), 7.94\left(1 \mathrm{H}, \mathrm{q}, J_{\mathrm{HF}}=1.4 \mathrm{~Hz}\right), 7.99(1 \mathrm{H}, \mathrm{d}, J=7.7 \mathrm{~Hz}) ;{ }^{13} \mathrm{C}$ NMR: $\delta=$ $21.6,112.9\left(\mathrm{q}, J_{\mathrm{CF}}=37 \mathrm{~Hz}\right), 113.6,120.1,122.8\left(\mathrm{q}, J_{\mathrm{CF}}=266 \mathrm{~Hz}\right), 124.2,125.6,125.9$, $126.1\left(\mathrm{q}, J_{\mathrm{CF}}=6 \mathrm{~Hz}\right) 127.1,130.2,134.6,134.7,145.9 ;{ }^{19} \mathrm{~F} \mathrm{NMR}: \delta_{\mathrm{F}}=102.3(\mathrm{br} \mathrm{s})$; HRMS (FAB): calcd for $\mathrm{C}_{16} \mathrm{H}_{13} \mathrm{~F}_{3} \mathrm{NO}_{2} \mathrm{~S}\left([\mathrm{M}+\mathrm{H}]^{+}\right) 340.0619$, found 340.0617 .

3-Bromodifluoromethyl-1-(4-methylbenzenesulfonyl)-1 $\boldsymbol{H}$-indole (15): To a solution of 12a $(75 \mathrm{mg}, 0.23 \mathrm{mmol})$ in $\mathrm{CCl}_{4}(3 \mathrm{~mL})$ was added $\mathrm{Br}_{2}(52 \mathrm{mg}, 0.32 \mathrm{mmol})$ in $\mathrm{CCl}$ $(0.3 \mathrm{~mL})$ at $\mathrm{rt}$. After the reaction mixture was stirred at $\mathrm{rt}$ for $2.5 \mathrm{~h}$, phosphate buffer $(\mathrm{pH} 7,10 \mathrm{~mL}$ ) was added to quench the reaction. Organic materials were extracted with EtOAc $(20 \mathrm{~mL} \times 3)$. The combined extracts were washed with aqueous $\mathrm{Na}_{2} \mathrm{~S}_{2} \mathrm{O}_{3}$ and brine, and dried over $\mathrm{Na}_{2} \mathrm{SO}_{4}$. After removal of the solvent under reduced pressure, the residue was purified by column chromatography on Florisil (hexane-EtOAc, 5:1) to give 15 (89 mg, 96\%) as colorless crystals. IR (neat): 3149, 3018, 2924, 1562, 1448, 1379, 1190, 1176, $958 \mathrm{~cm}^{-1}$; ${ }^{1} \mathrm{H}$ NMR: $\delta=2.38(3 \mathrm{H}, \mathrm{s}), 7.29(2 \mathrm{H}, \mathrm{d}, J=8.6 \mathrm{~Hz}), 7.35$ $(1 \mathrm{H}, \mathrm{dd}, J=7.6,7.6 \mathrm{~Hz}), 7.40(1 \mathrm{H}, \mathrm{dd}, J=7.6,7.6 \mathrm{~Hz}), 7.76(1 \mathrm{H}, \mathrm{d}, J=7.6 \mathrm{~Hz}), 7.83$ $(2 \mathrm{H}, \mathrm{d}, J=8.6 \mathrm{~Hz}), 7.89(1 \mathrm{H}, \mathrm{s}), 7.97(1 \mathrm{H}, \mathrm{d}, J=7.6 \mathrm{~Hz}) ;{ }^{13} \mathrm{C}$ NMR: $\delta=21.6,113.5$, $114.3\left(\mathrm{t}, J_{\mathrm{CF}}=297 \mathrm{~Hz}\right), 120.1\left(\mathrm{t}, J_{\mathrm{CF}}=28 \mathrm{~Hz}\right), 120.6,124.1,124.2\left(\mathrm{t}, J_{\mathrm{CF}}=7 \mathrm{~Hz}\right), 125.2$ $\left(\mathrm{t}, J_{\mathrm{CF}}=3 \mathrm{~Hz}\right), 125.8,127.1,130.2,134.5,134.8,145.8 ;{ }^{19} \mathrm{~F} \mathrm{NMR}: \delta_{\mathrm{F}}=121.9(\mathrm{br} \mathrm{s})$; elemental analysis: calcd (\%) for $\mathrm{C}_{16} \mathrm{H}_{12} \mathrm{BrF}_{2} \mathrm{NO}_{2} \mathrm{~S}$ : C 48.01, H 3.02, N 3.50, found: C $48.18, \mathrm{H} 3.18, \mathrm{~N} 3.27$.

3-Difluoromethyl-1-(4-methylbenzenesulfonyl)- $\mathbf{H}$-indole (16): To a solution of $\mathrm{NaI}$ (54 mg, $0.36 \mathrm{mmol})$ in $\mathrm{CH}_{3} \mathrm{CN}(2 \mathrm{~mL})$ was added $\mathrm{Me}_{3} \mathrm{SiCl}(39 \mathrm{mg}, 0.36 \mathrm{mmol})$, water $(3.2 \mathrm{mg}, 0.18 \mathrm{mmol})$, and then $12 \mathrm{a}(72 \mathrm{mg}, 0.23 \mathrm{mmol})$ at $\mathrm{rt}$. The reaction mixture was stirred at $\mathrm{rt}$ for $10 \mathrm{~h}$. The reaction was quenched with water $(10 \mathrm{~mL})$, and organic materials were extracted with EtOAc $(15 \mathrm{~mL} \times 3)$. The combined extracts were washed with aqueous $\mathrm{Na}_{2} \mathrm{~S}_{2} \mathrm{O}_{3}$ and brine, and dried over $\mathrm{Na}_{2} \mathrm{SO}_{4}$. After removal of the solvent under reduced pressure, the residue was purified by column chromatography (hexaneEtOAc, 10:1) to give $\mathbf{1 6}(69 \mathrm{mg}, 96 \%)$ as colorless crystals. IR (neat): $3114,3022,2968$ $1595,1568,1446,1373,1219,1174 \mathrm{~cm}^{-1} ;{ }^{1} \mathrm{H} \mathrm{NMR}: \delta=2.36(3 \mathrm{H}, \mathrm{s}), 6.86\left(1 \mathrm{H}, \mathrm{t}, J_{\mathrm{HF}}=\right.$ $55.6 \mathrm{~Hz}), 7.26(2 \mathrm{H}, \mathrm{d}, J=8.4 \mathrm{~Hz}), 7.30(1 \mathrm{H}, \mathrm{dd}, J=7.4,7.4 \mathrm{~Hz}), 7.38(1 \mathrm{H}, \mathrm{dd}, J=7.4$, $7.4 \mathrm{~Hz}), 7.68(1 \mathrm{H}, \mathrm{d}, J=7.4 \mathrm{~Hz}), 7.78\left(1 \mathrm{H}, \mathrm{t}, J_{\mathrm{HF}}=2.4 \mathrm{~Hz}\right), 7.80(2 \mathrm{H}, \mathrm{d}, J=8.4 \mathrm{~Hz})$, $7.98(1 \mathrm{H}, \mathrm{d}, J=7.4 \mathrm{~Hz}) ;{ }^{13} \mathrm{C}$ NMR: $\delta=21.6,111.8\left(\mathrm{t}, J_{\mathrm{CF}}=235 \mathrm{~Hz}\right), 113.7,116.6(\mathrm{t}$, $\left.J_{\mathrm{CF}}=26 \mathrm{~Hz}\right), 120.4,123.9,125.5\left(\mathrm{t}, J_{\mathrm{CF}}=10 \mathrm{~Hz}\right), 125.6,126.6,127.0,130.1,134.8$ 135.0, 145.6; ${ }^{19} \mathrm{~F}$ NMR: $\delta_{\mathrm{F}}=50.6\left(\mathrm{dd}, J_{\mathrm{FH}}=56,2 \mathrm{~Hz}\right)$; elemental analysis: calcd $(\%)$ for $\mathrm{C}_{16} \mathrm{H}_{13} \mathrm{~F}_{2} \mathrm{NO}_{2} \mathrm{~S}$ : C 59.80, H 4.08, N 4.36, found: C 59.83, H 4.18, N 4.14 3-Difluoromethylene-2,3-dihydro-1-benzothiophene (17): To a solution of 3 (106 mg, $0.432 \mathrm{mmol}$ ) in THF ( $3 \mathrm{~mL}$ ) was added potassium butoxide (KOt-Bu, $53 \mathrm{mg}, 0.48$ $\mathrm{mmol}$ ) at $0{ }^{\circ} \mathrm{C}$. The reaction mixture was heated under reflux for $2 \mathrm{~h}$, and then phosphate buffer $(\mathrm{pH} 7,10 \mathrm{~mL}$ ) was added to quench the reaction. Organic materials were extracted with $\mathrm{Et}_{2} \mathrm{O}(10 \mathrm{~mL} \times 3)$. The combined extracts were washed with brine, and dried over $\mathrm{MgSO}_{4}$. After removal of the solvent under reduced pressure, the residue was purified by column chromatography (hexane) to give $17(52 \mathrm{mg}, 65 \%)$ as a colorless liquid. IR (neat): 3018, 1732, 1464, 1446, 1327, 1252, 1217, 1105, 982, 906 $\mathrm{cm}^{-1}$; ${ }^{1} \mathrm{H}$ NMR: $\delta=4.04\left(2 \mathrm{H}, \mathrm{dd}, J_{\mathrm{HF}}=4.1,4.1 \mathrm{~Hz}\right), 7.06(1 \mathrm{H}, \mathrm{ddd}, J=7.7,7.7,1.3 \mathrm{~Hz})$, $7.13(1 \mathrm{H}, \mathrm{ddd}, J=7.7,7.7,1.3 \mathrm{~Hz}), 7.16(1 \mathrm{H}, \mathrm{dd}, J=7.7,1.3 \mathrm{~Hz}), 7.38(1 \mathrm{H}, \mathrm{dd}, J=7.7$, 
$1.3 \mathrm{~Hz}) ;{ }^{13} \mathrm{C}$ NMR: $\delta=30.1\left(\mathrm{~d}, J_{\mathrm{CF}}=3 \mathrm{~Hz}\right), 94.2\left(\mathrm{dd}, J_{\mathrm{CF}}=26,26 \mathrm{~Hz}\right), 122.1,124.0(\mathrm{dd}$, $\left.J_{\mathrm{CF}}=2,2 \mathrm{~Hz}\right), 124.6,128.3\left(\mathrm{dd}, J_{\mathrm{CF}}=3,3 \mathrm{~Hz}\right), 131.5\left(\mathrm{dd}, J_{\mathrm{CF}}=3,3 \mathrm{~Hz}\right), 142.7\left(\mathrm{~d}, J_{\mathrm{CF}}=\right.$ $5 \mathrm{~Hz}), 152.0\left(\mathrm{dd} . J_{\mathrm{CF}}=288,288 \mathrm{~Hz}\right) ;{ }^{19} \mathrm{~F}$ NMR: $\delta_{\mathrm{F}}=75.6\left(1 \mathrm{~F}, \mathrm{dt}, J_{\mathrm{FF}}=40 \mathrm{~Hz}, J_{\mathrm{FH}}=5\right.$ $\mathrm{Hz}), 78.4\left(1 \mathrm{~F}, \mathrm{dt}, J_{\mathrm{FF}}=40 \mathrm{~Hz}, J_{\mathrm{FH}}=5 \mathrm{~Hz}\right)$; elemental analysis: calcd $(\%)$ for $\mathrm{C}_{9} \mathrm{H}_{6} \mathrm{~F}_{2} \mathrm{~S}$ C 58.68, H 3.28, found: C 58.46, H 3.50 .

3-Trifluoromethyl-2,3-dihydro-1-benzothiophene (18): To a solution of $\mathbf{3}(97 \mathrm{mg}$, $0.39 \mathrm{mmol})$ in $\mathrm{MeOH}(3 \mathrm{~mL})$ was added $\mathrm{K}_{2} \mathrm{CO}_{3}(52 \mathrm{mg}, 0.378 \mathrm{mmol})$ at rt. After the mixture was heated under reflux for $1 \mathrm{~h}$, phosphate buffer $(\mathrm{pH} 7,10 \mathrm{~mL})$ was added to quench the reaction. Organic materials were extracted with $\mathrm{Et}_{2} \mathrm{O}(10 \mathrm{~mL} \times 3)$. The combined extracts were washed with brine, and dried over $\mathrm{MgSO}_{4}$. After removal of the solvent under reduced pressure, the residue was purified by column chromatography (hexane) to give $\mathbf{1 8}(49 \mathrm{mg}, 61 \%)$ as a colorless liquid. IR (neat): 3018, 1587, 1466, $1446,1350,1265,1215,1159,1107 \mathrm{~cm}^{-1} ;{ }^{1} \mathrm{H}$ NMR: $\delta=3.49(1 \mathrm{H}, \mathrm{dd}, J=12.0,6.6 \mathrm{~Hz})$ $3.59(1 \mathrm{H}, \mathrm{dd}, J=12.0,9.0 \mathrm{~Hz}), 4.12-4.20(1 \mathrm{H}, \mathrm{m}), 7.08(1 \mathrm{H}, \mathrm{dd}, J=7.6,7.6 \mathrm{~Hz}), 7.21$ $7.25(2 \mathrm{H}, \mathrm{m}), 7.34(1 \mathrm{H}, \mathrm{d}, J=7.6 \mathrm{~Hz}) ;{ }^{13} \mathrm{C} \mathrm{NMR}: \delta=31.4\left(\mathrm{q}, J_{\mathrm{CF}}=3 \mathrm{~Hz}\right), 51.5\left(\mathrm{q}, J_{\mathrm{C}}\right.$ $=28 \mathrm{~Hz}), 122.5,124.6,126.0,126.2\left(\mathrm{q}, J_{\mathrm{CF}}=280 \mathrm{~Hz}\right), 129.5,132.6,142.7 ;{ }^{19} \mathrm{~F} \mathrm{NMR}$ $\delta_{\mathrm{F}}=91.2\left(\mathrm{~d}, J_{\mathrm{FH}}=9 \mathrm{~Hz}\right)$; HRMS $(\mathrm{FAB})$ : calcd for $\mathrm{C}_{9} \mathrm{H}_{8} \mathrm{~F}_{3} \mathrm{~S}\left([\mathrm{M}+\mathrm{H}]^{+}\right)$205.0299, found 205.0295

Cyclization of 5 under aprotic conditions: To a solution of $\mathbf{5}(1.0 \mathrm{mmol})$ in DMF (10 $\mathrm{mL}$ ) was added $\mathrm{NaH}(60 \%$ dispersion in mineral oil; $52 \mathrm{mg}, 1.3 \mathrm{mmol})$ at $0{ }^{\circ} \mathrm{C}$. The reaction mixture was stirred at $0{ }^{\circ} \mathrm{C}$ for $15 \mathrm{~min}$ and then $120^{\circ} \mathrm{C}$ for $0.5-4 \mathrm{~h}$. Phosphate

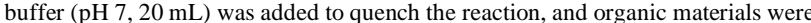
extracted with EtOAc $(10 \mathrm{~mL} \times 3)$. The combined extracts were washed with water and brine, and dried over $\mathrm{Na}_{2} \mathrm{SO}_{4}$. After removal of the solvent under reduced pressure, the residue was purified by column chromatography to give 3-difluoromethylene-1-(4methylbenzenesulfonyl)pyrrolidine (19).

4-Difluoromethylene-1-(4-methylbenzenesulfonyl)-2-phenylpyrrolidine (19a): Colorless crystals; yield 91\%; IR (neat): 3064, 3032, 2927, 2866, 1782, 1350, 1273 , $1219,1161,1093,1058 \mathrm{~cm}^{-1}$; ${ }^{1} \mathrm{H}$ NMR: $\delta=2.42(3 \mathrm{H}, \mathrm{s}), 2.54(1 \mathrm{H}, \mathrm{brd}, J=15.0 \mathrm{~Hz})$, $2.66-2.74(1 \mathrm{H}, \mathrm{m}), 4.13(1 \mathrm{H}, \mathrm{dm}, J=14.5 \mathrm{~Hz}), 4.19(1 \mathrm{H}, \mathrm{dm}, J=14.5 \mathrm{~Hz}), 4.95(1 \mathrm{H}$, ddd, $J=8.2,3.1,1.5 \mathrm{~Hz}), 7.22-7.31(7 \mathrm{H}, \mathrm{m}), 7.57(2 \mathrm{H}, \mathrm{d}, J=8.3 \mathrm{~Hz}) ;{ }^{13} \mathrm{C}$ NMR: $\delta=$ $21.5,33.9,47.0\left(\mathrm{~d}, J_{\mathrm{CF}}=4 \mathrm{~Hz}\right), 63.2,85.4\left(\mathrm{dd}, J_{\mathrm{CF}}=25,22 \mathrm{~Hz}\right), 126.2,127.4,127.7$, $128.5,129.6,134.8,140.8,143.7,149.8\left(\mathrm{dd}, J_{\mathrm{CF}}=283,283 \mathrm{~Hz}\right) ;{ }^{19} \mathrm{~F}$ NMR: $\delta_{\mathrm{F}}=72.0$ $\left(1 \mathrm{~F}, \mathrm{dm}, J_{\mathrm{FF}}=54 \mathrm{~Hz}\right), 74.5\left(1 \mathrm{~F}, \mathrm{~d}, J_{\mathrm{FF}}=54 \mathrm{~Hz}\right)$; elemental analysis: calcd $(\%)$ for $\mathrm{C}_{18} \mathrm{H}_{17} \mathrm{~F}_{2} \mathrm{NO}_{2} \mathrm{~S}$ : C 61.88, H 4.90, N 4.01, found: $\mathrm{C} 61.81, \mathrm{H} 4.95, \mathrm{~N} 3.74$.

2-(4-Bromophenyl)-4-difluoromethylene-1-(4-methylbenzenesulfonyl)pyrrolidine (19b): Colorless crystals; yield 79\%; m.p. $76-77{ }^{\circ} \mathrm{C}$; IR (neat): 3026, 1782, 1489, 1350 $1275,1219,1163 \mathrm{~cm}^{-1}$; ${ }^{\prime} \mathrm{H}$ NMR: $\delta=2.43(3 \mathrm{H}, \mathrm{s}), 2.49(1 \mathrm{H}, \mathrm{br} \mathrm{d}, J=15.0 \mathrm{~Hz}), 2.67-$ $2.74(1 \mathrm{H}, \mathrm{m}), 4.13(1 \mathrm{H}$, br d, $J=15.0 \mathrm{~Hz}), 4.16(1 \mathrm{H}, \mathrm{br} \mathrm{d}, J=15.0 \mathrm{~Hz}), 4.86(1 \mathrm{H}, \mathrm{dm}, J$ $=7.9 \mathrm{~Hz}), 7.11(2 \mathrm{H}, \mathrm{d}, J=8.4 \mathrm{~Hz}), 7.26(2 \mathrm{H}, \mathrm{d}, J=7.8 \mathrm{~Hz}), 7.40(2 \mathrm{H}, \mathrm{d}, J=8.4 \mathrm{~Hz})$, $7.57(2 \mathrm{H}, \mathrm{d}, J=7.8 \mathrm{~Hz}) ;{ }^{13} \mathrm{C}$ NMR: $\delta=21.5,33.9,47.0\left(\mathrm{~d}, J_{\mathrm{CF}}=4 \mathrm{~Hz}\right), 62.6,85.1(\mathrm{dd}$, $\left.J_{\mathrm{CF}}=26,24 \mathrm{~Hz}\right), 121.6,127.3,128.0,129.7,131.6,134.6,139.9,143.9,149.9\left(\mathrm{dd}, J_{\mathrm{CF}}=\right.$ $285,285 \mathrm{~Hz}) ;{ }^{19} \mathrm{~F}$ NMR: $\delta_{\mathrm{F}}=72.4\left(1 \mathrm{~F}, \mathrm{ddd}, J_{\mathrm{FF}}=53 \mathrm{~Hz}, J_{\mathrm{FH}}=3,3 \mathrm{~Hz}\right), 74.9\left(1 \mathrm{~F}, \mathrm{~d}, J_{\mathrm{FF}}\right.$ $=53 \mathrm{~Hz}$ ); elemental analysis: calcd $(\%)$ for $\mathrm{C}_{18} \mathrm{H}_{16} \mathrm{BrF}_{2} \mathrm{NO}_{2} \mathrm{~S}: \mathrm{C} 50.48, \mathrm{H} 3.77 ; \mathrm{N} 3.27$, found: C 50.49, H 3.93, N 3.15 .

4-Difluoromethylene-2-(2-furyl)-1-(4-methylbenzenesulfonyl)pyrrolidine (19c): Colorless crystals; yield 74\%; m.p. $63-64{ }^{\circ} \mathrm{C}$; IR (neat): $3120,3028,2924,2868,1784$, $1599,1350,1275,1163,1093 \mathrm{~cm}^{-1} ;{ }^{1} \mathrm{H}$ NMR: $\delta=2.40(3 \mathrm{H}, \mathrm{s}), 2.64-2.68(2 \mathrm{H}, \mathrm{m}), 3.99$ $(1 \mathrm{H}, \mathrm{dm}, J=13.4 \mathrm{~Hz}), 4.18(1 \mathrm{H}, \mathrm{dm}, J=13.4 \mathrm{~Hz}), 5.09(1 \mathrm{H}, \mathrm{ddd}, J=6.3,4.1,1.9 \mathrm{~Hz})$, $6.24(1 \mathrm{H}, \mathrm{brd}, J=3.3 \mathrm{~Hz}), 6.25(1 \mathrm{H}, \mathrm{dd}, J=3.3,1.9 \mathrm{~Hz}), 7.18-7.19(1 \mathrm{H}, \mathrm{m}), 7.23(2 \mathrm{H}$ $\mathrm{d}, J=8.3 \mathrm{~Hz}), 7.54(2 \mathrm{H}, \mathrm{d}, J=8.3 \mathrm{~Hz}) ;{ }^{13} \mathrm{C} \mathrm{NMR}: \delta=21.5,30.9\left(\mathrm{dd}, J_{\mathrm{CF}}=2,2 \mathrm{~Hz}\right)$, $46.2\left(\mathrm{dd}, J_{\mathrm{CF}}=4,1 \mathrm{~Hz}\right), 55.6,85.6\left(\mathrm{dd}, J_{\mathrm{CF}}=26,23 \mathrm{~Hz}\right), 107.6,110.1,127.2,129.6$, $134.8,142.3,143.5,149.9\left(\mathrm{dd}, J_{\mathrm{CF}}=282,282 \mathrm{~Hz}\right), 152.6 ;{ }^{19} \mathrm{~F}$ NMR: $\delta_{\mathrm{F}}=71.8(1 \mathrm{~F}$, ddd, $\left.J_{\mathrm{FF}}=55, J_{\mathrm{FH}}=3,3 \mathrm{~Hz}\right), 74.4\left(1 \mathrm{~F}, \mathrm{~d}, J_{\mathrm{FF}}=55 \mathrm{~Hz}\right)$; elemental analysis: calcd $(\%)$ for $\mathrm{C}_{16} \mathrm{H}_{15} \mathrm{~F}_{2} \mathrm{NO}_{3} \mathrm{~S}$ : C 56.63, H 4.46, N 4.13, found: C 56.45, H 4.45, N 3.86.

4-Difluoromethylene-2-hexyl-1-(4-methylbenzenesulfonyl)pyrrolidine (19d): A colorless liquid; yield 82\%; IR (neat): 3026, 2956, 2927, 2858, 1782, 1348, 1217, 1163, $912 \mathrm{~cm}^{-1}$; ${ }^{1} \mathrm{H}$ NMR: $\delta=0.89(3 \mathrm{H}, \mathrm{t}, J=6.5 \mathrm{~Hz}), 1.21-1.46(10 \mathrm{H}, \mathrm{m}), 2.06-2.16(2 \mathrm{H}, \mathrm{m})$ $2.43(3 \mathrm{H}, \mathrm{s}), 3.83-3.90(1 \mathrm{H}, \mathrm{m}), 3.96(1 \mathrm{H}, \mathrm{dm}, J=14.7 \mathrm{~Hz}), 4.03(1 \mathrm{H}, \mathrm{dm}, J=14.7 \mathrm{~Hz})$ $7.31(2 \mathrm{H}, \mathrm{d}, J=8.4 \mathrm{~Hz}), 7.70(2 \mathrm{H}, \mathrm{d}, J=8.4 \mathrm{~Hz}) ;{ }^{13} \mathrm{C}$ NMR: $\delta=14.1,21.5,22.6,25.7$, $29.0,30.2,31.7,35.4,46.2\left(\mathrm{~d}, J_{\mathrm{CF}}=3 \mathrm{~Hz}\right), 60.7,85.9\left(\mathrm{dd}, J_{\mathrm{CF}}=25,22 \mathrm{~Hz}\right), 127.3$, $129.8,135.1,143.7,149.9\left(\mathrm{dd}, J_{\mathrm{CF}}=282,282 \mathrm{~Hz}\right) ;{ }^{19} \mathrm{~F} \mathrm{NMR}: \delta_{\mathrm{F}}=71.4\left(1 \mathrm{~F}, \mathrm{ddd}, J_{\mathrm{FF}}=\right.$ $\left.56, J_{\mathrm{FH}}=3,3 \mathrm{~Hz}\right), 74.2\left(1 \mathrm{~F}, \mathrm{~d}, J_{\mathrm{FF}}=56 \mathrm{~Hz}\right)$; elemental analysis: calcd $(\%)$ for $\mathrm{C}_{18} \mathrm{H}_{25} \mathrm{~F}_{2} \mathrm{NO}_{2} \mathrm{~S}$ : C 60.48, H 7.05, N 3.92, found: C 60.50, H 7.10, N 3.63. 3-Difluoromethylene-1-(4-methylbenzenesulfonyl)-4-phenylpyrrolidine (19e): Colorless crystals; yield 65\%; IR (neat): 3030, 2924, 1774, 1597, 1495, 1350, 1271, $1163,1093 \mathrm{~cm}^{-1} ;{ }^{1} \mathrm{H}$ NMR: $\delta=2.45(3 \mathrm{H}, \mathrm{s}), 3.36(1 \mathrm{H}, \mathrm{ddd}, J=9.5,4.7,1.4 \mathrm{~Hz}), 3.61$ $(1 \mathrm{H}, \mathrm{dd}, J=9.5,7.7 \mathrm{~Hz}), 3,94-3.98(2 \mathrm{H}, \mathrm{m}), 4.02\left(1 \mathrm{H}\right.$, dddd, $J=13.2,3.7,1.4 \mathrm{~Hz}, J_{\mathrm{HF}}$ $=3.7 \mathrm{~Hz}), 7.15(2 \mathrm{H}, \mathrm{d}, J=6.8 \mathrm{~Hz}), 7.22-7.29(3 \mathrm{H}, \mathrm{m}), 7.34(2 \mathrm{H}, \mathrm{d}, J=8.1 \mathrm{~Hz}), 7.71$ $(2 \mathrm{H}, \mathrm{d}, J=8.1 \mathrm{~Hz}) ;{ }^{13} \mathrm{C}$ NMR: $\delta=21.5,43.2,47.2\left(\mathrm{~d}, J_{\mathrm{CF}}=4 \mathrm{~Hz}\right), 56.2,90.3\left(\mathrm{dd}, J_{\mathrm{CF}}=\right.$ $23,21 \mathrm{~Hz}), 126.9,127.3,127.9,128.8,129.8,132.0,139.9,144.1,150.8\left(\mathrm{dd}, J_{\mathrm{CF}}=288\right.$, $288 \mathrm{~Hz}) ;{ }^{19} \mathrm{~F}$ NMR: $\delta_{\mathrm{F}}=73.96\left(1 \mathrm{~F}, \mathrm{ddd}, J_{\mathrm{FF}}=48 \mathrm{~Hz}, J_{\mathrm{FH}}=3,3 \mathrm{~Hz}\right), 76.1\left(1 \mathrm{~F}, \mathrm{~d}, J_{\mathrm{FF}}=\right.$ $48 \mathrm{~Hz}$ ); elemental analysis: calcd (\%) for $\mathrm{C}_{18} \mathrm{H}_{17} \mathrm{~F}_{2} \mathrm{NO}_{2} \mathrm{~S}: \mathrm{C} 61.88, \mathrm{H} 4.90, \mathrm{~N} 4.01$, found: C 62.05, H 5.01, N 3.89 .

3-Difluoromethylene-1-(4-methylbenzenesulfonyl)pyrrolidine (19f): Colorles crystals; yield 83\%; IR (neat): 2924, 2864, 1782, 1348, 1269, 1161, 1093, 1072, 1039, $812 \mathrm{~cm}^{-1}$; ${ }^{1} \mathrm{H}$ NMR: $\delta=2.45(3 \mathrm{H}, \mathrm{s}), 2.44-2.48(2 \mathrm{H}, \mathrm{m}), 3.30(2 \mathrm{H}, \mathrm{ddd}, J=7.0,7.0,1.3$ $\mathrm{Hz}), 3.79-3.82(2 \mathrm{H}, \mathrm{m}), 7.36(2 \mathrm{H}, \mathrm{d}, J=8.1 \mathrm{~Hz}), 7.72(2 \mathrm{H}, \mathrm{d}, J=8.1 \mathrm{~Hz}) ;{ }^{13} \mathrm{C}$ NMR: $\delta=21.5,24.6,46.5\left(\mathrm{~d}, J_{\mathrm{CF}}=4 \mathrm{~Hz}\right), 48.0,85.8\left(\mathrm{dd}, J_{\mathrm{CF}}=27,22 \mathrm{~Hz}\right), 127.8,129.8,132.3$, $144.0,149.9\left(\mathrm{dd}, J_{\mathrm{CF}}=285,285 \mathrm{~Hz}\right) ;{ }^{19} \mathrm{~F} \mathrm{NMR}: \delta_{\mathrm{F}}=71.6\left(1 \mathrm{~F}, \mathrm{dm}, J_{\mathrm{FF}}=55 \mathrm{~Hz}\right), 74.0$ $\left(1 \mathrm{~F}, \mathrm{~d}, J_{\mathrm{FF}}=55 \mathrm{~Hz}\right)$; elemental analysis: calcd $(\%)$ for $\mathrm{C}_{12} \mathrm{H}_{13} \mathrm{~F}_{2} \mathrm{NO}_{2} \mathrm{~S}: \mathrm{C} 52.74, \mathrm{H} 4.79$, N 5.13, found: C 52.83, H 4.88, N 4.87.

Cyclization of 5 under protic conditions: To a solution of $5(0.3 \mathrm{mmol})$ in ethane-1,2 diol $(3 \mathrm{~mL})$ was added $\mathrm{KOH}$ powder $(84 \mathrm{mg}, 1.5 \mathrm{mmol})$ at $\mathrm{rt}$. After the reaction mixture was stirred at $130{ }^{\circ} \mathrm{C}$ for $10-20 \mathrm{~h}$, phosphate buffer $(\mathrm{pH} 7,10 \mathrm{~mL}$ ) was added to quench the reaction. Organic materials were extracted with EtOAc $(20 \mathrm{~mL} \times 3)$, and the combined extracts were washed with water and brine, and dried over $\mathrm{Na}_{2} \mathrm{SO}_{4}$. After removal of the solvent under reduced pressure, the residue was purified by column chromatography to give 3-trifluoromethyl-1-(4-methylbenzenesulfonyl)pyrrolidine (20) as a mixture of trans- and cis-isomers.

1-(4-Methylbenzenesulfonyl)-2-phenyl-4-(trifluoromethyl)pyrrolidine (20a): Colorless crystals; yield 85\% (trans:cis $=92: 8$ ); m.p. 90-91 ${ }^{\circ} \mathrm{C}$; IR (neat): 3030, 2983 , $2881,1452,1400,1348,1157,1120 \mathrm{~cm}^{-1}$; ${ }^{1} \mathrm{H}$ NMR: trans $\delta=2.05(2 \mathrm{H}, \mathrm{dd}, J=8.6,5.4$ $\mathrm{Hz}), 2.44(3 \mathrm{H}, \mathrm{s}), 2.88-3.06(1 \mathrm{H}, \mathrm{m}), 3.50(1 \mathrm{H}, \mathrm{dd}, J=10.5,8.8 \mathrm{~Hz}), 3.85(1 \mathrm{H}, \mathrm{dd}, J=$ $10.5,8.3 \mathrm{~Hz}), 4.94(1 \mathrm{H}, \mathrm{dd}, J=5.4,5.4 \mathrm{~Hz}), 7.23-7.48(7 \mathrm{H}, \mathrm{m}), 7.67(2 \mathrm{H}, \mathrm{d}, J=8.2$ $\mathrm{Hz})$; cis $\delta=2.42(3 \mathrm{H}, \mathrm{s}), 2.48-2.53(2 \mathrm{H}, \mathrm{m}), 2.58-3.68(1 \mathrm{H}, \mathrm{m}), 3.58(1 \mathrm{H}, \mathrm{dd}, J=11.5$, $9.8 \mathrm{~Hz}), 3.96(1 \mathrm{H}, \mathrm{dd}, J=11.5,8.1 \mathrm{~Hz}), 4.71(1 \mathrm{H}, \mathrm{dd}, J=9.3,7.3 \mathrm{~Hz}), 7.23-7.48(7 \mathrm{H}$, m), $7.54(2 \mathrm{H}, \mathrm{d}, J=8.2 \mathrm{~Hz}) ;{ }^{13} \mathrm{C}$ NMR: trans $\delta=21.6,34.8,40.9\left(\mathrm{q}, J_{\mathrm{CF}}=29 \mathrm{~Hz}\right), 47.7$, $62.6,125.9,126.1\left(\mathrm{q}, J_{\mathrm{CF}}=275 \mathrm{~Hz}\right), 127.5,127.7,128.6,129.7,134.2,141.1,143.9 ;{ }^{19} \mathrm{~F}$ NMR: trans $\delta_{\mathrm{F}}=91.1\left(\mathrm{~d}, J_{\mathrm{FH}}=8 \mathrm{~Hz},\right)$; cis $\delta_{\mathrm{F}}=91.3\left(\mathrm{~d}, J_{\mathrm{FH}}=8 \mathrm{~Hz}\right)$; elemental analysis: calcd (\%) for $\mathrm{C}_{18} \mathrm{H}_{18} \mathrm{~F}_{3} \mathrm{NO}_{2} \mathrm{~S}: \mathrm{C} 58.53, \mathrm{H} 4.91, \mathrm{~N} 3.79$, found: C 58.43, H 5.00, N 3.59. 2-(4-Bromophenyl)-1-(4-methylbenzenesulfonyl)-4-(trifluoromethyl)pyrrolidine (20b): Separation of cis- and trans-isomer was achieved by column chromatography (hexane-EtOAc, $5: 1)$ to give trans-20b (70\%) and cis-20b (6\%) as colorless crystals. (trans-20b) m.p. $119-120^{\circ} \mathrm{C}$; IR (neat): $3030,2910,1489,1400,1350,1163,1122,914$ $\mathrm{cm}^{-1}$; ${ }^{1} \mathrm{H}$ NMR: $\delta=2.01(1 \mathrm{H}, \mathrm{ddd}, J=12.9,7.2,3.3 \mathrm{~Hz}), 2.08(1 \mathrm{H}, \mathrm{ddd}, J=12.9,9.9$, $8.2 \mathrm{~Hz}), 2.45(3 \mathrm{H}, \mathrm{s}), 2.86-2.99(1 \mathrm{H}, \mathrm{m}), 3.47(1 \mathrm{H}, \mathrm{dd}, J=10.6,8.6 \mathrm{~Hz}), 3.85(1 \mathrm{H}, \mathrm{dd}$, $J=10.6,8.2 \mathrm{~Hz}), 4.83(1 \mathrm{H}, \mathrm{dd}, J=8.2,3.3 \mathrm{~Hz}), 7.17(2 \mathrm{H}, \mathrm{d}, J=8.5 \mathrm{~Hz}), 7.33(2 \mathrm{H}, \mathrm{d}, J$ $=8.1 \mathrm{~Hz}), 7.45(2 \mathrm{H}, \mathrm{d}, J=8.5 \mathrm{~Hz}), 7.65(2 \mathrm{H}, \mathrm{d}, J=8.1 \mathrm{~Hz}) ;{ }^{13} \mathrm{C}$ NMR: $\delta=21.6,34.8$ $\left(\mathrm{q}, J_{\mathrm{CF}}=2 \mathrm{~Hz}\right), 40.8\left(\mathrm{q}, J_{\mathrm{CF}}=29 \mathrm{~Hz}\right), 47.8\left(\mathrm{q}, J_{\mathrm{CF}}=3 \mathrm{~Hz}\right), 62.1,121.6,126.0\left(\mathrm{q}, J_{\mathrm{CF}}=\right.$ $276 \mathrm{~Hz}), 127.5,127.7,129.8,131.7,134.0,140.2,144.1 ;{ }^{19} \mathrm{~F} \mathrm{NMR:} \delta_{\mathrm{F}}=91.1\left(\mathrm{~d}, J_{\mathrm{FH}}=8\right.$ $\mathrm{Hz}$ ); elemental analysis: calcd (\%) for $\mathrm{C}_{18} \mathrm{H}_{17} \mathrm{BrF}_{3} \mathrm{NO}_{2} \mathrm{~S}: \mathrm{C} 48.23, \mathrm{H} 3.82, \mathrm{~N} 3.12$, found: C 48.04, H 3.84, N 2.87; (cis-20b) IR (neat): 2960, 2910, 1489, 1404, 1360, 1271, 1161, $912 \mathrm{~cm}^{-1}$; ${ }^{1} \mathrm{H}$ NMR: $\delta=1.99(1 \mathrm{H}, \mathrm{ddd}, J=13.3,11.0,9.4 \mathrm{~Hz}), 2.44(3 \mathrm{H}, \mathrm{s})$, $2.52(1 \mathrm{H}, \mathrm{ddd}, J=13.3,7.5,7.5 \mathrm{~Hz}), 2.58-2.71(1 \mathrm{H}, \mathrm{m}), 3.58(1 \mathrm{H}, \mathrm{dd}, J=11.5,9.7 \mathrm{~Hz})$, $3.94(1 \mathrm{H}, \mathrm{dd}, J=11.5,8.2 \mathrm{~Hz}), 4.65(1 \mathrm{H}, \mathrm{dd}, J=9.4,7.5 \mathrm{~Hz}), 7.14(2 \mathrm{H}, \mathrm{d}, J=8.4 \mathrm{~Hz})$, $7.27(2 \mathrm{H}, \mathrm{d}, J=8.0 \mathrm{~Hz}), 7.40(2 \mathrm{H}, \mathrm{d}, J=8.4 \mathrm{~Hz}), 7.54(2 \mathrm{H}, \mathrm{d}, J=8.0 \mathrm{~Hz}) ;{ }^{13} \mathrm{C}$ NMR: $\delta$ $=21.6,36.2,41.6\left(\mathrm{q}, J_{\mathrm{CF}}=30 \mathrm{~Hz}\right), 48.5\left(\mathrm{q}, J_{\mathrm{CF}}=3 \mathrm{~Hz}\right), 63.0,121.7,125.6\left(\mathrm{q}, J_{\mathrm{CF}}=276\right.$ $\mathrm{Hz}), 127.4,128.2,129.8,131.6,134.6,139.7,144.1 ;{ }^{19} \mathrm{~F} \mathrm{NMR}: \delta_{\mathrm{F}}=91.2\left(\mathrm{~d}, J_{\mathrm{FH}}=8\right.$ $\mathrm{Hz}$ ); elemental analysis: calcd (\%) for $\mathrm{C}_{18} \mathrm{H}_{17} \mathrm{BrF}_{3} \mathrm{NO}_{2} \mathrm{~S}: \mathrm{C} 48.23, \mathrm{H} 3.82, \mathrm{~N} 3.12$, found: C 48.30, H 3.90, N 2.90 .

2-(2-Furyl)-1-(4-methylbenzenesulfonyl)-4-(trifluoromethyl)pyrrolidine (20c): A colorless liquid; yield 69\% (trans: cis $=83: 17$ ); IR (neat): 2958, 2925, 1599, 1348, 1271 , $1159,1120,1011,912 \mathrm{~cm}^{-1}$; ${ }^{1} \mathrm{H}$ NMR: trans $\delta=2.10(1 \mathrm{H}$, ddd, $J=12.6,10.8,8.2 \mathrm{~Hz})$, $2.20(1 \mathrm{H}, \mathrm{ddd}, J=12.6,7.2,1.9 \mathrm{~Hz}), 2.41(3 \mathrm{H}, \mathrm{s}), 3.20-3.33(1 \mathrm{H}, \mathrm{m}), 3.52(1 \mathrm{H}, \mathrm{dd}, J=$ $10.0,8.4 \mathrm{~Hz}), 3.67(1 \mathrm{H}, \mathrm{dd}, J=10.0,8.8 \mathrm{~Hz}), 5.05(1 \mathrm{H}, \mathrm{br} \mathrm{d}, J=8.2 \mathrm{~Hz}), 6.28(1 \mathrm{H}, \mathrm{dd}$, $J=3.2,1.9 \mathrm{~Hz}), 6.30(1 \mathrm{H}, \mathrm{dm}, J=3.2 \mathrm{~Hz}), 7.20(1 \mathrm{H}, \mathrm{dd}, J=1.9,0.9 \mathrm{~Hz}), 7.26(2 \mathrm{H}, \mathrm{d}$, $J=8.3 \mathrm{~Hz}), 7.53(2 \mathrm{H}, \mathrm{d}, J=8.3 \mathrm{~Hz})$; $\boldsymbol{c i s} \delta=2.26-2.33(1 \mathrm{H}, \mathrm{m}), 2.41(3 \mathrm{H}, \mathrm{s}), 2.43-2.48$ $(1 \mathrm{H}, \mathrm{m}), 2.72-2.82(1 \mathrm{H}, \mathrm{m}), 3.45(1 \mathrm{H}, \mathrm{dd}, J=10.5,10.5 \mathrm{~Hz}), 3.94(1 \mathrm{H}, \mathrm{dd}, J=10.5$, $7.9 \mathrm{~Hz}), 4.96(1 \mathrm{H}, \mathrm{dd}, J=8.0,8.0 \mathrm{~Hz}), 6.27(1 \mathrm{H}, \mathrm{dd}, J=3.2,1.8 \mathrm{~Hz}), 6.31(1 \mathrm{H}, \mathrm{dm}, J=$ $3.2 \mathrm{~Hz}), 7.20-7.22(1 \mathrm{H}, \mathrm{m}), 7.26(2 \mathrm{H}, \mathrm{d}, J=8.3 \mathrm{~Hz}), 7.50(2 \mathrm{H}, \mathrm{d}, J=8.3 \mathrm{~Hz}),{ }^{13} \mathrm{C}$ NMR: trans $\delta=21.5,31.5\left(\mathrm{q}, J_{\mathrm{CF}}=2 \mathrm{~Hz}\right), 41.7\left(\mathrm{q}, J_{\mathrm{CF}}=29 \mathrm{~Hz}\right), 46.7\left(\mathrm{q}, J_{\mathrm{CF}}=3 \mathrm{~Hz}\right)$, $56.2,108.1,110.2,126.2\left(\mathrm{q}, J_{\mathrm{CF}}=275 \mathrm{~Hz}\right), 127.2,129.6,134.6,142.2,143.6,152.9 ;{ }^{19} \mathrm{~F}$ NMR: trans $\delta_{\mathrm{F}}=90.9\left(\mathrm{~d}, J_{\mathrm{FH}}=8 \mathrm{~Hz}\right) ;$ cis $\delta_{\mathrm{F}}=91.5\left(\mathrm{~d}, J_{\mathrm{FH}}=8 \mathrm{~Hz}\right)$; elemental analysis: calcd (\%) for $\mathrm{C}_{16} \mathrm{H}_{16} \mathrm{~F}_{3} \mathrm{NO}_{3} \mathrm{~S}: \mathrm{C} 53.48, \mathrm{H} 4.49, \mathrm{~N} 3.90$, found: C 53.52, H 4.65, N 3.72 . 2-Hexyl-1-(4-methylbenzenesulfonyl)-4-(trifluoromethyl)pyrrolidine (20d): Solvent (ethane-1,2-diol:THF, 10:1) was used. A colorless liquid; yield 67\% (trans:cis $=77: 23$ ); IR (neat): 2956, 2929, 2858, 1456, 1402, 1348, 1273, 1163, $914 \mathrm{~cm}^{-1}$; ${ }^{1} \mathrm{H}$ NMR: trans $\delta=0.89(3 \mathrm{H}, \mathrm{t}, J=7.0 \mathrm{~Hz}), 1.25-1.53(9 \mathrm{H}, \mathrm{m}), 1.60-1.68(1 \mathrm{H}, \mathrm{m}), 1.75-1.83(2 \mathrm{H}, \mathrm{m})$, $2.44(3 \mathrm{H}, \mathrm{s}), 2.89-3.02(1 \mathrm{H}, \mathrm{m}), 3.24(1 \mathrm{H}, \mathrm{dd}, J=10.5,9.1 \mathrm{~Hz}), 3.65(1 \mathrm{H}, \mathrm{dd}, J=10.5$, $8.3 \mathrm{~Hz}), 3.70-3.78(1 \mathrm{H}, \mathrm{m}), 7.33(2 \mathrm{H}, \mathrm{d}, J=8.0 \mathrm{~Hz}), 7.71(2 \mathrm{H}, \mathrm{d}, J=8.0 \mathrm{~Hz}) ;$ cis $\delta=$ $0.89(3 \mathrm{H}, \mathrm{t}, J=7.0 \mathrm{~Hz}), 1.25-1.53(9 \mathrm{H}, \mathrm{m}), 1.60-1.68(1 \mathrm{H}, \mathrm{m}), 1.87-1.94(1 \mathrm{H}, \mathrm{m}), 2.12$ $(1 \mathrm{H}, \mathrm{ddd}, J=12.8,8.1,8.1 \mathrm{~Hz}), 2.21-2.33(1 \mathrm{H}, \mathrm{m}), 2.45(3 \mathrm{H}, \mathrm{s}), 3.31(1 \mathrm{H}, \mathrm{dd}, J=10.5$, $8.8 \mathrm{~Hz}), 3.70-3.78(2 \mathrm{H}, \mathrm{m}), 7.34(2 \mathrm{H}, \mathrm{d}, J=8.0 \mathrm{~Hz}), 7.72(2 \mathrm{H}, \mathrm{d}, J=8.0 \mathrm{~Hz}) ;{ }^{13} \mathrm{C}$ NMR: trans $\delta=14.0,21.4,22.5,25.8,29.0,30.0,31.7,35.8,41.1\left(\mathrm{q}, J_{\mathrm{CF}}=29 \mathrm{~Hz}\right), 47.2$ $\left(\mathrm{q}, J_{\mathrm{CF}}=2 \mathrm{~Hz}\right), 60.1,126.2\left(\mathrm{q}, J_{\mathrm{CF}}=276 \mathrm{~Hz}\right), 127.4,129.7,134.0,143.7 ;{ }^{19} \mathrm{~F} \mathrm{NMR}$ : trans $\delta_{\mathrm{F}}=90.9\left(\mathrm{~d}, J_{\mathrm{FH}}=8 \mathrm{~Hz}\right)$; cis $\delta_{\mathrm{F}}=91.5\left(\mathrm{~d}, J_{\mathrm{FH}}=8 \mathrm{~Hz}\right)$; elemental analysis: calcd (\%) for $\mathrm{C}_{18} \mathrm{H}_{26} \mathrm{~F}_{3} \mathrm{NO}_{2} \mathrm{~S}$ : C 57.27, H 6.94, N 3.71, found: C 57.32, H 6.99, N 3.53. 1-(4-Methylbenzenesulfonyl)- 3-phenyl-4-(trifluoromethyl)pyrrolidine (20e): Yield 57\% (trans: cis $=72: 28$ ); (trans-20e) colorless crystals; m.p. $84-86{ }^{\circ} \mathrm{C}$; IR (neat): 3032 , 2956, 1599, 1348, 1265, 1163, 1113, 1028, $663 \mathrm{~cm}^{-1} ;{ }^{1} \mathrm{H}$ NMR: $\delta=2.48(3 \mathrm{H}, \mathrm{s}), 2.96$ $\left(1 \mathrm{H}\right.$, dddq, $\left.J=8.4,8.4,8.4 \mathrm{~Hz}, J_{\mathrm{HF}}=8.4 \mathrm{~Hz}\right), 3.33-3.43(3 \mathrm{H}, \mathrm{m}), 3.64(1 \mathrm{H}, \mathrm{dd}, J=9.3$, $8.4 \mathrm{~Hz}), 3.70(1 \mathrm{H}, \mathrm{dd}, J=10.7,8.8 \mathrm{~Hz}), 7.16(2 \mathrm{H}, \mathrm{d}, J=7.7 \mathrm{~Hz}), 7.24-7.33(3 \mathrm{H}, \mathrm{m})$, $7.38(2 \mathrm{H}, \mathrm{d}, J=7.9 \mathrm{~Hz}), 7.74(2 \mathrm{H}, \mathrm{d}, J=7.9 \mathrm{~Hz}) ;{ }^{13} \mathrm{C}$ NMR: $\delta=21.6,44.3,47.4\left(\mathrm{q}, J_{\mathrm{CP}}\right.$ $=3 \mathrm{~Hz}), 49.5\left(\mathrm{q}, J_{\mathrm{CF}}=28 \mathrm{~Hz}\right), 54.8,126.1\left(\mathrm{q}, J_{\mathrm{CF}}=279 \mathrm{~Hz}\right), 127.0,127.7,127.8,129.0$ $129.9,132.5,139.2,144.2 ;{ }^{19} \mathrm{~F}$ NMR: $\delta_{\mathrm{F}}=91.4\left(\mathrm{~d}, J_{\mathrm{FH}}=9 \mathrm{~Hz}\right)$; elemental analysis: calcd (\%) for $\mathrm{C}_{18} \mathrm{H}_{18} \mathrm{~F}_{3} \mathrm{NO}_{2} \mathrm{~S}$ : C 58.53, H 4.91, N 3.79, found: C 58.82, H 5.19, N 3.73; (cis-20e) colorless crystals; m.p. 96-97 ${ }^{\circ} \mathrm{C}$; IR (neat): 3032, 2960, 1599, 1400, 1348, 1281, 1163, 1120, $1049 \mathrm{~cm}^{-1}$; ${ }^{\mathrm{l}} \mathrm{H}$ NMR: $\delta=2.48(3 \mathrm{H}, \mathrm{s}), 3.00$ ( $1 \mathrm{H}, \mathrm{dddq}, J=8.5,8.5$, $\left.8.5 \mathrm{~Hz}, J_{\mathrm{HF}}=8.5 \mathrm{~Hz}\right), 3.56-3.75(5 \mathrm{H}, \mathrm{m}), 7.08-7.10(2 \mathrm{H}, \mathrm{m}), 7.24-7.26(3 \mathrm{H}, \mathrm{m}), 7.40$ $(2 \mathrm{H}, \mathrm{d}, J=8.0 \mathrm{~Hz}), 7.79(2 \mathrm{H}, \mathrm{d}, J=8.0 \mathrm{~Hz}) ;{ }^{13} \mathrm{C}$ NMR: $\delta=21.6,43.9,46.4\left(\mathrm{q}, J_{\mathrm{CF}}=3\right.$ $\mathrm{Hz}), 46.9\left(\mathrm{q}, J_{\mathrm{CF}}=27 \mathrm{~Hz}\right), 52.5,125.3\left(\mathrm{q}, J_{\mathrm{CF}}=280 \mathrm{~Hz}\right), 127.5,127.7,128.1,128.5$, 130.0, 133.5, 136.2, 144.1; ${ }^{19} \mathrm{~F}$ NMR: $\delta_{\mathrm{F}}=96.5\left(\mathrm{~d}, J_{\mathrm{HF}}=9 \mathrm{~Hz}\right)$; elemental analysis: calcd (\%) for $\mathrm{C}_{18} \mathrm{H}_{18} \mathrm{~F}_{3} \mathrm{NO}_{2} \mathrm{~S}$ : C $58.53, \mathrm{H} 4.91, \mathrm{~N} 3.79$, found: C 58.70, H 5.04, N 3.73 . Cyclization of 7: To a solution of $7(0.14 \mathrm{mmol})$ in THF $(2 \mathrm{~mL})$ was added $\mathrm{KO} t$-Bu (20.4 mg, $0.18 \mathrm{mmol}$ ) at rt. The reaction mixture was heated to reflux for $2.5-6 \mathrm{~h}$, and then phosphate buffer $(\mathrm{pH} 7,10 \mathrm{~mL})$ was added to quench the reaction. Organic materials were extracted with $\mathrm{Et}_{2} \mathrm{O}(5 \mathrm{~mL} \times 3)$. The combined organic extracts were washed with brine, and dried over $\mathrm{Na}_{2} \mathrm{SO}_{4}$. After removal of the solvent under reduced pressure, the residue was purified by preparative thin layer chromatography (hexaneEtOAc, 10:1) to give 3-difluoromethylene-2,3,4,5-tetrahydrofuran (21).

4-Difluoromethylene-3,3-dimethyl-2-phenyl-2,3,4,5-tetrahydrofuran (21a): A colorless liquid; yield 80\%; IR (neat): 3032, 2970, 2931, 2850, 1766, 1466, 1271, 1226, 1030, 723, $700 \mathrm{~cm}^{-1} ;{ }^{1} \mathrm{H}$ NMR: $\delta=0.74(3 \mathrm{H}, \mathrm{s}), 1.31(3 \mathrm{H}, \mathrm{s}), 4.42(1 \mathrm{H}, \mathrm{ddd}, J=12.3$ $\left.\mathrm{Hz}, J_{\mathrm{HF}}=4.7,4.1 \mathrm{~Hz}\right), 4.52(1 \mathrm{H}, \mathrm{s}), 4.67\left(1 \mathrm{H}, \mathrm{ddd}, J=12.3 \mathrm{~Hz}, J_{\mathrm{HF}}=2.8,2.8 \mathrm{~Hz}\right)$, $7.30-7.36(5 \mathrm{H}, \mathrm{m}) ;{ }^{13} \mathrm{C}$ NMR: $\delta=21.9,22.6,43.7\left(\mathrm{dd}, J_{\mathrm{CF}}=4,3 \mathrm{~Hz}\right), 65.0\left(\mathrm{~d}, J_{\mathrm{CF}}=4\right.$ 
$\mathrm{Hz}), 90.6,97.9\left(\mathrm{dd}, J_{\mathrm{CF}}=18,18 \mathrm{~Hz}\right), 126.7,127.8,127.9,136.8,149.2\left(\mathrm{dd}, J_{\mathrm{CF}}=287\right.$. $284 \mathrm{~Hz}) ;{ }^{19} \mathrm{~F}$ NMR: $\delta_{\mathrm{F}}=67.6\left(1 \mathrm{~F}, \mathrm{~d}, J_{\mathrm{FF}}=66 \mathrm{~Hz}\right), 75.4\left(1 \mathrm{~F}, \mathrm{~d}, J_{\mathrm{FF}}=66 \mathrm{~Hz}\right) ; \mathrm{HRMS}$ (FAB): calcd for $\mathrm{C}_{13} \mathrm{H}_{15} \mathrm{~F}_{2} \mathrm{O}\left([\mathrm{M}+\mathrm{H}]^{+}\right)$225.1091, found 225.1107 . 4-Difluoromethylene-1-phenyl-2-oxaspiro[4.4]nonane (21b): A colorless liquid; yield 70\%; IR (neat): 3032, 2956, 2870, 1765, 1454, 1265, 1217, 1051, 985, 729, 702 $\mathrm{cm}^{-1}$; ${ }^{1} \mathrm{H}$ NMR: $\delta=0.76-0.81(1 \mathrm{H}, \mathrm{m}), 1.40-1.50(3 \mathrm{H}, \mathrm{m}), 1.59-1.67(2 \mathrm{H}, \mathrm{m}), 1.86(1 \mathrm{H}$ ddd, $J=13.6,8.3,8.3 \mathrm{~Hz}), 2.09(1 \mathrm{H}, \mathrm{ddd}, J=13.6,8.8,6.7 \mathrm{~Hz}), 4.46(1 \mathrm{H}, \mathrm{ddd}, J=12.1$ $\left.\mathrm{Hz}, J_{\mathrm{HF}}=4.1,3.5 \mathrm{~Hz}\right), 4.65\left(1 \mathrm{H}, \mathrm{ddd}, J=12.1 \mathrm{~Hz}, J_{\mathrm{HF}}=2.9,2.9 \mathrm{~Hz}\right), 4.66(1 \mathrm{H}, \mathrm{s})$, 7.29-7.36 (5H, m); ${ }^{13} \mathrm{C}$ NMR: $\delta=24.9,25.6,34.2\left(\mathrm{~d}, J_{\mathrm{CF}}=2 \mathrm{~Hz}\right), 34.3,54.3\left(\mathrm{~d}, J_{\mathrm{CF}}=4\right.$ $\mathrm{Hz}), 65.6\left(\mathrm{~d}, J_{\mathrm{CF}}=4 \mathrm{~Hz}\right), 90.1,99.1\left(\mathrm{dd}, J_{\mathrm{CF}}=19,17 \mathrm{~Hz}\right), 127.3,127.9,127.9,137.4$ $148.9\left(\mathrm{dd}, J_{\mathrm{CF}}=286,283 \mathrm{~Hz}\right) ;{ }^{19} \mathrm{~F}$ NMR: $\delta_{\mathrm{F}}=68.2\left(1 \mathrm{~F}, \mathrm{~d}, J_{\mathrm{FF}}=65 \mathrm{~Hz}\right), 74.7(1 \mathrm{~F}, \mathrm{dd}$ $\left.J_{\mathrm{FF}}=65 \mathrm{~Hz}, J_{\mathrm{FH}}=4 \mathrm{~Hz}\right) ; \mathrm{HRMS}(\mathrm{FAB})$ : calcd for $\mathrm{C}_{15} \mathrm{H}_{17} \mathrm{~F}_{2} \mathrm{O}\left([\mathrm{M}+\mathrm{H}]^{+}\right) 251.1247$, found 251.1271 .

4-Difluoromethylene-3,3-dimethyl-2-(2-phenylethyl)-2,3,4,5-tetrahydrofuran (21c): A colorless liquid; yield 87\%; IR (neat): 3028, 2956, 2927, 2854, 1768, 1496, 1456, $1277,1227,1027,698 \mathrm{~cm}^{-1}$; ${ }^{1} \mathrm{H}$ NMR: $\delta=1.02(3 \mathrm{H}, \mathrm{s}), 1.17(3 \mathrm{H}, \mathrm{s}), 1.63-1.81(2 \mathrm{H}, \mathrm{m})$, $2.63(1 \mathrm{H}, \mathrm{ddd}, J=13.6,10.0,6.8 \mathrm{~Hz}), 2.91(1 \mathrm{H}, \mathrm{ddd}, J=13.6,10.4,5.2 \mathrm{~Hz}), 3.42(1 \mathrm{H}$, dd, $J=10.0,2.4 \mathrm{~Hz}), 4.25\left(1 \mathrm{H}\right.$, ddd, $\left.J=12.4 \mathrm{~Hz}, J_{\mathrm{HF}}=4.4,4.0 \mathrm{~Hz}\right), 4.47(1 \mathrm{H}$, ddd, $J=$ $\left.12.4 \mathrm{~Hz}, J_{\mathrm{HF}}=2.8,2.8 \mathrm{~Hz}\right), 7.17-7.31(5 \mathrm{H}, \mathrm{m}) ;{ }^{13} \mathrm{C} \mathrm{NMR:} \delta=20.8,22.7\left(\mathrm{~d}, J_{\mathrm{CF}}=4 \mathrm{~Hz}\right)$, $30.8,33.3,42.5\left(\mathrm{~d}, J_{\mathrm{CF}}=3 \mathrm{~Hz}\right), 64.9\left(\mathrm{~d}, J_{\mathrm{CF}}=4 \mathrm{~Hz}\right), 88.3,98.3\left(\mathrm{dd}, J_{\mathrm{CF}}=18,18 \mathrm{~Hz}\right)$, $125.9,128.4,128.4,142.0,149.1\left(\mathrm{dd}, J_{\mathrm{CF}}=286,283 \mathrm{~Hz}\right) ;{ }^{19} \mathrm{~F} \mathrm{NMR:} \delta_{\mathrm{F}}=67.3(1 \mathrm{~F}, \mathrm{~d}$, $\left.J_{\mathrm{FF}}=66 \mathrm{~Hz}\right), 75.1\left(1 \mathrm{~F}, \mathrm{~d}, J_{\mathrm{FF}}=66 \mathrm{~Hz}\right) ; \operatorname{HRMS}(\mathrm{FAB})$ : calcd for $\mathrm{C}_{15} \mathrm{H}_{19} \mathrm{~F}_{2} \mathrm{O}\left([\mathrm{M}+\mathrm{H}]^{+}\right)$ 253.1404 , found 253.1384

4-Difluoromethylene-2-phenyl-2,3,4,5-tetrahydrothiophene (22a): To a solution of $8 \mathbf{a}(80 \mathrm{mg}, 0.29 \mathrm{mmol})$ in DMF $(3 \mathrm{~mL})$ was added $\mathrm{NaOMe}(19 \mathrm{mg}, 0.36 \mathrm{mmol})$ at $0{ }^{\circ} \mathrm{C}$ After the reaction mixture was stirred at $100{ }^{\circ} \mathrm{C}$ for $10 \mathrm{~h}$, phosphate buffer $(\mathrm{pH} 7,20$ $\mathrm{mL}$ ) was added to quench the reaction. Organic materials were extracted with EtOAc $(20 \mathrm{~mL} \times 3)$. The combined extracts were washed with water and brine, and dried over $\mathrm{Na}_{2} \mathrm{SO}_{4}$. After removal of the solvent under reduced pressure, the residue was purified by column chromatography (hexane-EtOAc, $5: 1)$ to give $\mathbf{2 2 a}(51 \mathrm{mg}, 82 \%)$ as a colorless liquid. IR (neat): $3064,3030,2912,1765,1267,1219,1049 \mathrm{~cm}^{-1} ;{ }^{1} \mathrm{H}$ NMR: $\delta=2.72-2.78(1 \mathrm{H}, \mathrm{m}), 3.06(1 \mathrm{H}, \mathrm{dd}, J=13.7,5.7 \mathrm{~Hz}), 3.63(1 \mathrm{H}, \mathrm{d}, J=13.6 \mathrm{~Hz}), 3.69$ $(1 \mathrm{H}, \mathrm{d}, J=13.6 \mathrm{~Hz}), 4.52(1 \mathrm{H}, \mathrm{dd}, J=8.4,5.7 \mathrm{~Hz}), 7.26(1 \mathrm{H}, \mathrm{t}, J=7.3 \mathrm{~Hz}), 7.33(2 \mathrm{H}$ $\mathrm{dd}, J=7.3,7.3 \mathrm{~Hz}), 7.38(2 \mathrm{H}, \mathrm{d}, J=7.3 \mathrm{~Hz}) ;{ }^{13} \mathrm{C} \mathrm{NMR}: \delta=30.2\left(\mathrm{~d}, J_{\mathrm{CF}}=2 \mathrm{~Hz}\right), 38.5$ $\left(\mathrm{d}, J_{\mathrm{CF}}=2 \mathrm{~Hz}\right), 51.8,90.0\left(\mathrm{dd}, J_{\mathrm{CF}}=22,22 \mathrm{~Hz}\right), 127.3,127.6,128.6,140.6,150.3(\mathrm{dd}$, $\left.J_{\mathrm{CF}}=284,284 \mathrm{~Hz}\right) ;{ }^{19} \mathrm{~F} \mathrm{NMR}: \delta_{\mathrm{F}}=71.7\left(1 \mathrm{~F}, \mathrm{ddd}, J_{\mathrm{FF}}=54 \mathrm{~Hz}, J_{\mathrm{FH}}=3,3 \mathrm{~Hz}\right), 72.6(1 \mathrm{~F}$, $\left.\mathrm{dd}, J_{\mathrm{FF}}=54 \mathrm{~Hz}, J_{\mathrm{FH}}=4 \mathrm{~Hz}\right)$; HRMS (FAB): calcd for $\mathrm{C}_{11} \mathrm{H}_{11} \mathrm{~F}_{2} \mathrm{~S}\left([\mathrm{M}+\mathrm{H}]^{+}\right)$213.0550, found 213.0564

4-Difluoromethylene-2-hexyl-2,3,4,5-tetrahydrothiophene (22b): Compound 22b was prepared by the method described for $22 \mathrm{a}$ using $8 \mathbf{b}(80 \mathrm{mg}, 0.28 \mathrm{mmol}), \mathrm{NaOMe}$ (20 mg, $0.37 \mathrm{mmol}$ ) in DMF ( $3 \mathrm{~mL}$ ) at $100{ }^{\circ} \mathrm{C}$ for $15 \mathrm{~h}$. Purification by column chromatography (hexane-EtOAc, 50:1) gave $22 \mathrm{~b}$ (47 $\mathrm{mg}, 75 \%)$ as a colorless liquid. IR (neat): 2956, 2926, 2854, 1765, 1267, 1201, 1047, $912 \mathrm{~cm}^{-1}$; ${ }^{1} \mathrm{H}$ NMR: $\delta=0.88$ (3H, t, $J$ $=7.1 \mathrm{~Hz}), 1.22-1.41(8 \mathrm{H}, \mathrm{m}), 1.50-1.59(1 \mathrm{H}, \mathrm{m}), 1.60-1.68(1 \mathrm{H}, \mathrm{m}), 2.27-2.34(1 \mathrm{H}$, $\mathrm{m}), 2.78(1 \mathrm{H}, \mathrm{dm}, J=14.3 \mathrm{~Hz}), 3.31-3.37(1 \mathrm{H}, \mathrm{m}), 3.45(1 \mathrm{H}, \mathrm{dm}, J=12.9 \mathrm{~Hz}), 3.48$ $(1 \mathrm{H}, \mathrm{dm}, J=12.9 \mathrm{~Hz}) ;{ }^{13} \mathrm{C}$ NMR: $\delta=14.0,22.6,28.6,28.8\left(\mathrm{~d}, J_{\mathrm{CF}}=1 \mathrm{~Hz}\right), 29.1,31.7$, $36.1,36.4\left(\mathrm{dd}, J_{\mathrm{CF}}=2,2 \mathrm{~Hz}\right), 48.8,89.8\left(\mathrm{dd}, J_{\mathrm{CF}}=21,21 \mathrm{~Hz}\right), 150.4\left(\mathrm{dd}, J_{\mathrm{CF}}=283,283\right.$ $\mathrm{Hz}) ;{ }^{19} \mathrm{~F} \mathrm{NMR}: \delta_{\mathrm{F}}=70.6\left(1 \mathrm{~F}, \mathrm{dm}, J_{\mathrm{FF}}=56 \mathrm{~Hz}\right), 72.2\left(1 \mathrm{~F}, \mathrm{~d}, J_{\mathrm{FF}}=56 \mathrm{~Hz}\right) ;$ elemental analysis: calcd (\%) for $\mathrm{C}_{11} \mathrm{H}_{18} \mathrm{~F}_{2} \mathrm{~S}$ : C 59.97, H 8.23, found: C 59.84, H 8.21. 2-Phenyl-4-trifluoromethyl-2,3,4,5-tetrahydrothiophene (23a): To a solution of $\mathbf{8 a}$ $(87 \mathrm{mg}, 0.32 \mathrm{mmol})$ in $\mathrm{MeOH}(3 \mathrm{~mL})$ was added $\mathrm{K}_{2} \mathrm{CO}_{3}(47 \mathrm{mg}, 0.34 \mathrm{mmol})$ at rt. After the reaction mixture was heated at reflux for $2 \mathrm{~h}$, phosphate buffer $(\mathrm{pH} 7,10 \mathrm{~mL})$ was added to quench the reaction. Organic materials were extracted with EtOAc $(20 \mathrm{~mL} \times 3)$. The combined extracts were washed with water and brine, and dried over $\mathrm{Na}_{2} \mathrm{SO}_{4}$. After removal of the solvent under reduced pressure, the residue was purified by column chromatography (hexane-EtOAc, 20:1) to give 23a (>98:2 mixture, $66 \mathrm{mg}, 90 \%$ ) as a colorless liquid. IR (neat): 3064, 3020, 2945, 2875, 1381, 1267, 1215, 1151, $1107 \mathrm{~cm}^{-1}$; ${ }^{1} \mathrm{H}$ NMR: $\delta=2.35$ ( $1 \mathrm{H}$, ddd, $\left.J=13.3,6.2,6.2 \mathrm{~Hz}\right), 2.53(1 \mathrm{H}, \mathrm{ddd}, J=13.3,8.0,7.1 \mathrm{~Hz}$ ), $3.05-3.15(2 \mathrm{H}, \mathrm{m}), 3.23-3.30(1 \mathrm{H}, \mathrm{m}), 4.64(1 \mathrm{H}, \mathrm{dd}, J=7.1,6.2 \mathrm{~Hz}), 7.26(1 \mathrm{H}, \mathrm{t}, J=$ $7.4 \mathrm{~Hz}), 7.34(2 \mathrm{H}, \mathrm{dd}, J=7.4,7.4 \mathrm{~Hz}), 7.41(2 \mathrm{H}, \mathrm{d}, J=7.4 \mathrm{~Hz}) ;{ }^{13} \mathrm{C}$ NMR: $\delta=31.2(\mathrm{q}$, $\left.J_{\mathrm{CF}}=2 \mathrm{~Hz}\right), 39.4\left(\mathrm{q}, J_{\mathrm{CF}}=1 \mathrm{~Hz}\right), 46.0\left(\mathrm{q}, J_{\mathrm{CF}}=27 \mathrm{~Hz}\right), 50.8,127.0\left(\mathrm{q}, J_{\mathrm{CF}}=277 \mathrm{~Hz}\right)$, 127.4, 127.4, 128.6, 141.6; ${ }^{19} \mathrm{~F}$ NMR: $\delta_{\mathrm{F}}=91.8\left(\mathrm{~d}, J_{\mathrm{FH}}=8 \mathrm{~Hz}\right)$; HRMS (FAB): calcd for $\mathrm{C}_{11} \mathrm{H}_{12} \mathrm{~F}_{3} \mathrm{~S}\left([\mathrm{M}+\mathrm{H}]^{+}\right)$233.0612, found 233.0625 .

2-Hexyl-4-trifluoromethyl-2,3,4,5-tetrahydrothiophene (23b): Compound 23b was prepared by the method described for $23 \mathbf{a}$ using $\mathbf{8 b}(81 \mathrm{mg}, 0.29 \mathrm{mmol})$ and $\mathrm{K}_{2} \mathrm{CO}_{3}(43$ $\mathrm{mg}, 0.31 \mathrm{mmol})$ in $\mathrm{MeOH}(3 \mathrm{~mL})$ for $1 \mathrm{~h}$. Purification by column chromatography (hexane-EtOAc, 50:1) gave 23b (92:8 mixture, $56 \mathrm{mg}, 82 \%$ ) as a colorless liquid. IR (neat): 2956, 2927, 2873, 2856, 1380, 1269, 1161, $1111 \mathrm{~cm}^{-1} ;{ }^{1} \mathrm{H}$ NMR: $\delta=0.88(3 \mathrm{H}, \mathrm{t}$, $J=7.1 \mathrm{~Hz}), 1.23-1.65(10 \mathrm{H}, \mathrm{m}), 1.98-2.03(1 \mathrm{H}, \mathrm{m}), 2.19(1 \mathrm{H}, \mathrm{ddd}, J=12.9,8.4,7.0$ $\mathrm{Hz}), 2.91-3.05(3 \mathrm{H}, \mathrm{m}), 3.37-3.43(1 \mathrm{H}, \mathrm{m}) ;{ }^{13} \mathrm{C} \mathrm{NMR}: \delta=14.0,22.5,28.4,29.0,30.2$ $\left(\mathrm{q}, J_{\mathrm{CF}}=3 \mathrm{~Hz}\right), 31.7,36.5\left(\mathrm{q}, J_{\mathrm{CF}}=2 \mathrm{~Hz}\right), 37.7,46.0\left(\mathrm{q}, J_{\mathrm{CF}}=27 \mathrm{~Hz}\right), 47.4,127.1(\mathrm{q}$, $\left.J_{\mathrm{CF}}=277 \mathrm{~Hz}\right) ;{ }^{19} \mathrm{~F}$ NMR: $\delta_{\mathrm{F}}=91.8\left(\mathrm{~d}, J_{\mathrm{FH}}=9 \mathrm{~Hz}\right) ; \mathrm{HRMS}(\mathrm{FAB})$ : calcd for $\mathrm{C}_{11} \mathrm{H}_{19} \mathrm{~F}_{3} \mathrm{NaS}\left([\mathrm{M}+\mathrm{Na}]^{+}\right) 263.1057$, found 263.1046 Diethyl 4-difluoromethylene-2-phenylcyclopentane-1,1-dicarboxylate (24): To a solution of $10(83 \mathrm{mg}, 0.23 \mathrm{mmol})$ in DMF $(3 \mathrm{~mL})$ was added potassium hydride $(\mathrm{KH}$, $30 \%$ dispersion in mineral oil; $50 \mathrm{mg}, 0.37 \mathrm{mmol}$ ) at $0{ }^{\circ} \mathrm{C}$. After being stirred at $0{ }^{\circ} \mathrm{C}$ for $1 \mathrm{~h}$, the reaction mixture was heated at $110^{\circ} \mathrm{C}$ for $3 \mathrm{~h}$. Phosphate buffer $(\mathrm{pH} 7,20$ $\mathrm{mL}$ ) was added to quench the reaction, and organic materials were extracted with EtOAc $(20 \mathrm{~mL} \times 3)$. The combined extracts were washed with brine, and dried over $\mathrm{Na}_{2} \mathrm{SO}_{4}$. After removal of the solvent under reduced pressure, the residue was purified by column chromatography (hexane-EtOAc, $5: 1)$ to give $\mathbf{2 4}(60 \mathrm{mg}, 77 \%)$ as a colorless liquid. IR (neat): 3032, 2983, 1772, 1730, 1456, 1367, 1269, 1221, $1036 \mathrm{~cm}^{-1}$; ${ }^{1} \mathrm{H}$ NMR: $\delta=0.94(3 \mathrm{H}, \mathrm{t}, J=7.1 \mathrm{~Hz}), 1.25(3 \mathrm{H}, \mathrm{t}, J=7.1 \mathrm{~Hz}), 2.71(1 \mathrm{H}, \mathrm{dm}, J=16.4$ $\mathrm{Hz}), 2.82(1 \mathrm{H}, \mathrm{dm}, J=16.8 \mathrm{~Hz}), 2.92-2.99(1 \mathrm{H}, \mathrm{m}), 3.34(1 \mathrm{H}, \mathrm{dm}, J=16.8 \mathrm{~Hz}), 3.71$ $(1 \mathrm{H}, \mathrm{dq}, J=10.7,7.1 \mathrm{~Hz}), 3.90(1 \mathrm{H}, \mathrm{dq}, J=10.7,7.1 \mathrm{~Hz}), 4.05(1 \mathrm{H}, \mathrm{dd}, J=7.9,5.8$ $\mathrm{Hz}), 4.18(1 \mathrm{H}, \mathrm{dq}, J=10.7,7.1 \mathrm{~Hz}), 4.26(1 \mathrm{H}, \mathrm{dq}, J=10.7,7.1 \mathrm{~Hz}), 7.19-7.28(5 \mathrm{H}, \mathrm{m})$; ${ }^{13}$ C NMR: $\delta=13.5,13.9,31.7,33.2,49.6,61.2,61.7,65.1,87.1\left(\mathrm{dd}, J_{\mathrm{CF}}=23,22 \mathrm{~Hz}\right)$, $127.3,128.1,128.2,139.8,150.4\left(\mathrm{dd}, J_{\mathrm{CF}}=281,281 \mathrm{~Hz}\right), 168.9,171.0 ;{ }^{19} \mathrm{~F}$ NMR: $\delta_{\mathrm{F}}=$ $71.7\left(1 \mathrm{~F}, \mathrm{dm}, J_{\mathrm{FF}}=58 \mathrm{~Hz}\right), 71.9\left(1 \mathrm{~F}, \mathrm{dm}, J_{\mathrm{FF}}=58 \mathrm{~Hz}\right)$; elemental analysis: calcd $(\%)$ for $\mathrm{C}_{18} \mathrm{H}_{20} \mathrm{~F}_{2} \mathrm{O}_{4}$ : C 63.90, $\mathrm{H} 5.96$, found: $\mathrm{C} 63.74, \mathrm{H} 5.89$.

4-Difluoromethylene-2-phenylcyclopentane-1,1-dicarbonitrile (25): To a solution of $11(54 \mathrm{mg}, 0.21 \mathrm{mmol})$ in DMF (3 mL) was added $\mathrm{NaH}$ (60\% dispersion in mineral oil; $10.6 \mathrm{mg}, 0.265 \mathrm{mmol}$ ) at $0{ }^{\circ} \mathrm{C}$. After being stirred at $0{ }^{\circ} \mathrm{C}$ for $1 \mathrm{~h}$, the reaction mixture

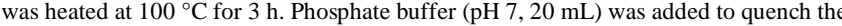
reaction, and organic materials were extracted with EtOAc $(20 \mathrm{~mL} \times 3)$. The combined extracts were washed with brine, and dried over $\mathrm{Na}_{2} \mathrm{SO}_{4}$. After removal of the solvent under reduced pressure, the residue was purified by column chromatography (hexaneEtOAc, 5:1) to give $\mathbf{2 5}(31 \mathrm{mg}, 61 \%)$ as a colorless liquid. IR (neat): 3033, 2935, 2360, $2332,1772,1498,1271,1078 \mathrm{~cm}^{-1} ;{ }^{1} \mathrm{H}$ NMR: $\delta=2.95(1 \mathrm{H}, \mathrm{ddm}, J=15.8,7.5 \mathrm{~Hz})$, $3.04(1 \mathrm{H}, \mathrm{ddm}, J=15.8,11.3 \mathrm{~Hz}), 3.16(1 \mathrm{H}, \mathrm{dm}, J=15.6 \mathrm{~Hz}), 3.37(1 \mathrm{H}, \mathrm{dm}, J=15.6$ $\mathrm{Hz}), 3.72(1 \mathrm{H}, \mathrm{dd}, J=11.3,7.5 \mathrm{~Hz}), 7.42-7.48(5 \mathrm{H}, \mathrm{m}) ;{ }^{13} \mathrm{C}$ NMR: $\delta=28.4,38.4$ (d, $\left.J_{\mathrm{CF}}=3 \mathrm{~Hz}\right), 41.5,54.4,83.3\left(\mathrm{dd}, J_{\mathrm{CF}}=27,23 \mathrm{~Hz}\right), 113.4,114.6,128.0,129.2,129.6$, $133.0,151.5\left(\mathrm{dd}, J_{\mathrm{CF}}=285,285 \mathrm{~Hz}\right) ;{ }^{19} \mathrm{~F} \mathrm{NMR}: \delta_{\mathrm{F}}=76.0\left(1 \mathrm{~F}, \mathrm{dm}, J_{\mathrm{FF}}=49 \mathrm{~Hz}\right), 76.3$ $\left(1 \mathrm{~F}, \mathrm{dm}, J_{\mathrm{FF}}=49 \mathrm{~Hz}\right)$; elemental analysis: calcd $(\%)$ for $\mathrm{C}_{14} \mathrm{H}_{10} \mathrm{~F}_{2} \mathrm{~N}_{2}: \mathrm{C} 68.85, \mathrm{H} 4.13, \mathrm{~N}$ 11.47, found: C $68.83, \mathrm{H} 4.21, \mathrm{~N} 11.37$

\section{Acknowledgements}

We are grateful to Central Glass Co., Ltd. for financial support and to Tosoh F-Tech, Inc. for a generous gift of 2-bromo-3,3,3-trifluoroprop-1-ene.

[1] a) J. E. Baldwin, J. Chem. Soc., Chem. Commun. 1976, 734; b) J. E. Baldwin, J. Cutting, W. Dupont, L. Kruse, L. Silberman, R. C. Thomas, J. Chem. Soc., Chem. Commun. 1976, 736; c) J. E. Baldwin, R. C. Thomas, L. Kruse, L. Silberman, J. Org. Chem. 1977, 42, 3846.

[2] J. Ichikawa, Y. Wada, M. Fujiwara, K. Sakoda, Synthesis 2002, 1917 and references therein.

[3] For recent reports, see: a) J. Ichikawa, G. Lapointe, Y. Iwai, Chem. Commun 2007, 2698; b) J. J. Caldwell, D. Craig, Angew. Chem. Int. Ed. 2007, 46, 2631; c) J. J. Caldwell, D. Craig, S. P. East, ARKIVOC 2007, XII, 67; d) J. Clayden, D. W. Watson, M. Helliwell, M. Chambers, Chem. Comm. 2003, 2582; e) R. Naitoh, Y. Nakamura, E. Katano, Y. Nakamura, E. Okada, M. Asaoka, Heterocycles 2004, 63, 1009; f) P. Auvray, P. Knochel, J. F. Normant, Tetrahedron Lett. 1985, 26, 4455; for recent reports on the cyclization of allenes, see: g) H. Ohno, Y. Kadoh, T. Tanaka, Org. Lett. 2006, 8, 947; h) M. A. Chowdhury, H.-U. Reissig, Synlett 2006, 2383.

[4] For a recent review, see: a) D. W. Knight in Progress in Heterocyclic Chemistry (Ed.: G. W. Gribble, T. L. Gilchrist), Pergamon, Amsterdam, 2002, Vol. 14 Chap. 2; for recent reports, see: b) A. D. Jones, A. L. Redfern, D. W. Knight, I R. Morgan, A. C. Williams, Tetrahedron 2006, 62, 9247; c) N. S. Karanjule, S. D. Markad, V. S. Shinde, D. D. Dhavale, J. Org. Chem. 2006, 71, 4667.

[5] For recent reports, see: a) A. J. Clark, C. P. Dell, J. M. McDonagh, J. Geden, P. Mawdsley, Org. Lett. 2003, 5, 2063; b) C. Chatgilialoglu, C. Ferreri, M. Guerra, V. Timokhin, G. Froudakis, T. Gimisis, J. Am. Chem. Soc. 2002, 124, 10765; for recent reviews, see: c) H. Ishibashi, Chem. Rec. 2006, 6, 23; d) H. Ishibashi, T. Sato, M. Ikeda, Synthesis 2002, 695; e) A. F. Parsons, C. R. Acad. Sci. 2001, 4, 391.

[6] a) J. Ichikawa, H. Fukui, Y. Ishibashi, J. Org. Chem. 2003, 68, 7800 and references therein; b) J.-P. Bégué, D. Bonnet-Delpon, M. H. Rock, J. Chem. Soc., Perkin Trans. 1 1996, 1409

[7] a) T. Mori, J. Ichikawa, Chem. Lett. 2004, 33, 1207; b) T. Mori, Y. Iwai, J. Ichikawa, Chem. Lett. 2005, 34, 778 .

[8] a) Organofluorine Chemistry: Principles and Commercial Applications (Ed.: R. E. Banks, B. E. Smart, J. C. Tatlow), Plenum Press, New York, 1994; b) P. Kirsch, Modern Fluoroorganic Chemistry: Synthesis, Reactivity, Applications, Wiley-VCH, Weinheim, 2004.

[9] R. Plantier-Royon, C. Portella, Carbohydr. Res. 2000, 327, 119

[10] Biomedical Frontiers of Fluorine Chemistry (Ed.: I. Ojima, J. R. McCarthy, J. T. Welch), American Chemical Society, Washington, DC, 1996.

[11] a) J. A. Erickson, J. I. McLoughlin, J. Org. Chem. 1995, 60, 1626; b) S. Kaneko, T. Yamazaki, T. Kitazume, J. Org. Chem. 1993, 58, 2302 and references therein; for a review, see: c) J. T. Welch, Tetrahedron 1987, 43, 3123.

[12] a) G. Wang, K. Sakthivel, V. Rajappan, T. W. Bruice, K. Tucker, P. Fagan, J. L. Brooks, T. Hurd, J. M. Leeds, P. D. Cook, Nucleosides, Nucleotides Nucleic Acids 2004, 23, 317; b) S. Marcotte, B. Gerard, X. Pannecoucke, C. Feasson, J.C. Quirion, Synthesis 2001, 929 and references therein.

[13] V. J. Lee in Comprehensive Organic Synthesis, Vol. 4 (Ed.: B. M. Trost), Pergamon, Oxford, 1991, p 69.

[14] C. Leriche, X. He, C. T. Chang, H. Liu, J. Am. Chem. Soc. 2003, 125, 6348 and references therein.

[15] R. Nadano, Y. Iwai, T. Mori, J. Ichikawa, J. Org. Chem. 2006, 71, 8748 and references therein.

[16] J. Ichikawa, T. Mori, Y. Iwai, Chem. Lett. 2004, 33, 1354

[17] B. Jiang, Q.-F. Wang, C.-G. Tang, M. Xu, Tetrahedron Lett. 2001, 42, 4083.

[18] T. Yamazaki, N. Ishikawa, Chem. Lett. 1984, 521.

[19] R. Nadano, J. Ichikawa, Synthesis 2006, 128.

[20] O. Mitsunobu, Synthesis 1981, 1. 
[21] T. Tsunoda, F. Ozaki, S. Ito, Tetrahedron Lett. 1994, 35, 5081.

[22] For a report on 3-(methylene)indolines, see: J. Barluenga, F. J. Fañanás, R. Sanz Y. Fernández, Chem. Eur. J. 2002, 8, 2034.

[23] For recent reports on 3-(trifluoromethyl)indoline derivatives, see: a) N. Shibata, H. Fujimoto, S. Mizuta, S. Ogawa, Y. Ishiuchi, S. Nakamura, T. Toru, Synlet 2006, 3484; b) B. Dolenský, J. Kvíčala, O. Paleta, J. Fluorine Chem 2005, 126 745; c) H. A. Schenck, P. W. Lenkowski, I. Choudhury-Mukherjee, S.-H. Ko, J. P. Stables, M. K. Patel, M. L. Brown, Bioorg. Med. Chem. 2004, 12, 979; d) V. A. Petrov, J. Fluorine Chem. 2000, 106, 25.

[24] For recent reports on 3-(trifluoromethyl)indoles, see: a) Y.-Q. Fang, M. Lautens, Org. Lett. 2005, 7, 3549; b) T. Konno, J. Chae, T. Ishihara, H. Yamanaka, J. Org. Chem. 2004, 69, 8258 and references therein; c) I. Choudhury-Mukherjee, H. A. Schenck, S. Cechova, N. Pajewski, J. Kapur, J. Ellena, D. S. Cafiso, M. L. Brown, J. Med. Chem. 2003, 46, 2494; d) I. Rodrigues, D. Bonnet-Delpon, J.-P. Bégué, J. Org. Chem. 2001, 66, 2098 and references therein.

[25] a) T. Fukuyama, M. Cheung, C.-K. Jow, Y. Hidai, T. Kan, Tetrahedron Lett. 1997, 38, 5831; b) T. Fukuyama, C.-K. Jow, M. Cheung, Tetrahedron Lett. 1995 , 36,6373 .

[26] G. Alvernhe, A. Laurent, G. Haufe, Synthesis 1987, 562.

[27] S. Irifune, T. Kibayashi, Y. Ishii, M. Ogawa, Synthesis 1988, 366

[28] There are no reports on 3-(difluoromethyl)indoles to our knowledge. For recent reports on 2-(difluoromethyl)indoles, see: a) F. Ge, Z. Wang, W. Wan, J. Hao, Synlett 2007, 447; b) ref. 24b.

[29] a) R. D. Chambers, Fluorine in Organic Chemistry, Antony Rowe; Chippenham, 1973, p 1; b) B. E. Smart in Organofluorine Chemistry: Principles and Commercial Applications (Ed.: R. E. Banks, B. E. Smart, J. C. Tatlow), Plenum Press, New York, 1994, p 57; c) A. D. Allen, T. T. Tidwell in Advances in Carbocation Chemistry (Ed.: X. Creary), Jai Press, Greenwich, 1989, Vol. 1, p 1.

[30] For recent reports on 3-trifluoromethyl-2,3-dihydrobenzothiophenes, see: a) E. Okada, N. Tsukushi, N. Shimomura, Synthesis 2000, 237; b) M. Yoshimatsu, T. Sugimoto, N. Okada, S. Kinoshita, J. Org. Chem. 1999, 64, 5162; c) E. Okada, R. Masuda, M. Hojo, N. Imazaki, H. Miya, Heterocycles 1992, 34, 103.

[31] For recent reports on 3-(difluoromethylene)pyrrolidines, see: a) J. Ichikawa, R. Nadano, N. Ito, Chem. Commun. 2006, 4425; b) X.-L. Qiu, F.-L. Qing, J. Org. Chem. 2005, 70, 3826; c) A. Kamal, P. S. M. M. Reddy, D. R. Reddy, E. Laxman, Y. L. N. Murthy, Bioorg. Med. Chem. Lett. 2004, 14, 5699; d) X.-L. Qiu, F.-L. Qing, Synthesis 2004, 334; e) X.-L. Qiu, F.-L. Qing, J. Org. Chem. 2002, 67, 7162.

[32] For recent reports on 3-(trifluoromethyl)pyrrolidines, see: a) T. Llamas, R. G. Arrayás, J. C. Carretero, Synthesis 2007, 950; b) V. B. Sokolov, A. Yu. Aksinenko, T. A. Epishina, T. V. Goreva, I. V. Martynov, Russ. Chem. Bull. 2005, 54, 2851; c) C. Brule, J.-P. Bouillon, C. Portella, Tetrahedron 2004, 60 , 9849; d) X.-L. Qiu, F.-L. Qing, J. Org. Chem. 2003, 68, 3614; e) X.-L. Qiu, F.-L. Qing, J. Chem. Soc., Perkin Trans. 1 2002, 2052; f) J. R. Del Valle, M. Goodman, Angew. Chem., Int. Ed. 2002, 41, 1600; g) P.-H. Liang, L.-W. Hsin, C.-Y. Cheng, Bioorg. Med. Chem. 2002, 10, 3267.

[33] The 2,4-trans/cis stereochemistry of the pyrrolidine ring was determined by a NOESY experiment on 2-(4-bromophenyl)-1-(4-methylbenzenesulfonyl)-4(trifluoromethyl)pyrrolidine (20b) as a representative example. A cross peak between the $\mathrm{C}-2$ and $\mathrm{C}-4$ protons was observed in the minor product, but not in the major product. As for the $\mathrm{C}-4$ proton of the pyrrolidine ring, the signal of the trans-isomer was observed at lower field $(\delta 2.92)$ than that of the $c i s$-isomer $(\delta$ $2.64)$, which allowed assignment of the configuration to the other stereoisomers 20a and 20c-d

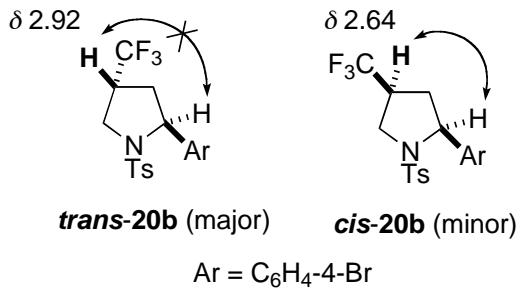

[34] The 3,4-trans/cis stereochemistry of 1-(4-methylbenzenesulfonyl)-3-phenyl-4(trifluoromethyl)pyrrolidine (20e) was determined by a NOESY experiment. A cross peak between the C-4 proton of the pyrrolidine ring and the $o$-protons of the 3-phenyl group was observed in the major product, but not in the minor product.

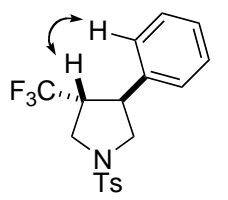

trans-20e (major)

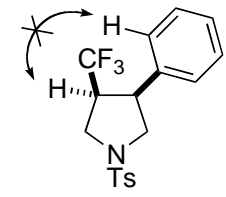

cis-20e (minor)
[35] For a recent review on the gem-dialkyl effect, see: M. E. Jung, G. Piizzi, Chem. Rev. 2005, 105, 1735.

[36] For recent reports on 3-(difluoromethylene)tetrahydrofurans, see: a) A. Gautier, G. Garipova, C. Salcedo, S. Balieu, S. R. Piettre, Angew. Chem. Int. Ed. 2004, 43, 5963; b) S. Marcotte, B. Gérard, X. Pannecoucke, C. Feasson, J.-C. Quirion, Synthesis 2001, 929. c) P. J. Serafinowski, C. A. Brown, Tetrahedron 2000, 56, 333 ; d) ref. 9.

[37] For a recent report on 3-(difluoromethylene)tetrahydrothiophenes, see: M. H. Lim, H. O. Kim, H. R. Moon, M. W. Chun, L. S. Jeong, Org. Lett. 2002, 4, 529.

[38] For recent reports on 3-(trifluoromethyl)tetrahydrothiophenes, see: a) R. Huisgen, E. Langhals, K. Polborn, K. Karaghiosoff, Helvetica Chim. Acta 2004, 87, 1426; b) X. Zhang, F.-L. Qing, J. Org. Chem. 2002, 67, 1016; c) R. Huisgen, X. Li, H. Giera, E. Langhals, Helvetica Chim. Acta 2001, 84, 981.

[39] For recent reports on (difluoromethylene)cyclopentane derivatives, see: a) $\mathrm{H}$ Yuan, R. B. Silverman, Bioorg. Med. Chem. Lett. 2007, 17, 1651; b) Y. Pan, J. Qiu, R. B. Silverman, J. Med. Chem. 2003, 46, 5292; c) A. Saito, M. Okada, Y. Nakamura, O. Kitagawa, H. Horikawa, T. Taguchi, J. Fluorine Chem. 2003, 123 , 75.

[40] J. R. Henry, L. R. Marcin, M. C. McIntosh, Tetrahedron Lett. 1989, $30,5709$.

[41] P. J. Stang, M. Hanack, L. R. Subramanian, Synthesis 1982, 85.

Received: ((will be filled in by the editorial staff))

Revised: ((will be filled in by the editorial staff)) Published online: ((will be filled in by the editorial staff)) 